DOI: $10.24275 /$ uama.5811.7967

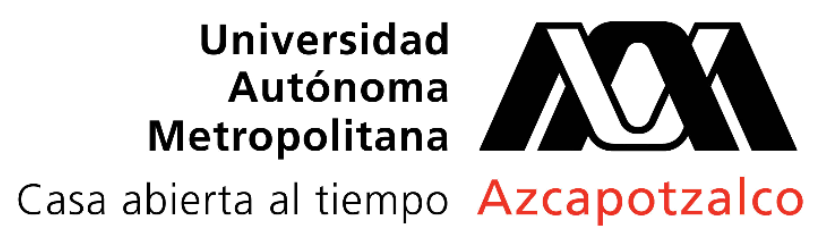

DIVISIÓN DE CIENCIAS Y ARTES PARA EL DISEÑO

Especialización, Maestría y Doctorado en Diseño

\title{
ANÁLISIS Y PROPUESTA DEL DISEÑO DE LA SILLA DE RUEDAS DE PROPULSIÓN MANUAL A PARTIR DE LA PERCEPCIÓN Y SATISFACCIÓN DE LOS USUARIOS CON DISCAPACIDAD MOTRIZ
}

\author{
José David Rojas Anaya
}

Tesis para optar por el grado de Maestro en Diseño

Posgrado en Diseño y Desarrollo de Productos

Miembros del jurado:

Mtra. Areli García González

Directora de la tesis

Mtro. Alejandro Ramírez Lozano

Codirector de la tesis

Mtra. Ruth Alicia Fernández Moreno Mtra. Karla Beranger Pagés Puente Mtro. Luis Yoshiaki Ando Ashijara

Dr. Alejandro Cerda García

Ciudad de México

Agosto 2021 
Dedicado a

Evangelina Rincón de Sandoval (Q,E,D.D)

Catalina Isabel Rangel Sandoval (Q,E,D,D) 


\section{Agradecimientos}

A la Universidad Autónoma Metropolitana por abrirme sus puertas y otorgarme una beca para poder realizar mi sueño de estudiar un posgrado.

A mi directora de tesis, la Mtra. Areli García González por su labor admirable como docente y por orientarme en cada etapa de esta investigación. Además, mi más profundo agradecimiento por su amistad y por cada uno de sus consejos.

Al Mtro. Alejandro Ramírez Lozano por aceptar ser el codirector de esta investigación, por su dedicación como coordinador del posgrado en Diseño y Desarrollo de Productos y por brindarme su colaboración en todos los trámites administrativos.

A mi grupo de lectores de tesis, la Mtra. Ruth Fernández, la Mtra. Karla Pagés, el Mtro. Yoshiaki Ando y el Dr. Alejandro Cerda por ofrecerme su tiempo, conocimiento y experiencia en cada una de sus observaciones para poder finalizar esta investigación de la mejor manera posible.

A la Fundación para la Inclusión y Desarrollo de Personas con Discapacidad - Findedis A.C y en especial a su directora Martha García por su disposición y colaboración en la recolección de la información en este proyecto.

Al Instituto de las Personas con Discapacidad de la Ciudad de México por proporcionarme el espacio para realizar las entrevistas necesarias en este estudio.

A mis padres Mariela y Antonio por su cariño y por apoyarme en cada una de mis decisiones.

A Leidy Abril Ardila y sus padres Patricia y Jairo, por la amistad y el impulso para continuar con mis estudios.

A Laura Ribeiro Florio porque a pesar de la distancia me ha brindado una amistad sincera e incondicional. También gracias por inspirarme a mejorar cada día y por motivarme en mis momentos difíciles.

A todas las personas con discapacidad que de manera voluntaria aceptaron participar en esta investigación.

A cada uno de mis amigos en México por hacerme sentir en familia. 


\section{RESUMEN}

La presente investigación buscó analizar el diseño de la silla de ruedas de propulsión manual y proponerle mejoras y adecuaciones a partir de la satisfacción y percepción de los usuarios con discapacidad motriz de la Ciudad de México. Por lo anterior, este estudio muestra resultados cuantitativos y cualitativos referentes a la satisfacción y percepción de los usuarios de silla de ruedas en relación con esta ayuda técnica.

Como objetos de estudio, se consideraron dos tipos de silla de ruedas de propulsión manual: la de estructura rígida y la de estructura plegable. Para obtener los resultados cualitativos se emplearon una serie de entrevistas de forma presencial en las que se obtuvieron hallazgos de tipo exploratorio donde se evidenciaron algunos factores emocionales y factores físicos de la silla de ruedas relacionados con la insatisfacción del usuario.

En cuanto a la parte cuantitativa, los resultados fueron obtenidos por medio de dos herramientas, que fueron aplicadas de manera presencial y virtual, esta última debido a la pandemia del COVID-19. La primera herramienta, consistió en el cuestionario QUEST 2.0 (Quebec User Evaluation of Satisfaction with Assistive Technology) que tuvo como propósito mostrar de forma numérica el grado de satisfacción de los usuarios con respecto a diferentes características de usabilidad de la silla de ruedas. La segunda, fue la Escala de Diferencial Semántico, en este caso, utilizada para la cuantificación de la percepción de los usuarios hacia su silla de ruedas.

Una vez fue recolectada y analizada la información descrita anteriormente, se procedió a la identificación de los requerimientos de diseño, que contribuyeron al planteamiento de las adecuaciones que fueron fue modeladas en SolidWorks y que posteriormente fueron sometidas a un análisis de elementos finitos en el mismo software.

Finalmente, la silla de ruedas con sus respectivas adecuaciones fue evaluada mediante la Rueda Emocional de Ginebra con el objetivo de medir las reacciones emocionales de los usuarios a partir de la interacción visual con esta. De la evaluación, se obtuvieron reacciones emocionales positivas en comparación con la silla de ruedas de estructura rígida y a la de estructura plegable. 


\section{CONTENIDO}

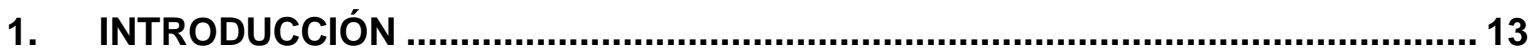

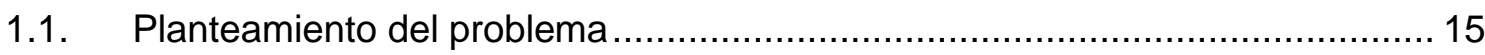

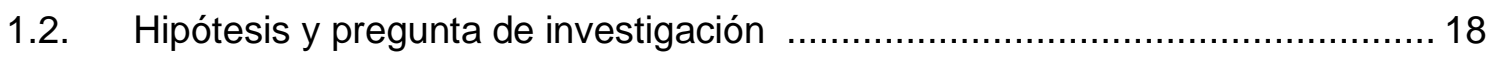

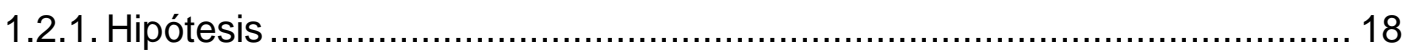

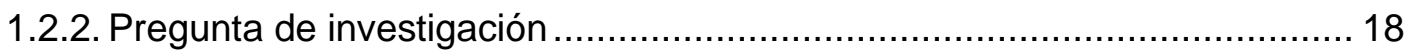

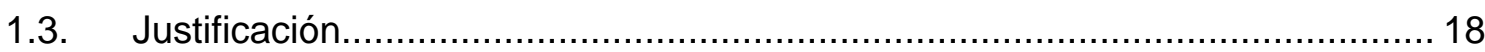

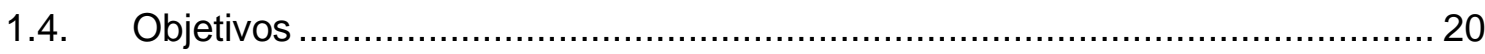

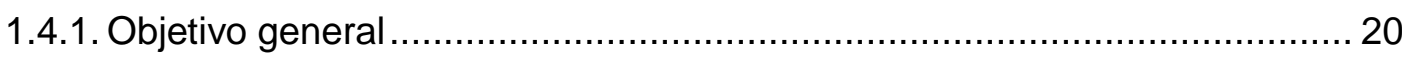

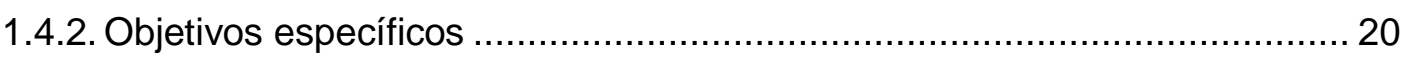

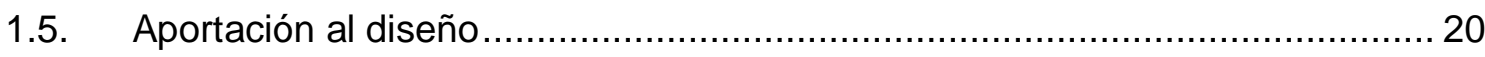

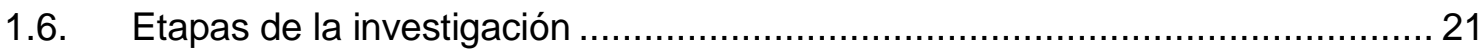

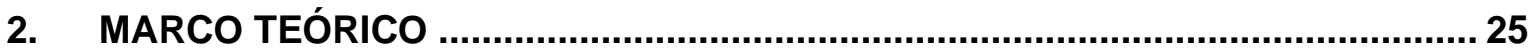

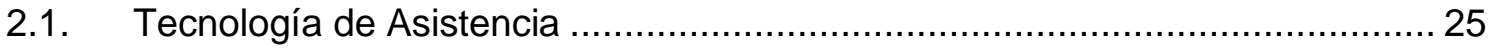

2.2. Ayudas técnicas para la movilidad personal y transporte …………………... 27

2.2.1. Clasificaciones de las ayudas técnicas para la movilidad y transporte ....... 28

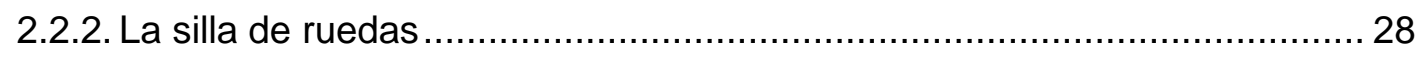

2.3. Experiencia del Usuario (User Experience - UX) ........................................... 31

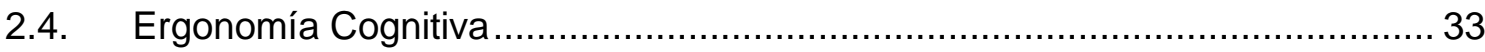

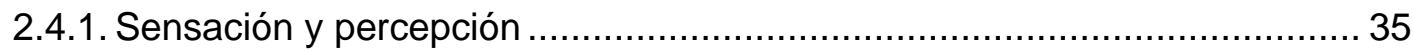

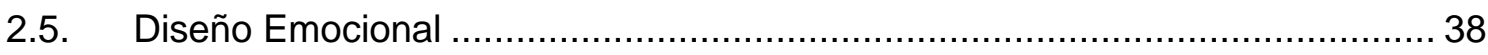

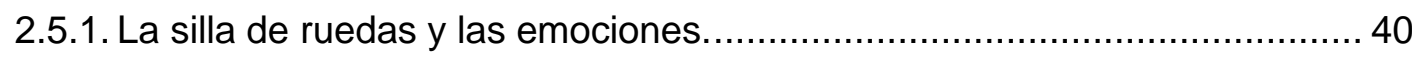

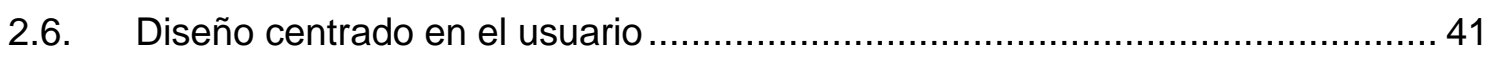

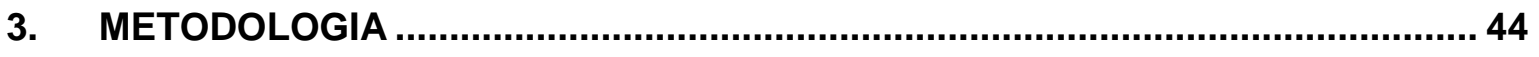

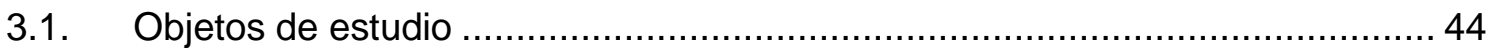

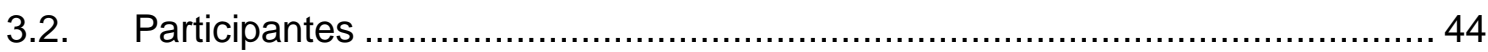




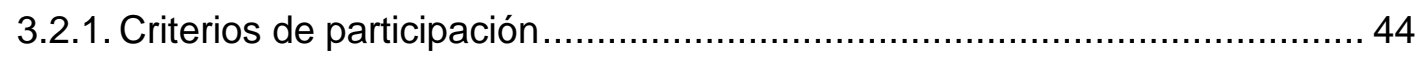

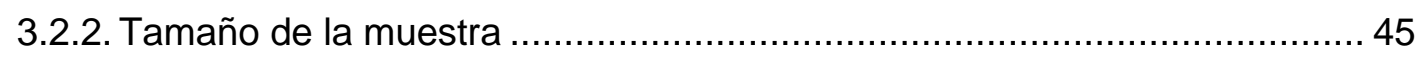

3.3. Instrumentos para la recolección de la información ......................................... 47

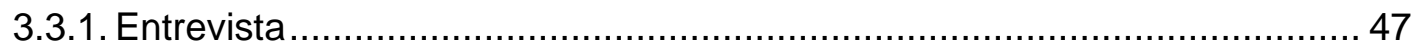

3.3.2. QUEST 2.0 (Quebec User Evaluation of Satisfaction with Assistive

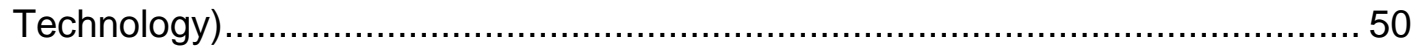

3.3.3. Escala de Diferencial Semántico............................................................ 51

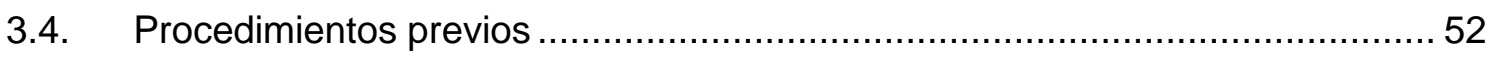

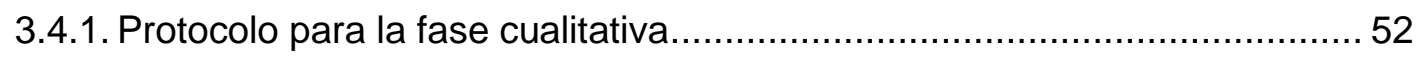

3.4.2. Protocolo para la fase cuantitativa .......................................................... 52

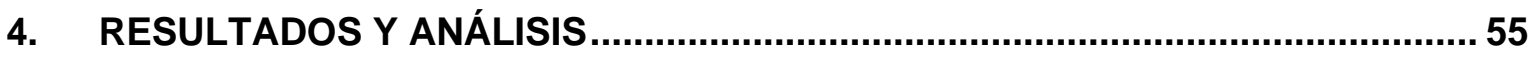

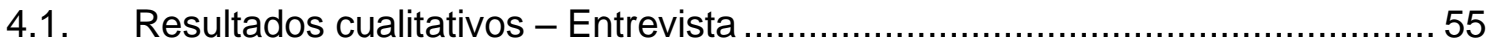

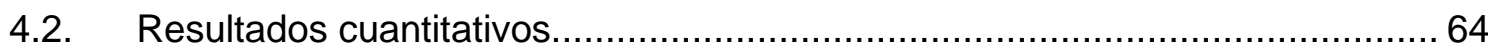

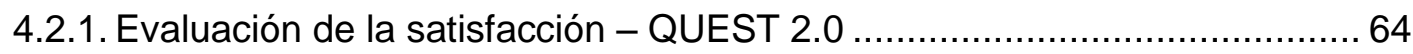

4.2.2. Cuantificación de la percepción - Escala de Diferencial Semántico ............ 77

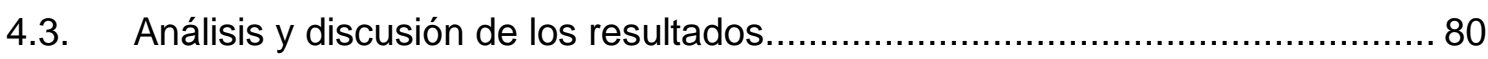

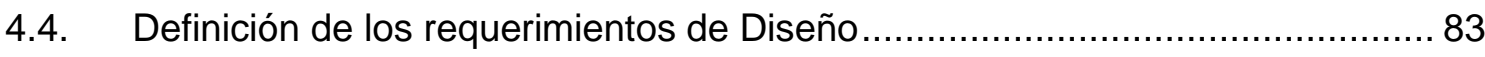

5. DESARROLLO Y SIMULACIÓN DE ESFUERZOS PARA EL MODELO

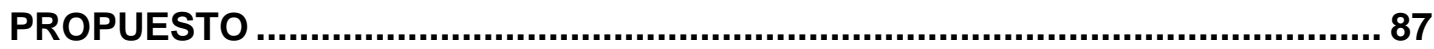

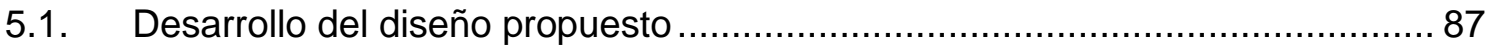

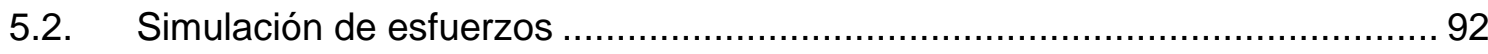

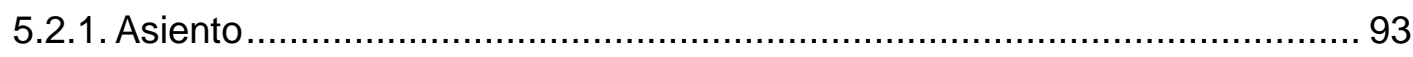

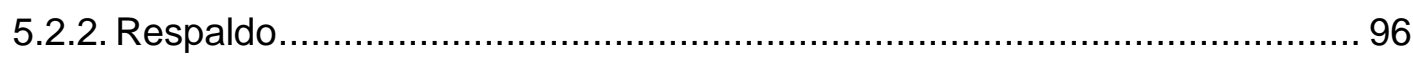

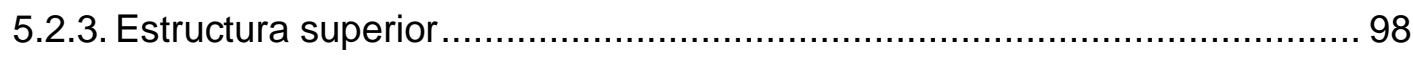

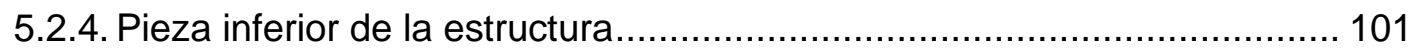

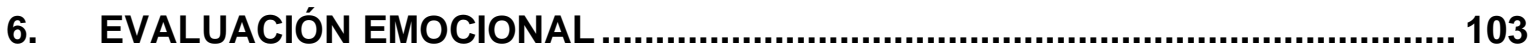

6.1. Muestra de población para la evaluación del diseño ..................................... 104 
6.2. Instrumento de la evaluación - Rueda Emocional de Ginebra (Geneva Emotion

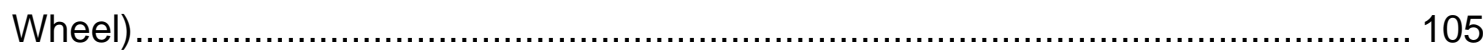

6.3. Configuración experimental de la Evaluación emocional ............................... 105

6.4. Procedimiento de la Evaluación Emocional ................................................. 105

6.5. Procesamiento de datos de la Evaluación Emocional ................................... 106

6.6. Resultados de la Evaluación Emocional.................................................... 106

6.7. Discusión de la evaluación emocional ....................................................... 108

7. CONCLUSIONES Y CONSIDERACIONES FINALES …..................................... 110

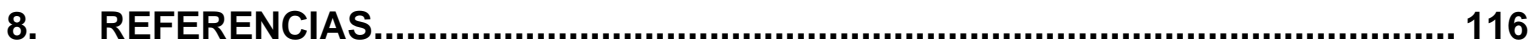

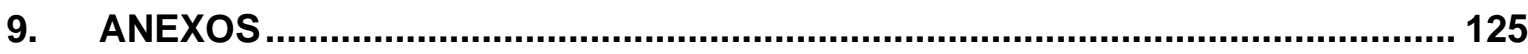




\section{LISTA DE FIGURAS}

Figura 1 Porcentaje de la población mexicana por tipo de discapacidad..............................16

Figura 2 Distribución porcentual de la ayuda técnica en personas con discapacidad motriz. ...16

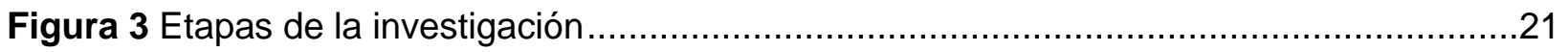

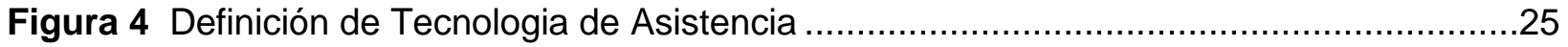

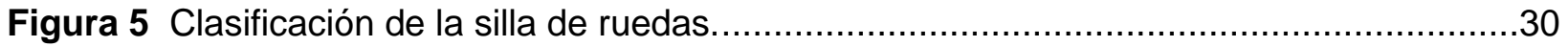

Figura 6 Disciplinas que intervienen en la Experiencia del Usuario .....................................32

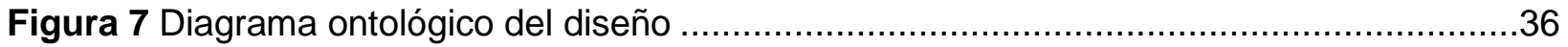

Figura 8 Relación entre el diseño emocional y las funciones de los objetos ...........................39

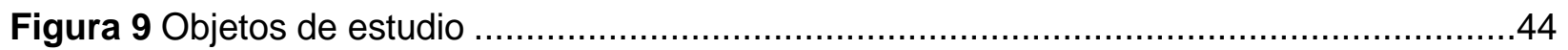

Figura 10 División de la muestra de población $(n=52)$ por tiempo de uso de la silla de ruedas.66

Figura 11 Resultados de la Escala de Diferencial Semántico .........................................79

Figura 12 Ideas / bocetos para la propuesta de la silla de ruedas ....................................8

Figura 13 Mecanismo Q-Lock Handlepost (bloqueo rápido) ........................................... 89

Figura 14 Propuesta final de la silla de ruedas de propulsión manual ..................................90

Figura 15 Plegado de la silla de ruedas de propulsión manual propuesta ...........................91

Figura 16 Vista lateral y frontal del diseño propuesto simulado con figura humana.................91

Figura 17 Vista lateral y frontal de la propuesta de diseño con sus principales medidas .........92

Figura 18 Simulación de tensiones para el asiento analizado en SolidWorks........................94

Figura 19 Simulación de desplazamientos para el asiento analizado en SolidWorks .............95

Figura 20 Factor de seguridad resultante en el asiento analizado en SolidWorks ..................95

Figura 21 Simulación de tensiones para el respaldo analizado en SolidWorks.......................96

Figura 22 Simulación de desplazamientos para el respaldo analizado en SolidWorks ............97

Figura 23 Factor de seguridad resultante en el respaldo analizado en SolidWorks ................97

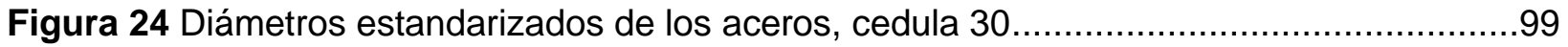


Figura 25 Simulación de tensiones para la estructura superior analizado en SolidWorks

Figura 26 Simulación de desplazamientos para la estructura analizado en SolidWorks .........100

Figura 27 Factor de seguridad resultante para la estructura analizado en SolidWorks ...........100

Figura 28 Diagrama de cuerpo libre de la estructura superior ........................................101

Figura 29 Simulación de tensiones para la pieza inferior de la estructura analizado en

SolidWorks.

Figura 30 Simulación de desplazamientos para la pieza inferior de la estructura analizado en

SolidWorks. .102

Figura 31 Factor de seguridad resultante en la pieza inferior de la estructura analizado en

SolidWorks.

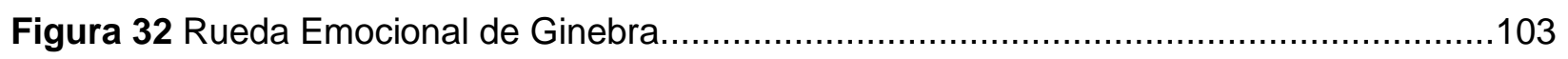

Figura 33 Resultados de la evaluación emocional para los usuarios de la silla de ruedas de

estructura plegable

Figura 34 Resultados de la evaluación emocional para los usuarios de la silla de ruedas de

estructura rígida. 


\section{LISTA DE TABLAS}

Tabla 1 Distribución y edades promedio de la muestra de participantes en la fase cualitativa.45

Tabla 2 Distribución y edades promedio de la muestra de participantes en la fase cuantitativa46

Tabla 3 Fundamentación teórica de las preguntas realizadas en la entrevista......................48

Tabla 4 Pares de adjetivos empleados en la Escala de Diferencial Semántico ......................54

Tabla 5 Categorías para la primera pregunta “¿Se encuentra usted satisfecho con su silla de

ruedas?"

Tabla 6 Categorías para la segunda pregunta “¿De qué manera considera que su silla de ruedas afecta positivamente su vida?"

Tabla 7 Categorías para la tercera pregunta “¿De qué manera considera que su silla de ruedas afecta negativamente su vida?" .57

Tabla 8 Categorías para cuarta la pregunta “¿Qué le cambiaria al diseño de la silla de

ruedas?". .58

Tabla 9 Categorías para la quinta pregunta “¿La silla de ruedas le ocasiona dolores o

molestias en su cuerpo?"

Tabla 10 Categorías para la sexta pregunta “¿Qué actividades le gustaría hacer con su silla de ruedas?".

Tabla 11 Categorías para la séptima pregunta “¿Le resulta fácil maniobrar su silla de ruedas?"61 Tabla 12 Categorías para la octava pregunta “¿Ha personalizado o realizado adaptaciones a su silla de ruedas para sentirse más cómodo?"

Tabla 13 Categorías para la novena pregunta “¿Cuáles reacciones emocionales cree usted que produce su silla de ruedas a las personas de su entorno?".

Tabla 14 Categorías para la décima pregunta “¿Cuáles reacciones emocionales le produce a usted su silla de ruedas?"

Tabla 15 Datos obtenidos de la aplicación del QUEST 2.0 para la silla de ruedas de propulsión manual de estructura plegable 68 
Tabla 16 Datos obtenidos de la aplicación del QUEST 2.0 para la silla de ruedas de propulsión manual de estructura rígida. 68

Tabla 17 Recurrencias de los aspectos evaluados en el QUEST 2.0 según la importancia indicada por los participantes.

Tabla 18 Comentarios recurrentes de los usuarios con respecto a las dimensiones de su silla de ruedas.

Tabla 19 Comentarios recurrentes de los usuarios con respecto al peso de su silla de ruedas 71

Tabla 20 Comentarios recurrentes de los usuarios con respecto a la facilidad de ajustar de su silla de ruedas

Tabla 21 Comentarios recurrentes de los usuarios con respecto a la estabilidad y seguridad de su silla de ruedas. .73

Tabla 22 Comentarios recurrentes de los usuarios con respecto a la durabilidad de su silla de ruedas

Tabla 23 Comentarios recurrentes de los usuarios con respecto a la facilidad de su silla de ruedas

Tabla 24 Comentarios recurrentes de los usuarios con respecto a la comodidad de su silla de ruedas

Tabla 25 Comentarios recurrentes de los usuarios con respecto a la efectividad de su silla de ruedas. .76

Tabla 26 Comentarios recurrentes de los usuarios con respecto a la atracción visual de su silla de ruedas. 77

Tabla 27 Ponderaciones de satisfacción resultantes de la aplicación del QUEST 2.0 .84

Tabla 28 Características consideradas más importantes por los usuarios de silla de ruedas ..84

Tabla 29 Pares de adjetivos con los menores índices de percepción .85

Tabla 30 Requerimientos de diseño planteados para la investigación .86

Tabla 31 Propiedades mecánicas de polipropileno .94 
Tabla 32 Propiedades mecánicas del Acero AISI 1020

Tabla 33 Distribución y edades promedio de la muestra de participantes en la evaluación emocional 


\section{INTRODUCCIÓN}

Al cuantificar el total de la población con discapacidad ${ }^{1}$ a nivel mundial, se estima que aproximadamente 1,000 millones de personas, es decir cerca del 15\% padece algún tipo de discapacidad (OMS, 2011)². Para el caso específico de México se estimó que para el año 2020 aproximadamente el 4,9\% de la población (más de 6 millones de personas) posee alguna discapacidad y concretamente en la Ciudad de México el $5.4 \%$ de sus habitantes se encuentran en condición de discapacidad (INEGI, 2020b). Asimismo, en México, el Instituto Nacional de Estadística, Geografía e Informática (INEGI) elaboró una clasificación por tipo de discapacidad en la cual se destacan cuatro grupos: discapacidades sensoriales y de comunicación, motrices, mentales y discapacidades múltiples (INEGI, 2017).

Las discapacidades anteriormente descritas, pueden ser apoyadas por servicios, equipos y/o instrumentos especiales denominados Tecnología de Asistencia ${ }^{3}$ que contribuyen a mejorar el bienestar de las personas con discapacidad (OMS, 2017). E término Tecnología de Asistencia o Tecnología de Apoyo está ligada al concepto de discapacidad. Sin embargo, a pesar de ser un tipo de tecnología reconocida y aceptada en el ambiente médico/científico, su uso y aprovechamiento por parte de usuarios finales es limitado (Mattozo, 2016). Específicamente, la Tecnología de Asistencia abarca múltiples recursos (capaces de proporcionar diferentes formas de apoyo práctico), que producen importantes beneficios sociales y de comportamiento en

\footnotetext{
1 "Discapacidad es un término general que abarca las deficiencias, las limitaciones de la actividad y las restricciones de la participación. Las deficiencias son problemas que afectan a una estructura o función corporal; las limitaciones de la actividad son dificultades para ejecutar acciones o tareas, y las restricciones de la participación son problemas para participar en situaciones vitales. Por consiguiente, la discapacidad es un fenómeno complejo que refleja una interacción entre las características del organismo humano y las características de la sociedad en la que vive". Organización Mundial de la Salud. (17 de julio del 2019). Recuperado de: https://www.who.int/topics/disabilities/es/

${ }^{2}$ Organización Mundial de la Salud. Recuperado de https://www.who.int/es

${ }^{3}$ Tecnología de Asistencia se refiere a una variedad de dispositivos y servicios destinados ayudar a las personas con discapacidad, manteniendo y/o mejorando su autonomía obteniendo como resultado una mejor calidad de vida (OMS, 2018).
} 
los usuarios, reduciendo el impacto negativo de sus discapacidades y afecciones relacionadas (Lancioni et al., 2013).

Entre las Tecnologías de Asistencia se encuentran las ayudas técnicas ${ }^{4}$ como la silla de ruedas. Este dispositivo es la herramienta de uso más frecuente para mejorar la movilidad personal y aproximadamente a nivel mundial el $10 \%$ de la población con discapacidad motriz requieren el uso de una silla de ruedas. Además, una silla de ruedas en condiciones adecuadas, puede establecer el primer paso para la inclusión y participación en la sociedad del individuo (OMS, 2008). Aunque el tener acceso a una silla de ruedas es de extrema importancia, se calcula que sólo una minoría de quienes la necesitan tiene acceso a ellas y a menudo, cuando tienen acceso al uso de una silla de ruedas, estas no son adecuadas a su entorno o necesidades (ISPO et al., $2006)^{5}$.

Por otro lado, en cuanto al diseño de ayudas técnicas existe una exigencia e intención de obtener productos con un mayor grado de satisfacción del usuario, por consiguiente, surge la necesidad de incorporar al mismo usuario, en metodologías de diseño y desarrollo de estos productos (Soares et al., 2017). Lo anterior, con el propósito de lograr ayudas técnicas que satisfagan las necesidades de los usuarios y por lo tanto que se mejore la percepción en cuanto al uso del producto. Sin embargo, existen investigaciones centradas en el diseño de sillas de ruedas para apoyar discapacidades de movilidad (Abreu e Lima et al., 2016; Olmedo-Torre et al., 2016; Sutradhar et al., 2017), no obstante, estos estudios basan el desarrollo del prototipo solo en cuestiones técnicas sin considerar la percepción y satisfacción del usuario

4 De acuerdo con la Organización Mundial de la Salud, las ayudas técnicas hacen referencia a cualquier dispositivo externo que tenga como propósito mejorar y/o mantener la funcionalidad e independencia de una persona. De esta manera, las ayudas técnicas son dispositivos indispensables para superar la condición de discapacidad, atenuar los efectos causados por perdida funcional progresiva, evitar la necesidad de recurrir a cuidadores y disminuir los gastos al sistema de salud y bienestar social. Algunos ejemplos de ayudas técnicas son las sillas de ruedas, audífonos, prótesis, órtesis, caminadores, muletas, entre otras, así como las Tecnologías de la Información y Comunicación (2017). Recuperado de https://apps.who.int/iris/handle/10665/274141

5 International Society for Prosthetics and Orthotics (ISPO). Recuperado de https://www.who.int/disabilities/technology/WCGconcensusconf/en/ 
final. Dentro del campo de desarrollo de productos es fundamental conocer las necesidades reales de los usuarios o consumidores durante el diseño y desarrollo de los mismos (Mattozo, 2016). Asimismo, una silla de ruedas es apropiada cuando es segura, cómoda y sobre todo cuando cumple las necesidades a las condiciones del entorno del individuo (Sheldon, 2007).

\subsection{Planteamiento del problema}

De acuerdo con información de la Organización Mundial de la Salud, la tasa de personas con discapacidad a nivel mundial está en constante aumento. Factores como el envejecimiento de la población y el incremento de las enfermedades crónicas incrementan esta población vulnerable (2011a). En América Latina, existen factores adicionales que incrementan esta cifra, como el conflicto armado, la violencia, los accidentes y el abuso de alcohol y drogas (OPS, 2006) ${ }^{6}$.

En el caso de México, el índice de personas con discapacidad en el año 2020 fue de $4.9 \%$, lo cual refleja que 6.1 millones de habitantes presentaron un tipo de limitación o deficiencia física. De todas las discapacidades presentes en la población mexicana, la discapacidad motriz un abarca un $47.6 \%$, siendo esta la más relevante. La Figura 1 muestra el porcentaje de población por tipo de discapacidad en la cual se evidencia la notoriedad de las limitaciones presentes en los miembros inferiores (INEGI, 2020b).

Como dato complementario a la Figura 1, del total de población con discapacidad motriz, cerca del $20 \%$ no utiliza ningún tipo de ayuda técnica (INEGI, 2014). La Encuesta Nacional de Hogares (INEGI, 2014) reporta a la silla de ruedas y el bastón como las ayudas técnicas que más utilizan las personas con discapacidad motriz. Lo anterior se puede apreciar en la Figura 2.

${ }^{6}$ Organización Panamericana de la Salud. Recuperado de https://www.paho.org/hq/index.php?lang=es 


\section{Figura 1}

Porcentaje de la población mexicana por tipo de discapacidad.

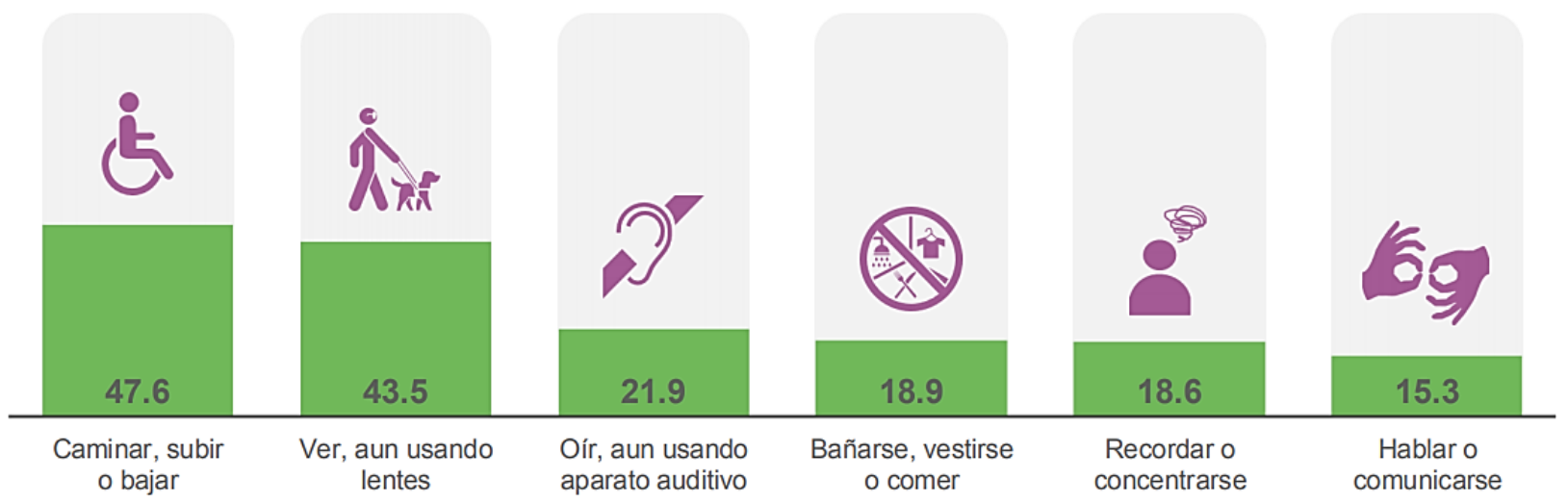

Nota. Según el autor, el porcentaje se calculó con base en el total de la población con distintos tipos de discapacidad. La suma de los porcentajes es mayor que 100 porque una persona puede tener más de un tipo de discapacidad. Tomado de Presentación de resultados, INEGI, 2020.

\section{Figura 2}

Distribución porcentual de la ayuda técnica en personas con discapacidad motriz.

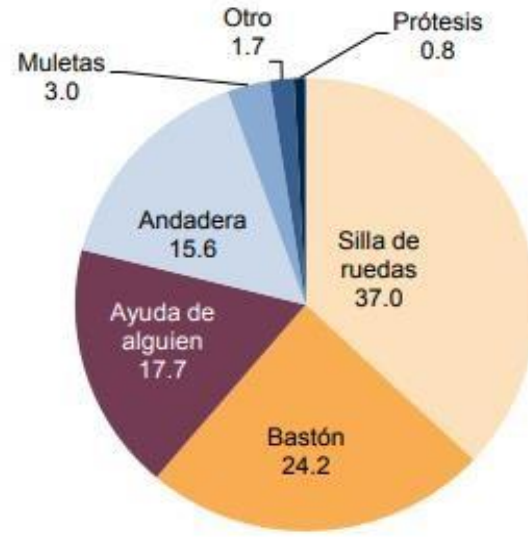

Nota. Tomado de La discapacidad en México, datos al 2014, INEGI, 2014.

La silla de ruedas se incluye en la Tecnología de Asistencia como un dispositivo que brinda apoyo postural y auxilia la movilidad de las personas con discapacidad motriz, por lo tanto, permite al individuo desplazarse con autonomía e independencia (Marín-Vásquez, 2017). La Tecnología de Asistencia se divide en dos aspectos: productos y servicios de apoyo. Los productos se refieren a los artículos, equipos, 
productos o sistemas fabricados en serie o sobre medida, utilizados para aumentar, mantener o mejorar las capacidades funcionales de las personas con algún tipo de discapacidad. Los servicios se refieren a aquellos elementos que auxilian directamente una persona con deficiencia a seleccionar, comprar o usar aquellos recursos definidos anteriormente y que son prestados por personal profesional a las personas con discapacidad (BERSCH, 2005). Además, la Tecnología de Asistencia comprende metodologías, estrategias, prácticas y procesos que intervienen directamente con la creación y el uso de ayudas técnicas (Soares et al., 2017). La Organización Mundial de la Salud (2008), afirma que las Tecnologías de Asistencia, cuando están adecuadas al usuario y su ambiente, son herramientas poderosas para aumentar su independencia y mejorar la participación social o comunitaria.

Cabe mencionar que, a pesar de la importancia de que los usuarios cuenten con una silla de ruedas correctamente diseñada, que proporcione independencia y que les permita sentirse parte de una sociedad, el diseño de esta no ha tenido mucho interés en el área científica, por lo tanto, existe ausencia de trabajos de investigación relacionados con el estudio ergonómico y de usabilidad de usuarios de sillas de ruedas convencionales. Adicional a lo mencionado anteriormente, pocas veces los usuarios son tomados en cuenta en el proceso de diseño y se desconoce el nivel de satisfacción con relación al uso de los productos de Tecnología de Asistencia en general (Magnusson et al., 2013). La silla de ruedas convencional presenta deficiencias por un inadecuado diseño ergonómico, ya que su versión convencional no cumple con los requisitos de seguridad y comodidad que los usuarios requieren para satisfacer sus necesidades (Herrera-Saray et al., 2013).

Por otro lado, en el diseño y desarrollo de dispositivos de Tecnología de Asistencia es de gran importancia considerar la percepción y satisfacción del usuario, los cuales son dos factores que están ligados a la usabilidad del producto e influenciados por las expectativas y valores personales de los usuarios (Rossi et al., 2010). Por lo tanto, según Rossi et al. (2010) la satisfacción del usuario es una evaluación crítica que refleja que tan bien el dispositivo cumple sus necesidades. Sin embargo, en cuanto a la satisfacción con el diseño y uso de la silla de ruedas, algunos estudios (Visagie et al., 2015) han indicado que los usuarios presentan un grado de 
insatisfacción con características propias de la misma. Además de los usuarios de las sillas de ruedas de propulsión manual, los cuidadores de estos usuarios también presentan posa satisfacción con el dispositivo dada que su interacción con el dispositivo se ve afectada por factores como la dimensiones, los freno y el peso de este (Marchiori et al., 2015). Por consiguiente, se puede destacar que los aportes y los puntos de vista del usuario son fundamentales para el éxito de un diseño: un diseño desde y para el usuario (Herrera-Saray et al., 2013)

La inclusión de los usuarios de la silla de ruedas convencional según la Organización Mundial de la Salud (2008), es un recurso clave en la gestión de diseño, dado que puede colaborar en buena medida a mejorar el diseño de la misma. Por lo anterior, se propone esta investigación la cual busca analizar el diseño de la silla de ruedas de propulsión manual y proponer un modelo de esta mediante la identificación de mejoras que pueden surgir de la satisfacción y percepción de los usuarios con discapacidad motriz, considerando su participación en el diseño.

\subsection{Hipótesis y pregunta de investigación}

\subsubsection{Hipótesis}

La satisfacción y percepción de los usuarios con discapacidad motriz pueden brindar elementos que permitan mejorar el diseño de la silla de ruedas convencional.

\subsubsection{Pregunta de investigación}

¿Qué aspectos se deben considerar para mejorar el diseño de la silla de ruedas convencional tomando en consideración la satisfacción y percepción de los usuarios con discapacidad motriz?

\subsection{Justificación}

De acuerdo con la información más reciente del Censo de Población y Vivienda, publicada por el INEGI (2020a), alrededor del 4.9\% de la población mexicana reportó tener algún tipo de discapacidad. La población más afectada fue la de los adultos mayores (personas de 60 años y más), con $40.9 \%$ del total. Del mismo modo, se 
resalta que una de cada seis personas vive con alguna discapacidad, limitación para realizar actividades o con algún problema de índole mental (INEGI, 2021). Las causas principales que ocasionan la condición de discapacidad en la población mexicana son enfermedades (41.2\%), edad avanzada (27\%), problemas congénitos (15.4\%) y accidentes (12,2\%) (INEGI, 2020a). Igualmente, como pronóstico se calcula que para el año 2050 la población con discapacidad en México será de 22 millones (UrquietaSalomón et al., 2008).

El proyecto se justifica en el campo social porque busca información relevante que puede contribuir de gran manera en la mejora de la calidad de vida de las personas con discapacidad, que como se mencionó anteriormente son un $15 \%$ de la población mundial y un $6 \%$ de la demografía de los Estados Unidos Mexicanos. Según la Organización Mundial de la Salud (2014), se estima que aproximadamente el 75\% de las ayudas técnicas son abandonadas por los usuarios, representando así un gran fallo en los sistemas y políticas de diseño. Muchos de los factores causantes del abandono de las ayudas técnicas pueden ser resueltos o tratados en el proceso de diseño, ya que son factores que están asociados a aspectos inadecuados e inadaptados a las capacidades y necesidades de los usuarios, baja atracción visual, incomodidad e inseguridad. Por consiguiente, se reafirma la necesidad de realizar una investigación para resaltar el grado de satisfacción y percepción del usuario como un factor importante en la gestión del diseño dado que según la Organización Mundial de la Salud (2014), es de carácter urgente realizar un cambio en la manera tradicional de cómo los productos de Tecnología de Asistencia son percibidos, diseñados, fabricados, distribuidos y financiados con el propósito de mejorar el panorama actual.

De igual modo, la investigación encuentra una justificación en el área académica porque existe un déficit o baja producción científica en temas relacionados a la Tecnología de Asistencia. Por lo tanto, se pretende realizar esta investigación para generar conocimiento en esta área de estudio en América Latina debido a que los creadores, diseñadores e ingenieros de productos de Tecnologías de Asistencia predominan en las naciones desarrolladas. Adicional a lo anterior, generalmente los ingenieros y diseñadores suelen recibir muy poca información en su capacitación 
profesional sobre personas con discapacidades o pautas de diseño para satisfacer las necesidades de todos los posibles consumidores con o sin discapacidades.

\subsection{Objetivos}

\subsubsection{Objetivo general}

Proponer mejoras y adecuaciones para la silla de ruedas de propulsión manual a partir de la percepción y satisfacción de los usuarios con discapacidad motriz en extremidades inferiores.

\subsubsection{Objetivos específicos}

- Conocer y medir el grado de satisfacción y la percepción del usuario con discapacidad motriz respecto al uso de la silla de ruedas convencional por medio de la aplicación de una metodología cualitativa y cuantitativa.

- Definir las mejoras en el diseño de la silla de ruedas de propulsión manual basadas en la satisfacción y percepción de los usuarios con discapacidad motriz en las extremidades inferiores.

- Desarrollar un modelo 3D en software de diseño CAD/CAE para visualizar la propuesta final y comprobar su resistencia mediante una simulación de esfuerzos.

- Evaluar las reacciones emocionales provocadas por la propuesta de diseño de la silla de ruedas convencional y comparar dichas reacciones emocionales con los modelos de sillas de ruedas estándar.

\subsection{Aportación al diseño}

Este proyecto busca brindar pautas metodológicas en el diseño y desarrollo de las ayudas técnicas como la silla de ruedas convencional mediante la inclusión del usuario en el proceso de planeación del producto, conociendo su satisfacción y percepción con el fin de lograr dispositivos los cuales cumplan las expectativas de los usuarios. Lo anterior, dado que se evidencia una preocupación recurrente con el bienestar del usuario, su inclusión y participación en los procesos de desarrollo de las ayudas técnicas. Asimismo, dado que existe una carencia en publicaciones científicas que 
aborden las Tecnologías de Asistencia desde la perspectiva de las necesidades reales de los usuarios, el proyecto busca aportar a la literatura un estudio en el cual se evidencie el grado de satisfacción y percepción de los usuarios con respecto al uso de la silla de ruedas convencional. En general, la investigación pretende dar mayor participación al usuario en un área donde los productos no siempre son desarrollados en función de este o de los cuidados a sus necesidades.

\subsection{Etapas de la investigación}

La Figura 3 muestra las etapas que se llevarán a cabo durante el desarrollo de la investigación:

Figura 3

Etapas de la investigación

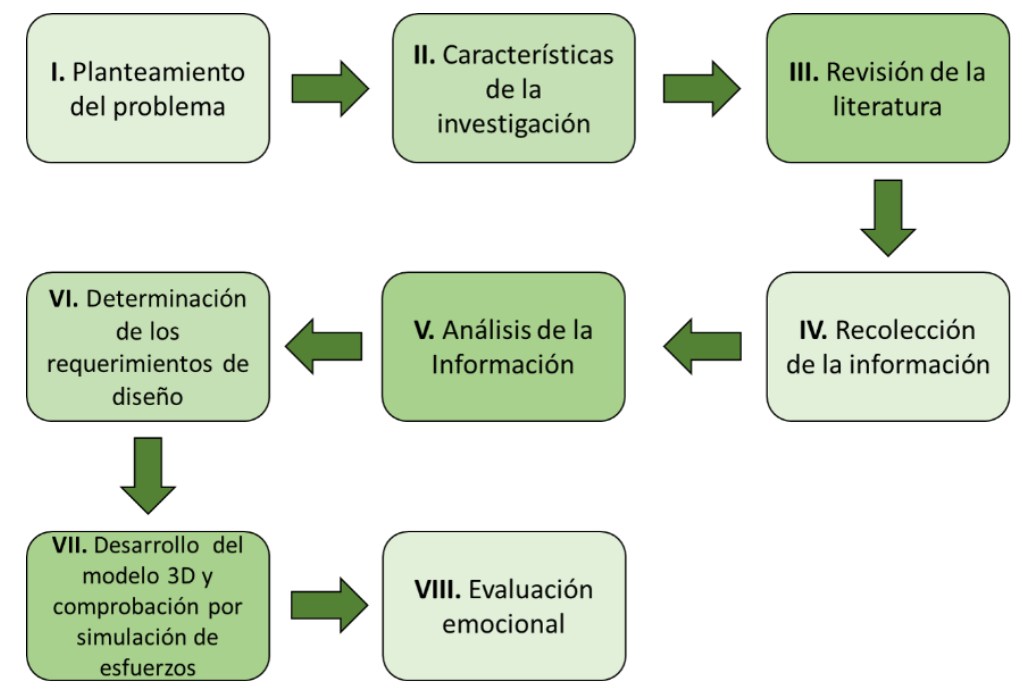

I. Planteamiento del problema. Esta etapa consiste en exponer el problema de estudio de manera delimitada y concreta. El planteamiento del problema se encuentra descrito en los numerales anteriores, que abordan los temas de planteamiento del problema, hipótesis, pregunta de investigación, justificación, objetivos y aportación al diseño. 


\section{Características de la investigación}

- Enfoque de la investigación: La investigación presenta un enfoque mixto (cuantitativo y cualitativo). En la parte cuantitativa se busca calcular por medio de la aplicación de un cuestionario, el grado de satisfacción de los usuarios de las sillas de ruedas convencionales, para determinar las necesidades más relevantes que intervendrán en el rediseño de esta. En la orientación cualitativa, se pretende conocer la percepción (emociones, prioridades, experiencias, y otros aspectos subjetivos) con respecto al uso la silla de ruedas convencional. Con lo anterior se busca generar investigación referente a la satisfacción y percepción de las sillas de ruedas de propulsión manual mediante la convergencia de varias "realidades" que son las cualidades únicas de los usuarios.

- Método de la investigación. El proyecto tiene como método el razonamiento inductivo dado que es una investigación que va de lo específico a lo general, dado que en la aplicación de un cuestionario de satisfacción se perciben unos patrones los cuales son generalizados para obtener resultados y conclusiones comunes. Además, es importante mencionar que se pretende abordar un tema del cual hasta el año 2019 se desconoce, como lo es el grado de satisfacción del usuario con relación al uso de la silla de rueda convencional. Lo anterior se pretende llevar a cabo con el método inductivo, puesto que explora y describe las interpretaciones de los usuarios para llegar a un nuevo conocimiento.

- Tipo y diseño de investigación. La investigación es de tipo exploratoria debido a que pretende abordar un tema poco estudiado en la población mexicana con discapacidad motriz como el grado de satisfacción respecto a la usabilidad de la silla de ruedas convencional. A su vez, se busca proponer un rediseño de esta desde la percepción y satisfacción del usuario. También, puede ser de tipo descriptivo pues se busca especificar los requerimientos de diseño de una silla de ruedas convencional mediante el análisis de una pequeña muestra de población. En efecto, este estudio se encuentra bajo un diseño de investigación transversal o transeccional descriptiva dado 
que se tiene como objetivo indagar en la satisfacción y percepción del usuario sin realizar un seguimiento de este a través del tiempo.

III. Revisión de la literatura. Hace referencia al marco teórico que da sustento a la investigación y mediante el cual se pueden revelar estudios anteriormente realizados respecto a la problemática en cuestión. Además, la revisión de diseños de investigación puede servir como guía para seleccionar los instrumentos apropiados en la recolección de los datos. Esta etapa no solo es de utilidad para la investigación, sino que es aquí donde se podrá formar un glosario que permita que cualquier lector se familiarice con el tema.

IV. Recolección de la información. Para recolectar información se recurrirá a fuentes primarias. Las fuentes primarias corresponden a las que vienen directamente de la población de estudio, para ello se hará uso principalmente de las siguientes herramientas: entrevistas, encuestas y observación participante. Las entrevistas tendrán como objetivo captar la información relevante de la percepción del usuario en cuanto a la usabilidad de la silla de ruedas convencional. La encuesta se realizará mediante la aplicación de un cuestionario estructurado que permita conocer la satisfacción de los usuarios con discapacidad motriz en el cual se aborden criterios tales como dimensiones, peso, seguridad, durabilidad, facilidad de uso, comodidad, efectividad y atractivo visual.

V. Análisis de la información. Esta fase debe ser deducida como un análisis y discusión de los resultados obtenidos. En ella la información obtenida de la aplicación del cuestionario y/o entrevista es interpretada y discutida, además se organizan aquellos datos cualitativos pues estos están descritos en un lenguaje propio de cada usuario. Dicha información cualitativa es comparada con la información cuantitativa para poder conocer el grado de satisfacción y percepción (utilizando estadística descriptiva con uso de gráficos, identificación de frecuencias y análisis de correlación) y las necesidades más significativas de los usuarios que podrán ser convertidas en requerimientos de diseño que hacen referencia a la lista de necesidades en un vocabulario fácil y de rápida comprensión para ingenieros y diseñadores. 
VI. Determinación de los requerimientos de diseño. Una vez obtenidos y analizados los resultados cuantitativos y cualitativos correspondientes a la aplicación de los instrumentos para la recolección de la información (cuestionarios y entrevistas), estos servirán para definir aquellos requerimientos asociados a las características finales del producto.

VII. Desarrollo del modelo 3D y simulación de esfuerzos. En esta fase del proyecto se hace uso de herramientas $\mathrm{CAD} / \mathrm{CAE}$ en el cual se modelará el producto final (propuesta de la silla de ruedas convencional con sus respectivas modificaciones) y a su vez, se comprobará la resistencia mecánica del producto mediante una simulación de esfuerzos. Esta simulación tendrá el propósito de evaluar el comportamiento mecánico de los diferentes componentes de la silla de ruedas, analizando sus deformaciones al ser sometidas a fuerzas que emulan las condiciones de uso.

VIII. Evaluación emocional. En la etapa final de la investigación se pretende evaluar las reacciones emocionales que provoca el diseño de la silla de ruedas propuesta, comparada con el diseño de una silla de ruedas de propulsión manual convencional en su versión estándar, es decir sin modificaciones. 


\section{MARCO TEÓRICO}

\subsection{Tecnología de Asistencia}

De acuerdo con la Organización Mundial de la Salud (2018), la Tecnología de Asistencia puede ser definida como todo producto (ayudas técnicas) o servicio especialmente diseñado para mejorar o mantener la autonomía e independencia de las personas con algún tipo de discapacidad. Sin embargo, la anterior definición limita la Tecnología de Asistencia a un enfoque médico y tecnológico, por lo tanto, se plantea un concepto en el cual se establece que esta abarca productos, modificaciones ambientales, servicios y procesos que además de ayudar a superar algún tipo de limitación, promueve el mejoramiento de la calidad de vida mediante la superación de barreras físicas de infraestructura, lo cual permite al usuario una plena participación en la sociedad al realizar todo tipo de actividades de manera fácil y segura. En esta última definición, se resalta la importancia de la infraestructura ya que no solo es importante el suministro de un dispositivo o producto, sino también la posibilidad de usarla en los diversos entornos ambientales sin ningún tipo de restricción (Cook y Polgar, 2014). De esta manera, el concepto de Tecnología de Asistencia se puede observar de manera gráfica en la Figura 4.

\section{Figura 4}

Definición de Tecnologia de Asistencia

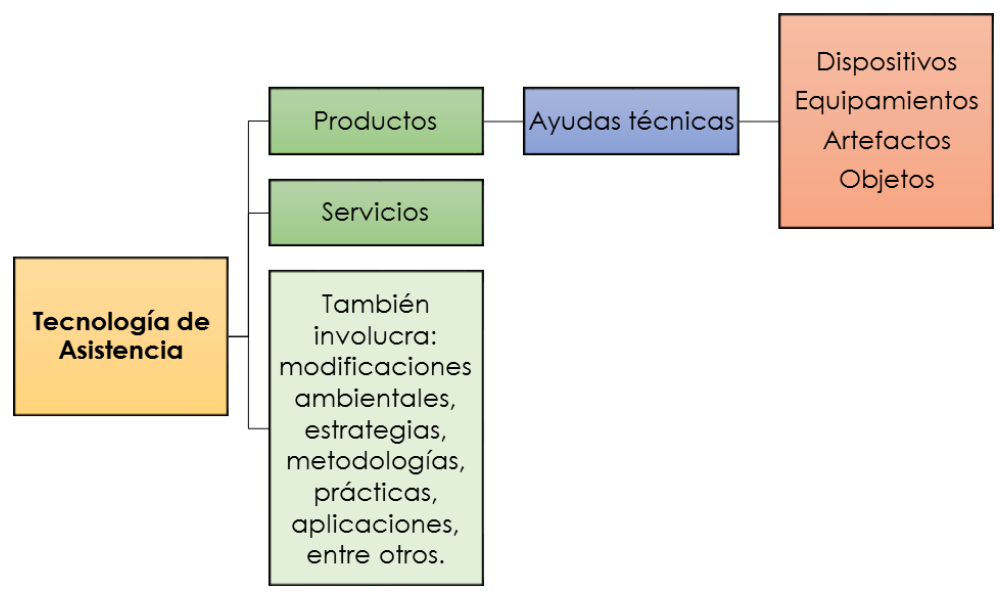


Asimismo, en la expresión genérica Tecnología de Asistencia el término "tecnología" hace referencia a la solución de problemas en el entorno físico a través de la aplicación del conocimiento científico, teniendo en cuenta que en el proceso de investigación que se lleva a cabo para encontrar solución a los problemas, se genera nuevo conocimiento científico. Por consiguiente, más que un servicio o producto tecnológico se entiende por "tecnología" como una metodología de trabajo que tiene por objetivo la búsqueda de soluciones a problemas relacionados con las deficiencias sensoriales, físicas y mentales de las personas con discapacidad (Alcantud-Marín y Soto-Pérez, 2003).

La Tecnología de Asistencia posee diversas áreas de aplicación y a su vez pretende alcanzar diversos objetivos dependiendo de la existencia o no de enfermedades y trastornos tales como: deficiencias cognitivas, retardos mentales, discapacidad visual, pérdida de audición, autismo, deficiencias del lenguaje, habla o comunicación y problemas de movilidad. Dados los múltiples campos de acción en los que interfiere la Tecnología de Asistencia, los cuales dependen exclusivamente de las necesidades y del tipo de deficiencia de la persona, de acuerdo a la norma internacional ISO 9999:20167 se clasifica a los productos de Tecnología de Asistencia, también llamados ayudas técnicas en los siguientes apartados: a) Ayudas técnicas para terapia y tratamiento médico personalizado, b) Para la educación y el entrenamiento de habilidades, c) Para apoyar funciones neuromusculoesqueléticas o relacionadas con el movimiento (órtesis) y reemplazar estructuras anatómicas (prótesis), d) Para el cuidado y protección personal, e) Para la movilidad personal y el transporte, f) Para actividades domésticas, g) Para actividades de apoyo en ambientes interiores y exteriores (mobiliarios y/o accesorios), h) Para la comunicación, la información y señalización, i) Para transportar, mover y manipular objetos, j) Para

7 La norma ISO 9999:2016 clasifica y define como ayudas técnicas a todos aquellos productos, instrumentos, equipos o sistemas técnicos utilizados por una persona con discapacidad, fabricados especialmente, o disponibles en el mercado, para prevenir, compensar, mitigar o neutralizar una deficiencia, discapacidad o minusvalía. International Organization for Standardization. Recuperado de: https://doi.org/10.1016/j.rh.2016.01.001 
mejoras ambientales, herramientas y máquinas y k) Para el apoyo de actividades laborales y participación en el empleo (Gómez-Beleño y López-Muñoz, 2016).

Por otro lado, es común que se confundan las expresiones Tecnologías de la Información y Comunicación (TIC), Tecnología de la educación y Tecnología de Rehabilitación con el término Tecnología de Asistencia, por ello, es de gran importancia aclarar brevemente sus diferencias. Las Tecnologías de la Información y Comunicación pueden definirse como herramientas que evitan la brecha digital y la dificultad de acceder a la educación y el aprendizaje. Del mismo modo las TIC promueven la inclusión de personas con algún tipo de discapacidad al ámbito relacionado con la información y comunicación como su nombre lo indica, partiendo de prácticas innovadoras que fomentan el desarrollo de la tecnología (Cabero-Almenara et al., 2016). Las TIC se diferencian de la Tecnología de Asistencia dado que esta última abarca un campo disciplinar más amplio, pues no solo se limita a una finalidad educacional, de aprendizaje, comunicación e información. Por lo tanto, se puede afirmar que las TIC son parte de las Tecnología de Asistencia, lo cual contrasta con la clasificación otorgada por la Norma Internacional ISO 9999 que las incluye en la clase de ayudas técnicas que apoyan las limitaciones referentes a la comunicación, información y señalización. Por último, la Tecnología de Rehabilitación se distingue de la Tecnología de Asistencia, debido a que la Tecnología de Rehabilitación se limita a la creación de dispositivos de uso clínico que ayudan a las personas a recuperar su funcionamiento después de una lesión o enfermedad (Cook y Polgar, 2014). Por consiguiente, se entiende que la Tecnología de Asistencia posee un área de trabajo más extenso y no limitado a solo propósitos hospitalarios.

\subsection{Ayudas técnicas para la movilidad personal y transporte}

Las ayudas técnicas para la movilidad personal poseen el objetivo de facilitar o mejorar el desplazamiento de las personas con algún tipo de limitación. Dicho desplazamiento se relaciona directamente con la facilidad de cambiar y mantener la posición de su cuerpo, caminar y moverse de un lugar a otro. El uso de las ayudas técnicas de movilidad se realiza por personas que padecen una 0 varias limitaciones 0 discapacidades de la salud, tales como: parálisis cerebral, artritis, poliomielitis, distrofia 
muscular, lesión medular traumática, lesión de la medula espinal, discapacidad visual y motriz. Todas las personas con acceso a las ayudas técnicas de movilidad tienen un impacto positivo en su independencia y participación social, debido a que reducen las necesidades de cuidados especiales, mitigan la carga física de los cuidadores y crean oportunidades para incorporarse a la educación y el trabajo. A su vez, son de gran utilidad para la prevención de caídas, lesiones y muerte prematura (OMS, 2011b).

\subsubsection{Clasificaciones de las ayudas técnicas para la movilidad y transporte}

Según la Norma Internacional ISO 9999, las ayudas técnicas para la movilidad y transporte de dividen en las siguientes clases: a) Ayudas técnicas para caminar manejados por un brazo, b) Manejados por ambos brazos (por ejemplo el bastón y la muleta de codo ), c) Accesorios adaptables a las ayudas técnicas para caminar, d) Automóviles, camionetas y camiones, e) Vehículos de transporte masivo, f) Accesorios de vehículos y adaptaciones para automóviles, g) Motocicletas y ciclomotores, $\quad$ h) Vehículos motorizados alternativos, i) Ciclos (por ejemplo, las bicicletas propulsadas a mano), j) Sillas de ruedas de propulsión manual, k) Sillas de ruedas de propulsión motorizada, I) Accesorios para sillas de ruedas, m) Vehículos alternativos propulsados por el hombre, n) Ayudas técnicas para transferencia y giro, o) Para la elevación de personas y q) Ayudas técnicas de apoyo para orientación.

\subsubsection{La silla de ruedas}

La silla de ruedas es una ayuda técnica cuyo propósito es auxiliar la movilidad de las personas con discapacidad motriz para que puedan interactuar con su entorno. Su uso puede ser temporal o permanente dependiendo del grado de discapacidad de cada usuario y el tipo de silla de ruedas adecuada depende del tipo de discapacidad del usuario (Herrera, 2016). La discapacidad motriz puede ser el resultado de diferentes factores, ya sean de naturaleza genética o adquiridas a lo largo de la vida como consecuencia de traumas, envejecimiento y accidentes. Para el año 2014, el 6\% de la población mexicana presentó algún tipo de discapacidad, de esta cifra, el 64.1\% mencionaron tener problemas de movilidad en sus piernas y de esta cifra el $37 \%$ de 
personas con discapacidad motriz en sus piernas reportaron ser usuarios de la silla de ruedas (INEGI). Lo anterior se pudo apreciar en la Figura 2.

Según Bertoncello y Gomes (2002), las sillas de ruedas pueden ser clasificadas en los siguientes tres grupos, en el primer grupo, se encuentran las sillas de ruedas de alta complejidad tecnológica como las sillas de ruedas electrónicas o inteligentes, dichas sillas de ruedas poseen dispositivos de funcionamiento computacional como aquellas que son manipuladas y conducidas por sistema de reconocimiento de voz. Este tipo de silla de ruedas generalmente es empleada por personas con pérdidas funcionales y motoras muy graves. En el segundo grupo se encuentran las sillas de ruedas de media complejidad tecnológica como las sillas de ruedas electromecánicas, este tipo de sillas de ruedas ofrece autonomía al usuario en recorridos de largas distancia por lugares externos, gracias al accionamiento manual de motores; también son denominadas sillas de ruedas motorizadas. Por último, en el tercer grupo se encuentran las sillas de ruedas de propulsión manual (mecano-manuales) o dispositivos de baja complejidad tecnológica las cuales son impulsadas por el accionamiento manual y muscular del propio usuario o de su cuidador.

Este último grupo, puede ser dividido en tres tipos de sillas de ruedas. El primer tipo son las optimizadas, que hacen referencia a las sillas de ruedas de propulsión manual mejor desarrolladas y con gran tecnología aplicada en su proceso de diseño. Estas se caracterizan principalmente por su comodidad, su peso reducido considerablemente y por contar con marcos o estructuras que permiten su fácil transporte, desmonte y practicidad en las transferencias). El segundo tipo de sillas de ruedas de propulsión manual, son las especiales y se caracterizan principalmente por ser usadas en situaciones particulares y por estar desarrolladas bajo un proceso de diseño altamente tecnológico y costoso. Algunos ejemplos de sillas de ruedas de propulsión manual especiales son las deportivas y aquellas que poseen sistemas de bipedestación. El tercer tipo de sillas de ruedas de propulsión manual son las estándar, las cuales poseen diseños simples y de acuerdo al tipo de marco o estructura pueden ser plegables o rígidas. Comercialmente, estas se encuentran en el mercado en varios modelos y sus características son tan varias que dependen de los fabricantes 
(Bertoncello y Gomes, 2002). En la Figura 5, se evidencia la clasificación anteriormente descrita.

Figura 5

Clasificación de la silla de ruedas.

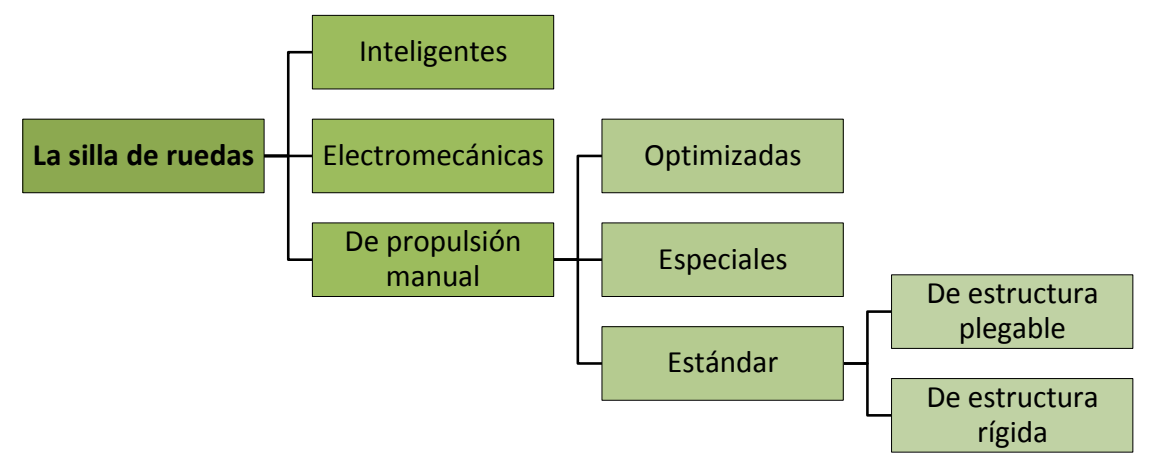

Nota. Traducido del portugués. Tomado de Análise diacrônica e sincrônica da cadeira de rodas mecanomanual (p. 74), por Bertoncello y Gomes, 2002, Revista Produção

La silla de ruedas de propulsión manual se define como un dispositivo que proporciona movilidad sobre ruedas y soporte corporal a personas con capacidad limitada para desplazarse de un lugar a otro. Dicho dispositivo es impulsado por el mismo usuario o por el cuidador. La silla de ruedas de propulsión manual, la cual se incluye en la clasificación de las ayudas técnicas para la movilidad y el transporte, se divide en 7 subgrupos (según la Norma internacional ISO 9999) que son los siguientes: a) Silla de ruedas bimanual propulsada por ruedas, b) Bimanual manejadas por palancas, c) De propulsión manual y de conducción mono-lateral, d) De potencia asistida propulsada manualmente, e) Propulsada por los pies, f) Controladas por el cuidador y g) Silla de ruedas manual de propulsión asistida y controlada por el asistente.

Existen diversas clasificaciones de sillas de ruedas, sin embargo, no existe un modelo que satisfaga en su totalidad las necesidades de todos los usuarios, es por ello que el diseño de la silla de ruedas puede variar dependiendo de las características y necesidades de los usuarios (Marín-Vásquez, 2017). Para la Organización Mundial de la Salud (2008), la silla de ruedas puede dividirse en 3 grupos según las necesidades 
físicas de los usuarios: 1) Silla de ruedas para usuario temporal, su diseño no ofrece un perfecto ajusto, apoyo postural ni alivio de presión. Ejemplo, la silla de ruedas hospitalaria, 2) Silla de ruedas para usuario permanente y 3) Silla de ruedas para usuario que requiere de apoyo postural.

\subsection{Experiencia del Usuario (User Experience - UX)}

De acuerdo con la Norma Internacional ISO $9241-210^{8}$ el término User Experience, en español Experiencia del Usuario, se define como el conjunto de percepciones y respuestas de una persona, las cuales son resultantes del uso y/o uso previo de un producto, sistema o servicio. Según la definición de esta norma, la Experiencia de Usuario involucra también todo tipo de emociones, percepciones, respuestas físicas, psicológicas y preferencias que ocurren antes, durante y después del uso de un producto. Con relación a las percepciones previas, el usuario crea expectativas, opiniones y valoraciones, partiendo de una interacción indirecta con el producto que se puede dar a través imágenes, publicidad u opiniones de otras personas. De esta manera, el concepto de Experiencia del Usuario está influenciado por las características y funciones del producto, abordando además, percepciones, subjetivas durante su interacción con el mismo y tomando en cuenta las reacciones emocionales que también pueden ser previas o posteriores a esta interacción (Carneiro, 2018).

La Experiencia del Usuario abarca una serie de factores tales como, atributos emocionales (predisposición, expectativas, sentimientos, necesidades personales, motivaciones, estado de ánimo) y características propias del producto o sistema diseñado (complejidad, usabilidad, propósito, funcionalidad), sin contar además que involucra en su connotación factores ambientales o del entorno donde se produce la interacción (Carneiro et al., 2015). De acuerdo con Saffer (2010), la Experiencia del usuario es un área del diseño interdisciplinar debido a que en ella interfieren diferentes áreas de conocimiento. En la Figura 6 se establecen algunas de estas áreas en la cuales, interviene el diseño industrial. Con relación al diseño industrial, este se

8 Ergonomics of human-system interaction - Part 210: Human-centred design for interactive systems (ISO 9241-210:2019). International Organization for Standardization (ISO). 
involucra con la Experiencia del Usuario ya que es una disciplina que crea soluciones físicas, objetos que comunican intuitivamente su uso y a su vez son funcionales, relacionándose directamente con los factores humanos y asegurándose que todo objeto se ajuste a las limitaciones físicas del cuerpo humano (ergonomía física), así como a las expectativas y emociones del usuario (ergonomía cognitiva).

\section{Figura 6}

Disciplinas que intervienen en la Experiencia del Usuario

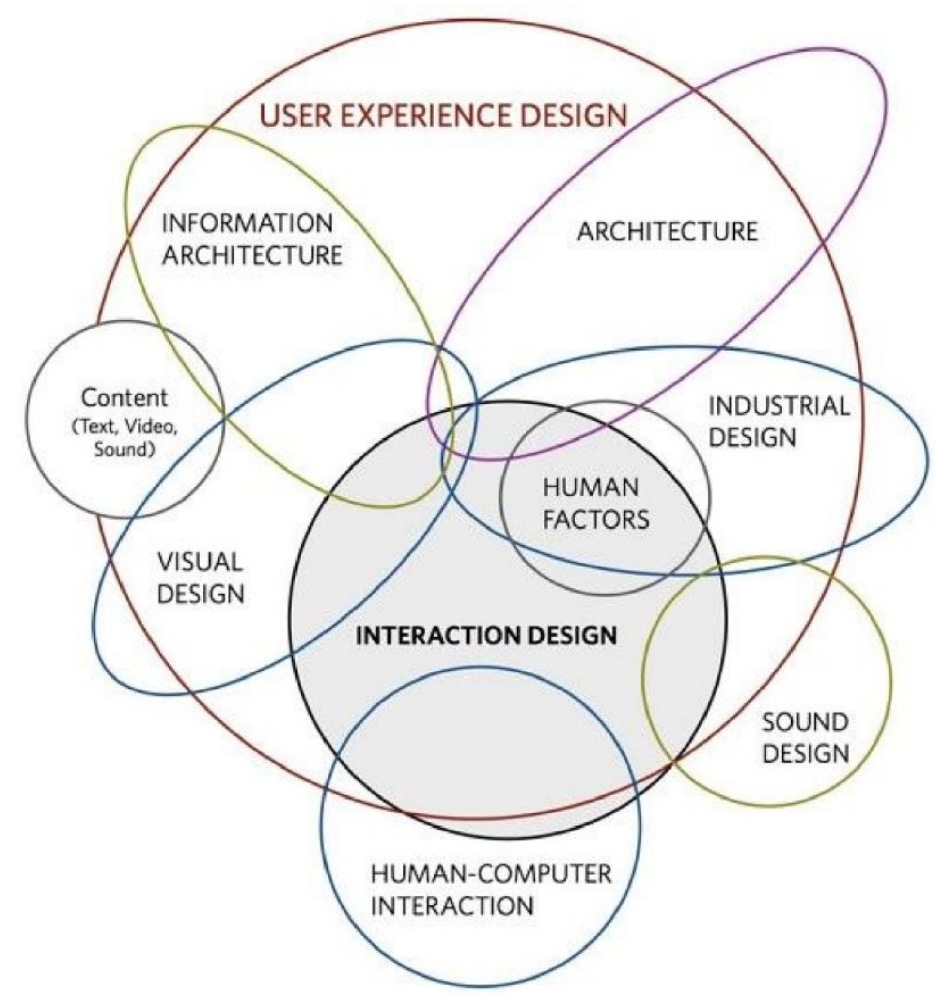

Nota: Tomado de Designing for Interaction: Creating Innovative Applications and Devices (p. 21), por Dan Saffer, 2010, New Riders

En cuanto a las ayudas técnicas, especialmente en el diseño de la silla de ruedas, la mayoría de los estudios realizados han sido enfocados a cuestiones biomecánicas y funcionales y no en temas alusivos a la usabilidad, experiencia, expectativas y emociones del usuario hacia el producto. Dichos temas, ligados a los factores psicológicos han tenido gran relevancia en el diseño y evaluación de productos en los últimos años. Gracias a estudios relacionados con la Experiencia del Usuario se ha demostrado que aspectos físicos de la silla de ruedas están adheridos a la 
personalidad del usuario, por lo tanto, hacer modificaciones en las características del diseño de esta puede provocar diferentes reacciones emocionales que alteren la satisfacción del usuario (Carneiro et al., 2019).

\subsection{Ergonomía Cognitiva}

Según la Sociedad de Ergonomistas de México $^{9}$, la ergonomía es un área científica que estudia la interacción entre el ser humano y los elementos de su entorno. Dicha área del conocimiento se preocupa por la implementación de teorías, principios, datos y métodos para diseñar entornos que propicien el bienestar humano. A su vez, la Asociación Internacional de Ergonomía (IEA) ${ }^{10}$ define este término como una disciplina científica de carácter multidisciplinar que se dedica a la compresión de las interacciones que ocurren entre humano y los elementos de un sistema. De acuerdo con la IEA la ergonomía contribuye al diseño y evaluación de tarea, trabajas, productos, entornos y sistemas, con la finalidad de hacerlos más compatibles con las necesidades, capacidades y limitaciones de las personas.

La ergonomía es de dominio multidisciplinar que estudia las interacciones humanas desde un enfoque holístico, que abarca aspectos físicos, cognitivos, sociales, organizativos, ambientales entre otros. Es por ello, que la ergonomía abarca tres campos de aplicación en las cuales se representan competencias más profundas y puntuales respecto a las características de la interacción humana, estos dominios son: Ergonomía física, Ergonomía Cognitiva y Ergonomía Organizacional (Asociación Internacional de Ergonomía). Existe un aspecto que tiene que ver con la manera como una persona interactúa y conoce un entorno y/o dispositivo. Dicho conocimiento es producto de la percepción y estímulos que se generan al interactuar con los elementos y es justamente esto lo que interpreta y analiza la ergonomía cognitiva. El objetivo de la ergonomía cognitiva es estudiar los aspectos y procesos cognitivos (percepción, aprendizaje, memoria, razonamiento, respuesta motora, entre otros.) en la interacción

9 Sociedad de Ergonomistas de México, A. C. Definición de Ergonomía. [Consultado el 13 de octubre de 2019] Recuperado de: http://www.semac.org.mx/index.php/ergonomia.html

10 International Ergonomics Association. What is Ergonomics? [Consultado el 13 de octubre de 2019] Recuperado de: https://www.iea.cc/whats/index.html 
del ser humano con el entorno y los objetos que encontramos en él, con el propósito de mejorar su diseño para que su interacción sea más eficaz (Salmerón et al., 2004).

Un análisis ergonómico abarca la ergonomía clásica que es aquella que estudia la interacción física, en la cuales se incluyen áreas de investigación como la antropometría, biomecánica y el análisis de procesos sensoriales. Adicional a esto, la ergonomía cognitiva aporta al análisis ergonómico el estudio de los procesos mentales involucrados en la interacción y en los componentes propios de las necesidades de los usuarios relacionados con valores sociales, culturales y emocionales. Es decir, la ergonomía pasa de investigar procesos objetivos de la interacción (funcionalidad, usabilidad, efectividad, eficiencia, entre otros) a componentes subjetivos y emocionales (Zolotova y Giambattista, 2019). Además, la ergonomía cognitiva está estrechamente relacionada con la percepción que es el resultado de un procesamiento de estímulos sensoriales que son recibidos, organizados e integrados en información relevante sobre objetos y el ambiente. En este proceso de estímulos, llamado percepción, se emplea información ya almacenada en la memoria, proveniente de experiencias previas, la cual convierte las sensaciones en significados, opiniones, críticas y/o apreciaciones (Lanutti, 2019).

Por consiguiente, la ergonomía desempeña un gran esfuerzo para garantizar el bienestar del usuario no solo en un nivel físico sino también en un nivel cognitivo, abarcando en esta área el bienestar emocional del ser humano. Actualmente, es de pleno conocimiento que no se puede separar los procesos cognitivos de las emociones, debido a que estos interactúan continuamente y contribuyen así a controlar los comportamientos y razonamientos humanos. Estas emociones afectan en la manera en que las personas interactúan con los productos o servicios ya que se establece una conexión emocional. Así, esta conexión emocional evoca que los productos que transmiten emociones positivas sean aceptados y aquellos que producen emociones negativas, sean evitados y descartados. Por lo tanto, provocar una emoción positiva puede ser un gran diferenciador de los productos y un factor subjetivo importante, para tener en cuenta en el diseño y desarrollo de estos (Lida y Buarque, 2016). 


\subsubsection{Sensación y percepción}

La sensación y la percepción son etapas de un mismo fenómeno cognitivo el cual se relaciona con la captación de estímulos ambientales que después son traducidos en información. Se puede definir como sensación al proceso biológico que capta la energía del ambiente, dicha energía es captada por los órganos sensoriales a través de sus células nerviosas para ser transformado en un impulso electroquímico que se transmite al sistema nervioso central en donde puede o no ser procesado. A su vez, la percepción se refiere al resultado del procesamiento del estímulo sensorial en el cual se le otorga un significado. Estos estímulos son recibidos, organizados y traducidos en información relevante sobre un objeto o entorno, en este proceso, se hace uso de la información almacenada en la memoria de experiencias pasadas de tal forma que sirvan para estructurar una opinión, juicio o significado (Lida y Buarque, 2016). Con ello, se hace énfasis en que la sensación es la respuesta específica a un determinado estímulo sensorial y la percepción es considerada como el procesamiento de las sensaciones a través de diversos mecanismos que construyen un significado (Lanutti, 2019).

En el caso específico de la silla de ruedas, debido al tiempo prolongado de interacción de esta con el usuario, esta ayuda técnica es percibida socialmente como un producto que representa a quien la usa. Además, en la silla de ruedas, la percepción puede verse influencia por el género del usuario; en el masculino se percibe la silla de ruedas de manera más positiva en lo práctico, estético y simbólico en comparación con el femenino. Así mismo, la aceptación o el rechazo de la silla de ruedas por parte de los usuarios también está relacionado con la importancia que el usuario le atribuye a la ayuda técnica y a lo que esta refleja y comunica social y emocionalmente, es decir, que estas dos reacciones no solo dependen de las funciones prácticas del producto (Lanutti et al., 2015).

Del mismo modo, la silla de ruedas es un producto que produce una percepción negativa y un impacto emocional desagradable debido a múltiples razones tales como, la baja atracción visual y la aparente disminución de la movilidad que representa el uso de este sistema. Por esta razón, la silla de ruedas puede ser vista como un producto 
que genera exclusión en la sociedad. Las personas sin discapacidad tienen diferentes percepciones dependiendo del diseño de la silla de ruedas en cuestiones de atracción visual, llegando a considerar los diseños modernos u orgánicos como saludables, emotivos e inclusivos y en contraparte, los diseños geométricos son considerados como enfermos, antiguos y excluyentes. De manera que, la atracción visual de la silla de ruedas está estrechamente relacionada con la estimulación de significados y juicios de carácter social y personal (Marín et al., 2015).

De forma semejante, para Marín-Vázquez (2017), la percepción de la silla de ruedas se ve influenciada por el nivel de experiencia o dominio del dispositivo que posee el usuario. A su vez, se destaca que el estigma y percepción de esta ayuda técnica se asocia directamente con la atracción visual de esta, pero a su vez el ámbito cultural es un factor determinante en la manera de cómo se perciben los objetos. Por lo anterior, al realizar el estudio de percepción en diferentes países se investiga como el estigma relacionado a la ayuda técnica es influenciado por los aspectos culturales.

Por otro lado, la sensación y la percepción están relacionadas con lo que Bonsiepe (1999) ha denominado la interfaz (Carrasco-Zannini et al., 2009). Según Bonsiepe (1999), una de las habilidades del diseñador industrial es analizar la interacción entre el usuario y el producto. De esta manera, se pueden llevar a cabo acciones eficaces con los productos y esto, es posible gracias a las interfaces. Por lo tanto, el diseño industrial crea interfaces no solamente proyectando o diseñando un producto desde el punto de vista de funcional, sino también teniendo en cuenta la complejidad de la interacción usuario-producto. Lo anterior, se puede observar en el diagrama ontológico de diseño expuesto en la Figura 7, el cual posee una categoría central o núcleo que entrelaza tres distintos ámbitos. El primero se refiere al usuario o agente social que tiene la intención de realizar una acción efectiva. El segundo, consiste en la acción o tarea que el usuario desea llevar a cabo. Por último, el tercer ámbito es la herramienta o producto que necesita el agente social para ejecutar la acción.

Figura 7

Diagrama ontológico del diseño 


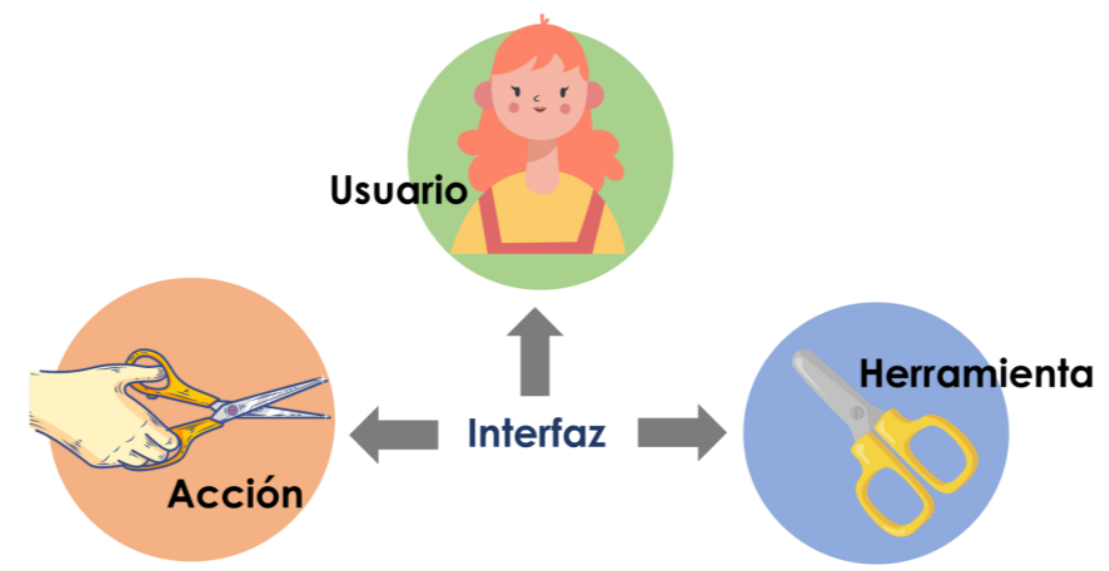

Nota. Tomado y adaptado Del objeto a la interfaz (p. 18), por Bonsiepe, 1999.

Una vez que se ha realizado el planteamiento de los tres ámbitos del diagrama ontológico de diseño, surge la interrogante de cómo poder integrar los tres ámbitos en una sola unidad, teniendo en cuenta que estos son elementos heterogéneos (la persona, la intención de realizar una acción y la herramienta o producto). Como respuesta a esto, se deduce que la conexión de estos tres ámbitos se da por medio de la interfaz. Es importante aclarar que la interfaz no es un objeto; esta puede interpretarse como el espacio en el cual ocurre la interacción entre el producto, el humano y la acción. Asimismo, se resalta que la interfaz aporta la entidad de herramienta a los objetos, le transfiere información al usuario, convierte los objetos en productos y transforma la presencia física de los productos en disponibilidad (Bonsiepe, 1999).

De acuerdo con Secomand (2015), en el concepto de interfaz propuesto por Bonsiepe, esta se contempla en el diseño de todo tipo de productos, los tangibles (producto material) e intangibles (producto digital). En ambos casos, el acoplamiento perfecto entre los tres ámbitos de diseño (usuario, herramienta y acción) ocurren cuando la interfaz es transparente a la percepción del usuario.

Teniendo en cuenta la transparencia Scolari (2021), menciona que una interfaz bien diseñada es aquella que desaparece cuando el usuario realiza una tarea o acción, de tal manera que el usuario centra toda su atención esta y no en el producto. Sin embargo, dice que el concepto de transparencia de una interfaz puede llegar a ser ambiguo ya que la interacción y su transparencia pueden ser interpretadas desde 
diferentes perspectivas. Por ello, Scolari (2021) dice que atribuirle una transparencia total a la interfaz es la manera más fácil de ocultar la complejidad y simplificar todos los procesos que se llevan a cabo en la interacción de los humanos con cualquier tipo de tecnología.

Finalmente como se mencionó, la interfaz está directamente involucrada con la sensación y percepción ya que, cuando se diseña una interfaz se generan procesos interpretativos, se evocan experiencias previas y se realiza un proceso comunicativo donde ocurre un intercambio de información (Carrasco-Zannini et al., 2009). Del mismo modo, la interfaz interviene en los estados emocionales del usuario, ya que, tiene una estrecha relación con el uso de un producto. Cuando se diseña una interfaz se determina la complejidad de la interacción, la cual repercute en las emociones de usuario (Scolari, 2021).

\subsection{Diseño Emocional}

De acuerdo con Silva y Cavalcanti (2015), la relaciones entre usuario producto no se limitan únicamente a aquellas derivadas de la funcionalidad del producto, en dichas relaciones también se contempla el campo de las experiencia y las emociones. Asimismo, las emociones se hacen presentes en los productos $u$ objetos con los que interactuamos en nuestro día a día, formando parte de las funciones de los productos y de manera intrínseca en el diseño de estos.

Según Silva (2019), las funciones de un productos (estética, practica y simbólica) planteadas por Löbach (2001), pueden ser incorporadas en el diseño emocional y mejor comprendidas con la clasificación de los aspectos y/o niveles del diseño propuesto por Norman (2008), la cual involucra: el diseño visceral, conductual y reflexivo. Esto, se puede observar de manera gráfica en la Figura 8.

El diseño visceral está relacionado con las apariencias perceptibles de un producto, es decir, aquellas percepciones que se captan a través de los sentidos, por ello, este aspecto está asociado a la función estética. El diseño conductual se vincula con la experiencia del usuario y la facilidad de uso del producto, esto, por medio de la funcionalidad, el desempeño y la usabilidad. De esta manera, el diseño conductual se relaciona con la función practica el producto. Finalmente, el diseño reflexivo se enlaza 
a la forma de cómo el usuario intelectualiza y racionaliza un producto, interfiriendo con factores altamente personales y subjetivos, en los cuales, el producto es capaz de transmitir una historia con que el usuario se relaciona y se identifica. Por esta razón, el diseño reflexivo se conecta con la función simbólica del producto (Silva y Cavalcanti, 2015).

\section{Figura 8}

Relación entre el diseño emocional y las funciones de los objetos

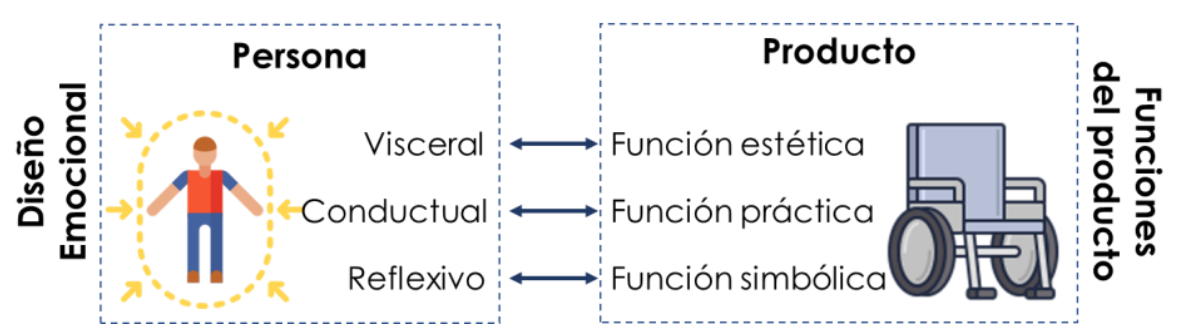

Nota. Traducido del portugués. Tomado y adaptado de SINTO, LOGO EXISTO: validação de um modelo para análise do design emocional (p. 78), por Silva, 2019.

De lo anterior, se puede mencionar que los tres niveles de diseño al igual que las tres funciones de un producto se encuentran presentes en el diseño de cualquier objeto y están relacionadas entre sí. Estas relaciones, interfieren con las emociones, la razón y la cognición del usuario, en donde la cognición y/o razón facilitan la comprensión y entendimiento de nuestro entorno y las emociones permiten que tomemos decisiones sobre este (Silva, 2019).

De esta manera, el diseño emocional es un área del diseño multidisciplinar cuyo objetivo no es solo la creación de productos funcionales y visualmente atractivos, sino también estimular la formación de vínculos ya sea afectivos, subjetivos o simbólicos entre el usuario y el objeto (Linhares y Pereira, 2017). Asimismo, Linhares y Pereira (2017) mencionan que el diseño emocional es el responsable de aprobar o rechazar un producto, ya que está relacionado con las emociones que se producen cuando se interactúa con el objeto. Sin embargo, tampoco se debe considerar como finalidad del diseño emocional la manipulación o control de las emociones del usuario. Dicha área del diseño interpreta a través de las emociones los deseos y los demás factores que llevan a una persona a adquirir y usar un objeto. Lo anterior, se lleva a cabo en el proceso de diseño y desarrollo del producto mediante estudios e investigaciones que den forma a un dispositivo que supla las necesidades emocionales de los individuos. 


\subsubsection{La silla de ruedas y las emociones.}

Hasta la fecha, en la sociedad aún existen estigmas hacia las personas con discapacidad, lo cual ocasiona que las ayudas técnicas sean vistas por las mismas personas con discapacidad como un producto que causa rechazo. Dichos estigmas ocasionan un aislamiento, que en muchas ocasiones son el resultado de no tener la claridad en la manera de cómo tratar o acercarse a las personas con discapacidad. Este tipo de situaciones forman parte del día a día de las personas con discapacidad y tiene gran influencia en la forma de interactuar socialmente y con la ayuda técnica, puesto que se generan emociones negativas (Lanutti, 2019). Lo anterior, hace contraste con el hecho que la movilidad reducida y el uso de las ayudas técnicas se relacionan con el prejuicio de la incapacidad lo cual influye fuertemente en la forma de cómo se relaciona el usuario con el dispositivo afectando negativamente su experiencia de uso con las ayudas técnicas, evocando emociones que provocan ansiedad, depresión, baja autoestima y exclusión en la sociedad por parte de sí mismos (Carneiro et al., 2015).

Generalmente, las necesidades referentes a la autonomía y pertenecía social de las personas con discapacidad son influenciadas y modificadas por la ayuda técnica y esto, está relacionado con las respuestas emocionales que dichas personas dan al dispositivo. Por esta razón, realizar modificaciones en el diseño de la silla de ruedas e incentivar en ellas características de personalización (colores, materiales y texturas), promueve el sentido de pertenencia social e identificación personal, de tal manera que se genera la oportunidad de sentir a la silla de ruedas como una extensión de su propio cuerpo. Sin embargo, aunque se reconoce la gran variedad de sillas de ruedas en el mercado, aun no existen muchas posibilidades de personalización y cuando estas se incorporan en el diseño, muy pocas personas pueden acceder a ellas (Lanutti, 2019). Así, una silla de ruedas puede significar un producto deseado por una persona con discapacidad, amado por su diseño innovador y bien estructurado, pero a su vez, odiado por las dificultades de acceder a ella económicamente (Mallin y Carvalho, 2015). 
Según el estudio realizado por Carneiro et al. (2019), la silla de ruedas tradicional provoca emociones negativas (preocupación, miedo, tristeza, desesperación y decepción), tanto en usuarios de dicha ayuda técnica como en personas no usuarias, en cambio, una silla de ruedas con un diseño moderno, genera emociones positivas (interés, asombro, placer y diversión). Lo anterior, indica que un diseño moderno provoca reacciones emocionales más favorables que el diseño de una silla de ruedas tradicional, debido a que un diseño innovador genera gran interés en la sociedad. Por consiguiente, en las sillas de ruedas, las respuestas emocionales de la experiencia del usuario están relacionas con la atracción visual del dispositivo dado que repercute directamente con la personalidad e imagen del usuario.

\subsection{Diseño centrado en el usuario}

El Diseño centrado en el usuario, puede definirse como un proceso de diseño en el cual se coloca al usuario como elemento primordial en cada etapa del proceso de desarrollo de un producto o servicio. En este proceso de diseño se abordan todos los tipos de capacidades humanas: sensoriales (visión, audición, tacto, gusto y olfato), cognitivas (pensamiento y comunicación) y motoras (movimiento y destreza). Dichas capacidades sensoriales se tratan en conjunto con las dimensiones temporales (las diferentes etapas de vida) y sociales (aspectos culturales y del entorno), dando forma a un proceso de diseño en el cual se comprenda al usuario desde diferentes puntos de vista. Por consiguiente, el gran desafío en el Diseño Centrado en el Usuario radica en la capacidad de recolectar, identificar, comprender y transformar la información del usuario (Merino, 2016). Por otra parte, la implementación del proceso de Diseño Centrado en el Usuario mejora el bienestar y la satisfacción del usuario debido a que suple las necesidades de estos desde diferentes enfoques (Almenara, 2018). Según la Norma ISO 9241-21011 el Diseño Centrado en el Usuario posee los siguientes principios: a) El diseño se basa en una comprensión explícita de los usuarios, tareas y

11 La norma ISO 9241 parte 210: Human-centred design for interactive systems menciona que los productos abordados bajo una perspectiva de Diseño Centrado en el Usuario tienden a ser más satisfactorios dado que aumentan la productividad del individuo y la usabilidad del dispositivo, mejorando la experiencia del usuario y reduciendo los niveles de estrés e incomodidad. (Franck y Schmidt, 2017) 
entornos de los mismos, b) Los usuarios participan durante el diseño y desarrollo, c) El diseño es impulsado y perfeccionado por la evaluación centrada en el usuario, d) El proceso debe de ser iterativo, e) El diseño se basa en toda la experiencia del usuario y f) El equipo de diseño incluye habilidades y perspectivas multidisciplinarias. Asimismo, dicha norma plantea el Diseño Centrado en el Usuario en las siguientes 4 etapas: 1) Comprender y especificar el contexto, 2) Especificar los requerimientos del usuario, 3) Producir soluciones de diseño para cumplir con estos requisitos y 4) Evaluar los diseños respecto a los requerimientos.

Según Mallin y Carvalho (2015), mencionan que no ha habido una discusión amplia en cuanto al significado y las emociones que las ayudas técnicas evocan o transmiten al usuario, por lo tanto, las investigaciones en diseño e innovación de productos y servicios relacionados a la Tecnología de Asistencia revelan la importancia y urgencia de considerar al usuario en las etapas del proceso de diseño y desarrollo de estos. Por ello, aplicar un Diseño Centrado en el Usuario para el diseño de ayudas técnicas, implica ubicar al usuario y a sus emociones en el centro del proceso para la creación de nuevos diseños e innovaciones. A su vez, la implementación de dicho proceso para estos productos involucra tener en cuenta la emoción y el placer del usuario, lo cual ayuda a mejorar su rehabilitación y promueve una mejor interacción social de este.

En consecuencia, lo anterior presenta similitudes con Pichler y Merino (2017) al destacar la necesidad de implementar nuevas formas de diseñar las ayudas técnicas, las cuales, por un enfoque de Diseño Centrado en el Usuario podrían contribuir al desarrollo de soluciones más precisas a las necesidades reales de los usuarios y a la creación o rediseño de productos más satisfactorios que ayuden a disminuir el poco interés de estos. En el desarrollo de ayudas técnicas orientado por el Diseño Centrado en el Usuario, se deben considerar los siguientes tres factores para la recolección de la información: 1) El factor producto en el cual se definen las características físicas, de atracción visual y propiedades simbólicas del dispositivo, 2) El factor usuario donde se analizan las capacidades motoras y sensoriales de este y a la vez se estudia sus condiciones cognitivas (percepciones y emociones) y 3 ) El factor contexto en el que se 
considera la interacción usuario-producto teniendo en cuenta el ambiente de dicha interacción y las personas del entorno. 


\section{METODOLOGIA}

\subsection{Objetos de estudio}

De acuerdo con la clasificación de Bertoncello y Gomez (2002), los modelos seleccionados para ser evaluados en esta investigación fueron los dos modelos estándar de sillas de ruedas de propulsión manual o de baja complejidad tecnológica. El primer modelo, la silla de ruedas de estructura rígida la cual posee un marco sin articulaciones, que no es posible plegar para su guardado. El segundo modelo, la silla de ruedas de estructura plegable y de cierre vertical que se caracteriza por tener un marco articulado con un mecanismo en "X" que permite cerrar la estructura. Por otra parte, las dos sillas de ruedas son de $u$ so diario y frecuentemente donadas por fundaciones y/o entidades gubernamentales. En la Figura 9, se pueden observar los dos modelos elegidos para ser evaluados en la investigación.

Figura 9

Objetos de estudio

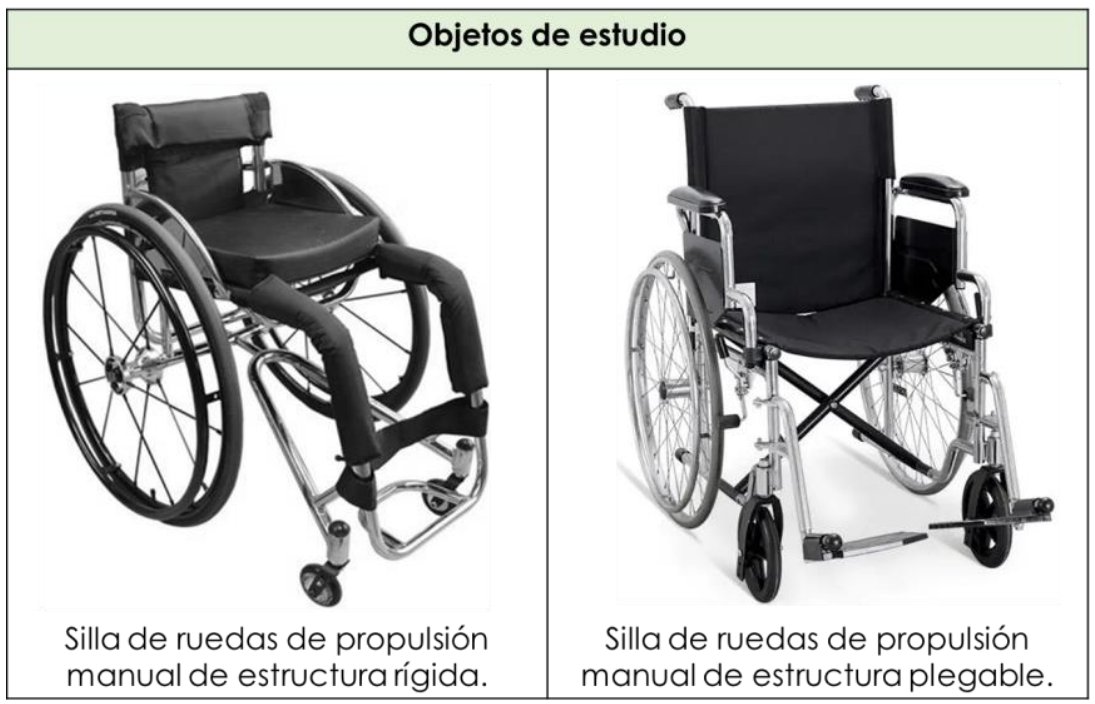

\subsection{Participantes}

\subsubsection{Criterios de participación}

Para la muestra de usuarios se consideró el cumplimiento total de los siguientes criterios de participación: a) Tener más de 18 años, b) No tener ninguna discapacidad 
cognitiva, c) Tener pleno control de los miembros superiores, d) Ser usuario permanente de silla de ruedas, d) Tener una experiencia mínima de 2 años en el uso de la silla de ruedas.

\subsubsection{Tamaño de la muestra}

En la recolección de la información cualitativa, se consideró una muestra de 10 personas usuarias de silla de ruedas de estructura plegable. Dicha muestra estuvo conformada por 5 hombres y 5 mujeres. En la Tabla 1, se evidencia lo anteriormente descrito.

Tabla 1

Distribución y edades promedio de la muestra de participantes en la fase cualitativa

\begin{tabular}{|c|c|c|c|}
\hline \multirow{2}{*}{ Tipo de silla de ruedas } & \multicolumn{2}{|c|}{$\begin{array}{c}\text { Distribución de los } \\
\text { participantes por género } \\
(\boldsymbol{n}=\mathbf{1 0})\end{array}$} & $\begin{array}{c}\text { Edad promedio } \\
(\overline{\boldsymbol{X}})\end{array}$ \\
\hline \multirow{2}{*}{$\begin{array}{c}\text { Silla de ruedas de estructura } \\
\text { plegable }\end{array}$} & Hombres & 5 & 36.8 \\
\cline { 2 - 4 } & Mujeres & 5 & 40 \\
\hline
\end{tabular}

Por otro lado, en la investigación cuantitativa se contó con la participación de 52 usuarios de silla de ruedas de propulsión manual, de los cuales 26 de ellos eran usuarios de la silla de ruedas de estructura plegable y los otros 26 , usuarios de la silla de ruedas de estructura rígida. Con respecto al género de los participantes, 26 de ellos fueron de género masculino divididos de manera equitativa entre los dos tipos de sillas de ruedas: 13 usuarios masculinos de silla de ruedas de estructura plegable y 13 usuarios masculinos de silla de ruedas de estructura rígida. En cuanto al género femenino, se obtuvieron respuesta de 26 participantes que estuvieron dividas de la misma forma que los participantes de género masculino. Por lo tanto, no hubo una predominancia en términos de género que pudiera impactar en las conclusiones de esta investigación. A continuación, en la Tabla 2 se muestra la distribución de los participantes por género y sus respetivas edades promedio. 


\section{Tabla 2}

Distribución y edades promedio de la muestra de participantes en la fase cuantitativa

\begin{tabular}{|c|c|c|c|}
\hline Tipo de silla de ruedas & \multicolumn{2}{|c|}{$\begin{array}{c}\text { Distribución de los } \\
\text { participantes por género } \\
(n=26)\end{array}$} & \multirow{2}{*}{$\begin{array}{c}\begin{array}{c}\text { Edad promedio* } \\
(\overline{\boldsymbol{X}} \pm \boldsymbol{\sigma})\end{array} \\
39.3 \pm 10.2\end{array}$} \\
\hline Silla de ruedas de estructura & Hombres & 13 & \\
\hline plegable & Mujeres & 13 & $41.1 \pm 9.2$ \\
\hline \multirow{2}{*}{$\begin{array}{l}\text { Silla de ruedas de estructura } \\
\text { rígida }\end{array}$} & Hombres & 13 & $42.2 \pm 13.8$ \\
\hline & Mujeres & 13 & $35.8 \pm 9.1$ \\
\hline
\end{tabular}

Nota. *El valor de la edad promedio está acompañado por el valor de la desviación estándar

Según Lanutti (2019), el número de participantes en investigaciones previas, en las cuales se aborda la silla de ruedas y sus usuarios, desde los temas del diseño emocional, usabilidad y experiencia del usuario resulta ser muy variado y podría mencionarse que también este número es muy reducido en la mayoría de estas investigaciones. Dicha autora, mostró los siguientes estudios:

- Carneiro et al. (2015), con n=8 (4 mujeres y 4 hombres). Esta investigación indagó en la usabilidad y la experiencia del usuario en diferentes tipos de silla de ruedas mediante la entrevista a los usuarios.

- Desmet et al. (2003), con n=8. Esta investigación tuvo como objetivo evaluar la percepción de una pequeña muestra de población infantil (de 7 a 12 años), usando como objetos de estudio 6 modelos de sillas de ruedas.

- Mokdad et al. (2017), con $n=74$. En este estudio, se buscó abordar las diferentes reacciones emocionales empleando la Rueda Emocional de Ginebra como instrumento para la recolección de la información.

Por otro lado, además de los estudios citados por Lanutti (2019), también se pueden mencionar otras investigaciones, en las cuales el número de usuarios de silla de ruedas contemplados en el tamaño de la muestra es reducido. Dichos estudios son los siguientes: 
- (Lanutti, 2019), con $\mathrm{n}=20$ (10 hombres y 10 mujeres). Esta investigación abordó diferentes aspectos emocionales de los usuarios mediante el uso de diversas herramientas cualitativas y cuantitativas.

- (Manzano-Hernandez et al., 2020), con $n=4$ (2 adolescentes y 2 adultos). Investigación cualitativa en la cual se abordaron las actitudes de los usuarios hacia su silla de ruedas. Este estudio se realizó con usuarios mexicanos.

- (Carneiro et al., 2019), con $n=30$ (9 mujeres y 21 hombres). Este estudio cuantificó las diferentes reacciones emocionales de los usuarios, en el cual se tuvo como objetos de estudios dos tipos de silla de ruedas.

- (Marín-Vásquez, 2017), con n=30 (15 mujeres y 15 hombres). Esta pesquisa tuvo como objetivo evaluar la percepción simbólica de los usuarios hacia tres tipos de sillas de ruedas, empleando para la recolección de su información la Escala de Diferencial Semántico.

- (Lanutti et al., 2015), con n=10 (5 mujeres y 5 hombres). Esta investigación cuantificó la percepción de los usuarios de la silla de ruedas, tomando en cuenta el género del usuario. La herramienta empleada para dicho propósito fue la Escala de Diferencial Semántico.

\subsection{Instrumentos para la recolección de la información}

\subsubsection{Entrevista}

En la recolección de la información cualitativa, con el propósito de evaluar aspectos relacionados a la usabilidad (mantenimiento, facilidad de uso, capacitación y seguridad) y a la experiencia del usuario, se formuló una entrevista con diez preguntas, algunas de ellas basadas en las investigaciones de Carneiro (2018) y Lanutti (2019). En la Tabla 3, se encuentran estipuladas las diez preguntas junto con su justificación teórica. 


\section{Tabla 3}

Fundamentación teórica de las preguntas realizadas en la entrevista

\begin{tabular}{|c|c|c|}
\hline \multicolumn{3}{|r|}{ Entrevista } \\
\hline & Preguntas & Fundamentación teórica. \\
\hline & & $\begin{array}{l}\text { Tiene como objetivo identificar factores inherentes a la satisfacción } \\
\text { debido que en países en desarrollo es importante aclarar que áreas o } \\
\text { cuestiones deben priorizarse en el diseño y desarrollo de tecnologías } \\
\text { de bajo costo (Magnusson y Ahlström, 2017). }\end{array}$ \\
\hline 1 & $\begin{array}{c}\text { ¿Está satisfecho con } \\
\text { su silla de ruedas? } \\
\text { ¿por qué? }\end{array}$ & $\begin{array}{l}\text { Según Štefanac et al. (2018), estudiar y comprender los niveles o } \\
\text { grado de satisfacción de los usuarios de silla de ruedas con respecto a } \\
\text { esta ayuda técnica, puede ayudar a los terapeutas ocupaciones y a } \\
\text { otros profesionales, entre estos los diseñadores a aumentar el } \\
\text { rendimiento de los usuarios de sillas de ruedas en las actividades de la } \\
\text { vida cotidiana, facilitar la participación social y comunitaria y mejorar } \\
\text { su movilidad. }\end{array}$ \\
\hline
\end{tabular}

¿De qué manera

2 considera que su silla

de ruedas afecta positivamente su vida?

¿De qué manera considera que su silla de ruedas afecta negativamente su vida?
Se pretende identificar aquellas barreras ya sean físicas o psicológicas que afectan la calidad de vida del usuario y que a la vez estas son atribuidas por el mismo usuario a la ayuda técnica. Dichas barreras u obstáculos en el uso de la silla de ruedas disminuye la satisfacción en general de la silla de ruedas (Sumner et al., 2017).

Según Domingues et al. (2019) es de gran importancia identificar objetivamente aquellas barreras y facilitadores que interactúan con la movilidad debido a que estas repercuten directamente con la participación social del usuario. Además, participación social podría estar vinculada con la morbilidad y la calidad de vida de las personas
¿Le gustaría que el diseño de ruedas fuera diferente? ¿Por qué? ¿Qué le cambiaria al diseño de la silla de ruedas?
Gran parte de los usuarios de silla de ruedas obtienen su ayuda técnica como beneficiarios de programas de caridad y donaciones gubernamentales las cuales, las características de estas sillas de ruedas distan de las preferencias y necesidades de los usuarios. A su vez, podría decirse que los beneficiarios de dichos programas en su gran mayoría no tienen una fuente de ingresos económicos, por lo tanto, no tienen los recursos en realizar modificaciones o comprar accesorios que mejoren las características de la silla de ruedas y por ende su satisfacción. Entonces, la retroalimentación en el diseño de ayudas técnicas es esencial para la búsqueda de un diseño óptimo que mejore la calidad de vida de los usuarios (Bane et al., 2019).

También, los usuarios han manifestado una satisfacción incompleta con respecto a la silla de ruedas ya que, después de un tipo prolongado de uso de esta, han evidenciado algunos problemas tales como: poca durabilidad, incomodidad y difícil transporte (Sumner et al. 2017).

Se busca comprender las causas de las molestias en el cuerpo de los usuarios generadas por el uso de la ayuda técnica. Dichas molestias son ocasionadas por los largos periodos de uso la silla de ruedas, tienen un gran efecto con la satisfacción y percepción hacia esta por parte de los usuarios. De acuerdo con Medola et al. (2014) y Requejo et al. (2015), existe gran incidencia de dolor en el hombro, muñeca, cuello y espalda entre los usuarios de sillas de ruedas manuales, lo 
cual ocasiona un impacto negativo en la dependencia y en la realización de la gran mayoría de las actividades diarias. De hecho, la incidencia de dolor entre los usuarios de sillas de ruedas se ha relacionado con la mala calidad de vida del usuario y de los cuidadores. Por lo tanto, se evidencia la necesidad de soluciones en el diseño de la silla de ruedas, con el fin de mejorar la seguridad, la comodidad y la satisfacción con el uso a largo plazo de la silla de ruedas. Por otra parte, se reveló que el $71.6 \%$ de los usuarios beneficiarios de una donación de silla de ruedas en India, abandonaron o vendieron las sillas de ruedas, y entre las razones más comunes se encontró el dolor ocasionado, la fatiga, la incomodidad y la calidad de esta (Sumner et al., 2017)

¿Qué actividades le

gustaría hacer con su silla de ruedas?
Muchos usuarios de sillas de ruedas han señalado que la silla en sí misma es el principal factor que limita su participación comunitaria. Por lo tanto, es importante investigar cómo los usuarios perciben diferentes aspectos de su interacción diaria con la silla de ruedas para identificar problemas de usabilidad, lo que puede ser útil para que los diseñadores y fabricantes produzcan ayudas técnicas más adecuadas a las necesidades y expectativas de los usuarios (Medola et al., 2014).

A su vez, Medola et al. (2014) reporta que usuarios de sillas de ruedas han informado que perciben su movilidad como restringida, por lo tanto era importante evaluar las principales dificultades que experimentan los usuarios al realizar cualquier actividad con sus sillas de ruedas. Los problemas más comunes reportados por los usuarios durante su movilidad son las rampas, escalones y transferencias.
¿Le es fácil maniobrar su silla de ruedas?

¿Recibió capacitación en el manejo de esta?
Algunos estudios informaron que el entrenamiento en habilidades para sillas de ruedas es un medio para mejorar de calidad de vida de los usuarios debido a su papel preventivo contra las lesiones por uso de esta ayuda técnica y, por lo tanto, repercute en la satisfacción y percepción del usuario hacia la silla de ruedas (Ebrahimi et al., 2016).

Así mismo, en cuanto a silla de ruedas de donación, los usuarios de sillas de ruedas apreciaban el recibir dicha ayuda técnica, sin embargo a menudo se enfrentaban a desafíos relacionados con un mal ajuste, falta de capacitación en las maniobras adecuadas de la silla de ruedas, y frecuentes necesidades de reparación de neumáticos y otras partes (Williams et al., 2017). Entonces, se podría decir que lo anterior repercute en la satisfacción general con el uso de la silla de ruedas.

\begin{tabular}{|c|c|c|}
\hline 8 & $\begin{array}{l}\text { ¿Ha personalizado o } \\
\text { realizado } \\
\text { adaptaciones a su silla } \\
\text { de ruedas para } \\
\text { sentirse más cómodo? }\end{array}$ & $\begin{array}{l}\text { La estabilidad y la seguridad son aspectos importantes que } \\
\text { contribuyen a la satisfacción de los usuarios con el equipo (Medola } \\
\text { et al., 2014). Por otra parte, los usuarios generalmente reciben las } \\
\text { sillas de ruedas completamente ensambladas, pero algunos usuarios } \\
\text { realizan modificaciones en los reposapiés, reposabrazos o el cojín, e } \\
\text { incluso algunos han agregaron bolsillos o bolsos para llevar sus } \\
\text { objetos. Sin embargo, cambiar el cojín es una de las modificaciones } \\
\text { más comunes para mejorar la comodidad, reducir el riesgo de úlceras } \\
\text { por presión y ajustar las sillas de ruedas que eran demasiado grandes } \\
\text { o demasiado bajas (Williams et al., 2017). }\end{array}$ \\
\hline 9 & $\begin{array}{l}\text { ¿Cuáles reacciones } \\
\text { emocionales cree } \\
\text { usted que produce su }\end{array}$ & $\begin{array}{l}\text { Se busca abordar de manera directa la Experiencia del Usuario (UX) } \\
\text { durante el uso de la silla de ruedas desde una perspectiva emocional } \\
\text { propia e influenciada por persona de su entorno. Considerando que la }\end{array}$ \\
\hline
\end{tabular}




\begin{tabular}{ccc}
\hline $\begin{array}{c}\text { silla de ruedas a las } \\
\text { personas de su } \\
\text { entorno? }\end{array}$ & $\begin{array}{c}\text { Experiencia del Usuario está relacionada con el estado de ánimo de } \\
\text { estos, Carneiro et al (2015), plantea el interrogante de cómo se debe } \\
\text { evaluar la Experiencia del usuario en las ayudas técnicas y a su vez, } \\
\text { menciona que aún no existe un enfoque metodológico que permita } \\
\text { evaluarla de manera simultánea con la usabilidad del producto. }\end{array}$ \\
$\begin{array}{c}\text { ¿Cuáles reacciones } \\
\text { emocionales le } \\
\text { produce a usted su } \\
\text { silla de ruedas? }\end{array}$ & $\begin{array}{l}\text { Partiendo de los resultados de Lanutti (2019), estas dos preguntas } \\
\text { pretenden evidenciar la influencia de estigma social en la relación } \\
\text { emocional de las personas con discapacidad y su silla de ruedas. }\end{array}$ \\
\hline
\end{tabular}

\subsubsection{QUEST 2.0 (Quebec User Evaluation of Satisfaction with Assistive Technology)}

Como parte de la investigación cuantitativa, se empleó este instrumento con el propósito de otorgar un valor numérico a la satisfacción del usuario con respecto a la silla de ruedas. EI QUEST 2.0, o Quebec User Evaluation of Satisfaction with Assistive Technology (en español, Evaluación de Quebec de Usuarios con Tecnología de Asistencia) consta de un cuestionario que tiene como objetivo avaluar la satisfacción de los usuarios con respecto a las ayudas técnicas, abarcando dos importantes ámbitos: las características del producto y los servicios relacionados a este.

EI QUEST 2.0 fue creado en Canadá por la investigadora Louise Demers, quien desarrolló una primera versión para su tesis de maestría en 1995. En esta primera versión se tomaron en cuenta 24 aspectos para evaluar la satisfacción del usuario con respecto a la ayuda técnica. Sin embargo, Louise Demers en sus estudios de doctorado basándose en pruebas de validación y confiabilidad, sintetizó la primera versión para evaluar solo 12 aspectos de satisfacción, creando así la segunda y última versión de esta herramienta (Mattozo, 2016). EI QUEST 2.0 ha sido una herramienta con gran difusión académica y por lo tanto validada en varios idiomas; la traducción y validación de este cuestionario al idioma español se llevó a cabo por Mora (2010) como su trabajo de especialización en Medicina Física y Rehabilitación.

Según Demers, el QUEST 2.0 es una herramienta multidisciplinar dado que fue desarrollado para profesionales e investigadores de diferentes áreas tales como terapeutas ocupacionales, fisioterapeutas, ingenieros, psicólogos diseñadores y fabricantes de ayudas técnicas (Mattozo, 2016). El cuestionario, considera 8 aspectos relacionados al diseño del producto: 1) Dimensiones, 2) Peso, 3) Ajustes, 4) Seguridad, 
5) Durabilidad, 6) Facilidad de uso, 7) Comodidad y 8) Eficiencia. A su vez, también se contemplan 4 factores relacionados a la prestación de servicios: 9) Proceso de entrega, 10) Reparación y mantenimiento, 11) Calidad de servicios profesionales y 12) Servicios de seguimiento. Cada uno de los aspectos se evalúa mediante una escala del 1 al 5 que varía entre: 1- Nada satisfecho, 2- Poco satisfecho, 3- Más o menos satisfecho, 4Satisfecho y 5- Muy Satisfecho (Lima-Barroso, 2018).

\subsubsection{Escala de Diferencial Semántico}

Con el objetivo de cuantificar la percepción de los usuarios hacia la silla de ruedas se empleó la Escala de Diferencial Semántico. Esta herramienta fue desarrollada en la década de 1950 por el psicólogo político-social Charles E. Osgood, con el propósito de medir el significado connotativo de los productos u objetos (Holdschip, 2015). La herramienta se caracteriza por no ser un cuestionario específico, sin embargo, puede ser catalogada como una técnica de medición general que puede ser aplicada para el estudio de diferentes problemas en diversas áreas tales como psicología, lingüística, diseño, entre otros (Boiani, 2018). La Escala de Diferencial semántico ha sido utilizada anteriormente para estudiar las ayudas técnicas con el propósito de buscar comprender las cuestiones perceptivas relacionadas al significado que se le atribuye a dichos productos (Lanutti, 2019).

La escala de Diferencial Semántico es un instrumento de medición que se relaciona con el diseño emocional debido a que es utilizado para obtener las percepciones de carácter emotivo y simbólico de los usuarios hacia los objetos. Esta medición se realiza mediante la representación de pares opuestos de adjetivos, cada uno en un extremo. Cada par de adjetivos cuenta con una escala de 5 a 7 puntos, por ejemplo una escala de $-3,-2,-1,0,1,2,3$, con el propósito de que el usuario asigne el grado afectivo al objeto que está observando o usando (Marín-Vásquez, 2017). Según Crepaldi y Santos (2018), la medición de la percepción por medio de la Escala de Diferencial Semántico es un método que consta de ventajas tales como su fácil aplicación y su bajo costo, además, se menciona que sus resultados poseen gran confiabilidad y validez. A su vez, este instrumento brinda la posibilidad la cuantificar factores subjetivos como la percepción y las emociones de los usuarios. En consecuencia, en el área del diseño 
esta herramienta puede ser utilizada para evaluar los sentimientos o la percepción de los usuarios con respecto a los productos, sin embargo, el desafío de utilizar esta técnica semántica es la selección de los adjetivos correctos, para los cuales, diversos autores han señalado la importancia de utilizar el diccionario para encontrar los antónimos adecuados a cada adjetivo (J. C. R. P. da Silva et al., 2019).

\subsection{Procedimientos previos}

\subsubsection{Protocolo para la fase cualitativa}

Como protocolo, antes de iniciar la entrevista se solicitó permiso a cada uno de los participantes para el manejo de la información. Aquellos que estuvieron de acuerdo firmaron de manera voluntaria un Consentimiento Informado (ANEXO A) puesto a disposición por el autor de esta investigación. Solo después de haber firmado dicho documento, se inició la realización de las preguntas.

Las entrevistas se llevaron a cabo en las instalaciones del Instituto de las Personas con Discapacidad en la Delegación Venustiano Carranza de la Ciudad de México, en donde los participantes y/o usuarios de sillas de ruedas respondieron directamente cada pregunta. Las preguntas se formularon de manera muy clara, de tal manera que los entrevistados pudieron hablar libremente sobre lo que pensaban, sentían y las impresiones que tenían sobre su silla de ruedas. Todas las respuestas a las preguntas fueron grabadas para una posterior etapa de transcripción de estas.

Una vez recolectado y transcrito el material cualitativo, se procedió a la fase de lectura y posteriormente a la fase de categorización. En esta última fase, las respuestas cada pregunta fueron agrupadas en categorías y se presentaron en una tabla. Estas serán descritas en el capítulo de resultados.

\subsubsection{Protocolo para la fase cuantitativa}

La investigación contó con la colaboración de dos fundaciones de la Ciudad de México, la primera INDISCAPACIDAD CDMX (Instituto de las Personas con Discapacidad de la Ciudad de México) y la segunda, FINDEDIS, A.C. (Fundación para la Inclusión y 
Desarrollo de Personas con Discapacidad A.C.). Por otra parte, se llevaron a cabo dos modalidades para la recolección de los datos: presencial y virtual. La recopilación de los datos de manera presencial se llevó a cabo en las instalaciones de INDISCAPACIDAD y para la modalidad virtual, se usó la plataforma digital de Google Forms. Esta última, fue estrictamente necesaria debido a la emergencia sanitaria ocasionada por la pandemia de la enfermedad del coronavirus Covid-19. De igual manera, todos los participantes de esta fase de la investigación firmaron el Consentimiento Informado mencionado anteriormente. Una vez que se contó con la autorización de los participantes, se les aplicó los dos instrumentos para la recolección de la información, el cuestionario QUEST 2.0 y la Escala Diferencial Semántico. Dichos instrumentos se pueden observar en el Anexo A y Anexo B.

Específicamente en la Escala Diferencial Semántico, se contemplaron 19 pares de adjetivos opuestos que fueron relacionados con tres dimensiones de diseño y ordenados de manera aleatoria. Dichos pares de adjetivos fueron obtenidos y seleccionados de la literatura existente. Asimismo, las tres dimensiones de diseño fueron las siguientes: la dimensión de atracción visual, la dimensión práctica y la dimensión simbólica. En la Tabla 4, se evidencia la relación de cada par de adjetivos con una de las tres dimensiones de diseño. 


\section{Tabla 4}

Pares de adjetivos empleados en la Escala de Diferencial Semántico

\begin{tabular}{|c|c|c|c|c|}
\hline \multicolumn{2}{|c|}{ Dimensión } & \multicolumn{3}{|c|}{ Par de adjetivos } \\
\hline \multirow{2}{*}{1.} & \multirow{2}{*}{ Dimensión de atracción visual } & Atractiva & - & No atractiva \\
\hline & & Moderna & - & Anticuada \\
\hline \multirow{10}{*}{2.} & \multirow{10}{*}{ Dimensión práctica } & Fácil de transportar & - & Difícil de transportar \\
\hline & & Personalizable & - & No personalizable \\
\hline & & Satisfactorio & - & Insatisfactorio \\
\hline & & Simple & - & Complicada \\
\hline & & Segura & - & Peligrosa \\
\hline & & Fácil de usar & - & Difícil de usar \\
\hline & & Cómoda & - & Incómoda \\
\hline & & Fácil mantenimiento & - & Difícil mantenimiento \\
\hline & & Resistente & - & Frágil \\
\hline & & Lenta & - & Rápida \\
\hline \multirow{7}{*}{3.} & \multirow{7}{*}{ Dimensión simbólica } & Incluyente & - & Excluyente \\
\hline & & Sociable & - & Introvertida \\
\hline & & Independiente & - & Dependiente \\
\hline & & Productiva & - & Improductiva \\
\hline & & Motivadora & - & Frustrante \\
\hline & & Positiva & - & Negativa \\
\hline & & Innovadora & - & Tradicional \\
\hline
\end{tabular}




\section{RESULTADOS Y ANÁLISIS}

\subsection{Resultados cualitativos - Entrevista}

Primera pregunta: ¿Se encuentra usted satisfecho con su silla de ruedas? Los participantes respondieron de manera dicotómica (sí o no), por ello, se les pidió que dieran una descripción explicita de sus respuestas en las cuales se identificaron tres categorías. La primera categoría, Insatisfacción por factores físicos de la silla de ruedas indicó la inconformidad con respecto a factores de diseño de esta, así como el peso, los apoyabrazos, los reposapiés, las dimensiones, etc.

USUARIO 1: "- No. Porque como yo soy una persona que sale a la calle todo el tiempo, es muy complicada porque... haz de cuenta que los apoyabrazos me estorban demasiado para "darle", porque a veces hay personas que no me pueden acompañar y pues como voy sola, pues tengo que hacer "esto" (imita la propulsión manual) y me lastima aquí (señala su brazo) ... se me hace muy incómodo... El asiento también lo siento demasiado duro y también voy, así como... encorvada. Normalmente yo acostumbro a sentarme derecha y el asiento está como (realiza una $U$ con sus manos) ... no sé cuál material sea, pero a la hora de sentarse se va para atrás. No, no me gusta."

La segunda categoría, Insatisfacción por factores emocionales, la cual indicó la inconformidad a cuestiones relacionadas al estigma social de la discapacidad que se manifiesta en emociones como la lástima y el despreció.

USUARIO 2: "- No, porque la gente que se te queda viendo y dice 'pobrecito' y hacen que uno se sienta un poco mal".

La tercera categoría, Satisfacción por factores emocionales reveló información acerca de la satisfacción positiva ligada a cuestiones de afecto y sentimientos, tales como el agradecimiento.

USUARIO 5: "- No mucho, pero le agradezco. Afortunadamente si le agradezco a la silla de ruedas porque me enseñó a movilizarme. Gracias a ella aprendí hacer muchas cosas. Es muy limitante esta silla, demasiado limitante, pero si le encuentras el modo y la maña, estás del otro lado." 


\section{Tabla 5}

Categorías para la primera pregunta "¿Se encuentra usted satisfecho con su silla de ruedas?"

\begin{tabular}{ccc}
\hline $\mathbf{N}^{\circ}$ & Categorías & Frecuencia \\
\hline 1 & Insatisfacción por factores físicos de la silla de ruedas & 7 \\
\hline 2 & Insatisfacción por factores emocionales & 1 \\
\hline 3 & Satisfacción por factores emocionales & 2 \\
\hline
\end{tabular}

Segunda pregunta: ¿De qué manera considera que su silla de ruedas afecta positivamente su vida? En las respuestas de los usuarios se identificó solo una categoría la cual hace referencia al sentimiento de independencia que los usuarios le atribuyen al uso de la silla de ruedas.

USUARIO 1: "- Positivamente me ayuda mucho porque es una necesidad, porque yo sin la silla no me muevo... me ayuda a salir y pues tengo que trabajar".

USUARIO 10: “- Positivamente... evito la pena de que me ayuden tanto".

\section{Tabla 6}

Categorías para la segunda pregunta "¿De qué manera considera que su silla de ruedas afecta positivamente su vida?"

\begin{tabular}{ccc}
\hline $\mathbf{N}^{\circ}$ & Categorías & Frecuencia \\
\hline 1 & Sentimiento de independencia y agradecimiento & 10 \\
\hline
\end{tabular}

Tercera pregunta: ¿De qué manera considera que su silla de ruedas afecta negativamente su vida? En las respuestas de los usuarios se encontraron tres categorías. La primera categoría Afectaciones corporales, los usuarios mencionaron los posibles daños en el cuerpo que pueden surgir por el uso prolongado de la silla de ruedas.

USUARIO 1: "- Negativamente... la silla de ruedas me puede afectar a la columna, de tanto tiempo estar sentada".

La segunda categoría Afectaciones emocionales, los usuarios relataron cuestiones relacionadas al estigma social de la discapacidad que los ha llevado a experimentar un sentimiento de inferioridad. 
USUARIO 5: "- Negativamente, hay veces que te encuentras a gente y te ve raro; $y$ con el simple hecho de verte raro, ya te apagas. Lo único malo, es que la gente te vea raro... es lo más negativo que se puede encontrar en las sillas de ruedas"

La tercera categoría Afectaciones por el uso, los usuarios mencionaron las afectaciones que surgen en la interacción con la silla de ruedas debido a sus características físicas. Algunas de ellas que se mencionaron fueron el peso, las dimensiones y los tipos de materiales empleados en la fabricación de estas.

USUARIO 3: “- Negativamente me afecta porque la silla es muy pesada, muy estorbosa... las llantas delanteras son muy malas y además sus ejes se rompen muy seguido. También los rines son muy frágiles."

USUARIO 9: "- Negativamente más que nada me afecta el peso porque hace que me agite más y como tengo problemas en el corazón tengo que hacer más esfuerzo y me sofoco. Incluso, luego hasta me llego a marear".

\section{Tabla 7}

Categorías para la tercera pregunta "¿De qué manera considera que su silla de ruedas afecta negativamente su vida?"

\begin{tabular}{ccc}
\hline $\mathbf{N}^{\circ}$ & Categorías & Frecuencia \\
\hline 1 & Afectaciones corporales & 1 \\
\hline 2 & Afectaciones emocionales & 2 \\
\hline 3 & Afectaciones de usabilidad & 7 \\
\hline
\end{tabular}

Cuarta pregunta: ¿Le gustaría que el diseño de su silla de ruedas fuera diferente?, todos usuarios respondieron de manera afirmativa. A partir de dicha información, se les pregunto ¿Qué le cambiarían al diseño de su silla de ruedas?, donde se evidenciaron dos categorías. La primera Características físicas, los usuarios relataron algunas sugerencias de cambio en diferentes partes de la silla de ruedas, como el asiento, el respaldo, los reposapiés, y los apoyabrazos. También, para esta categoría se tomaron en cuenta los usuarios que manifestaron su inconformidad con respecto a los materiales, las dimensiones y el peso de la silla de ruedas. 
USUARIO 2: "- Que, si tenga apoyabrazos, pero a una estatura razonable porque están muy altos, entonces al momento de estar en tu silla y quererte trasladar a un coche, o una silla normal no puedes porque los apoyabrazos están muy altos.

USUARIA 4: "- Sí. Le cambiaria que los materiales fueran un poquito menos pesados y que la silla fuera un poquito menos estorbosa, menos grande. Que sea más ligera porque eso es lo que más me complica, está muy pesada. A la hora de subirla para guardarla está muy pesada. El diseño para cerrarla está perfecto".

USUARIO 9: "- Yo le cambiaría el peso. Bueno, los apoyabrazos... se los quitaría. Los haría como en el caso de una silla activa... o sea para hacerla con mejor movilidad en los brazos... para bracear un poco mejor. Lo que son de los reposapiés... se los haría más chiquitos"

En la segunda categoría Atracción visual, dos participantes mencionaron que les gustaría cambiar la apariencia de su silla de ruedas.

USUARIO 3: "- Sí, completamente porque no me gusta el diseño. Para mí en lo particular es muy complicado, es muy voluminoso... y sería más práctico una silla que se pueda maniobrar más y que no tenga los apoyabrazos... También le cambiaría la estética.

\section{Tabla 8}

Categorías para cuarta la pregunta "¿Qué le cambiaria al diseño de la silla de ruedas?"

\begin{tabular}{ccc}
\hline $\mathbf{N}^{\circ}$ & Categorías & Frecuencia \\
\hline 1 & Características físicas & 8 \\
\hline 2 & Atracción visual & 2 \\
\hline
\end{tabular}

Quinta pregunta: "¿La silla de ruedas le ocasiona dolores o molestias en su cuerpo?", los participantes respondieron sus molestias mencionando diferentes partes del cuerpo. Las respuestas a esta pregunta se categorizaron dependiendo el tipo de molestia y la zona del cuerpo nombrada por los usuarios.

USUARIO 1: "- Sí, en la espalda, te digo... es que luego voy así (hace una posición encorvada) ... yo creo que es el respaldo y el asiento por los materiales que usan. Me ocasiona dolor en la espalda baja y en la cadera" 
USUARIO 3: "- Sí, en la espalda baja... y lo mismo por el sudor de la espalda pues causa comezón y sarpullido."

USUARIO 9: "- Sí, presión en nalgas y en la cadera. Tal vez es porque estoy operado de la cadera, pero ya me di cuenta de que es una silla que no tiene la adaptabilidad para descansar ni un poquito."

\section{Tabla 9}

Categorías para la quinta pregunta "¿La silla de ruedas le ocasiona dolores o molestias en su cuerpo?"

\begin{tabular}{ccc}
\hline $\mathbf{N}^{\circ}$ & Categorías & Frecuencia \\
\hline 1 & Dolor espalda & 5 \\
\hline 2 & Dolor cadera & 3 \\
\hline 3 & Presión nalgas & 1 \\
\hline 4 & Comezón espalda & 1 \\
\hline
\end{tabular}

Sexta pregunta: “¿Qué actividades le gustaría hacer con su silla de ruedas?”, los usuarios mencionaron las actividades en las cuales se sienten limitados por usar su silla de ruedas. Las respuestas a esta pregunta se dividieron en tres categorías. La primera, 'Moverse con libertar en lugares públicos' en la cual los participantes citaron las diferentes barreras físicas (especialmente las banquetas y escaleras) de los lugares públicos, como parques y el sistema de transporte.

USUARIO 1: "- Salir libre, porque la ciudad no está para silla de ruedas. Salir al parque, por ejemplo, el parque Bicentenario está muy bonito, pero hay unas rampotas, y yo no lo puedo hacer. Y no sé... correr, bueno no correr... rodar... divertirme... ir más rápido, más dinámico porque al vernos en silla pues es sinónimo de enfermedad y entonces pues de esa manera nos ven".

USUARIO 3: "- Muchísimas... por ejemplo jugar basquetbol... jugar tenis... subir y bajar rampas... pasar topes, los obstáculos de la calle de la Ciudad de México sin voltearme porque normalmente en esta silla me volteo por lo mismo que las llantas las tiene verticales, entonces cualquier desvío... mi peso le gana y se va. Entonces me gustaría mucho las llantas un poquito... diagonales, porque he visto personas que al pasar un tope solas se les va la silla, por lo mismo que las llantas están verticales... y la misma silla pues los aplasta porque se dobla". 
La segunda categoría, "Realizar un deporte" en el cual los participantes coincidieron en querer una silla de ruedas más liviana para moverse rápidamente y practicar algún tipo de actividad física o deporte como el basquetbol.

USUARIO 2: "- Me gustaría jugar basquetbol, ir más rápido. Ser más activo"

USUARIO 9: "- Basquetbol, pista, boliche... un deporte."

Por último, en la tercera categoría "Actividad laboral" un usuario mencionó el deseo de volver a ejercer una actividad laboral donde la silla de ruedas no represente ningún impedimento.

USUARIO 7: "- Volver a regresar a mi vida cotidiana que es trabajar y ser productivo en la sociedad. Eso es lo que yo quisiera hacer, estando en la silla, ya manejándola bien sin ningún obstáculo... trabajar y volver a mi vida cotidiana. Se puede decir que es lo mismo, pero con limitaciones, pero todo eso se puede vencer, poco a poco. Solo hay que estar consciente que la silla es tu amiga, no hay que verla como nuestra enemiga $o$ como algo del otro mundo porque no, ella es una ayuda"

\section{Tabla 10}

Categorías para la sexta pregunta "¿Qué actividades le gustaría hacer con su silla de ruedas?"

\begin{tabular}{ccc}
\hline $\mathbf{N}^{\circ}$ & Categorías & Frecuencia \\
\hline 1 & Moverse con libertar en lugares públicos & 6 \\
\hline 2 & Realizar un deporte & 3 \\
\hline 3 & Actividad Laboral & 1 \\
\hline
\end{tabular}

Séptima pregunta: “¿Le resulta fácil maniobrar su silla de ruedas?”, los participantes respondieron de forma dicotómica (sí o no). Asimismo, se formuló otra pregunta alusiva al entrenamiento o capacitación en el manejo de la silla de ruedas, “¿Recibió usted capacitación en el manejo de su silla de ruedas?”. Como resultado, todos los participantes manifestaron no haber tenido ningún tipo de capacitación en el manejo de la silla de ruedas y como consecuencia, muchos de ellos relataron haber sufrido caídas debido a la falta de destreza en el uso de esta. De lo anterior, para dicha pregunta se establecieron dos categorías, la primera "Fácil" y la segunda "Difícil", 
ambas hacen referencia a la percepción de los usuarios en cuanto al uso de la silla de ruedas.

USUARIO 1: "- Sí, yo me he adaptado muy bien porque ya llevo tiempo con ella... a los dos meses me salí a la calle y he sido muy mañosa, pero si me ha costado trabajo salir yo sola a la calle. No recibí capacitación ninguna, ni cómo usarla, ni que hacer... nada. Me caí dos veces. No me dijeron como usarla, ni siquiera en el hospital."

USUARIO 3: "- No es fácil... por los apoyabrazos... los reposapiés son muy frágiles... yo he tenido tres sillas de ruedas y a las tres los reposapiés se enchuecan luego... entonces no sé qué sea, si el diseño o el material..."

USUARIO 10: "- Si, me es fácil porque ya tengo unos años, pero me da miedo todavía porque me he caído. No es tan adecuada. Cuesta trabajo porque tiene las piezas guangas, las gomas no son gomas, son como de plástico corriente."

\section{Tabla 11}

Categorías para la séptima pregunta “¿Le resulta fácil maniobrar su silla de ruedas?"

\begin{tabular}{ccc}
\hline $\mathbf{N}^{\circ}$ & Categorías & Frecuencia \\
\hline 1 & Fácil & 5 \\
\hline 2 & Difícil & 5 \\
\hline
\end{tabular}

Los usuarios que manifestaron que el uso de la silla de ruedas les resultaba complicado debido a la falta de entrenamiento también lo atribuyen a características propias del diseño de la silla de ruedas, tales como la altura de los apoyabrazos y el peso. Es importante mencionar que todos los usuarios que percibieron el manejo de la silla de ruedas como una tarea fácil, reconocieron que es algo que se debe a la destreza adquirida con el tiempo, ya que mencionaron que cuando comenzaron al usar la silla de ruedas les resultaba difícil el manejo de esta.

Octava pregunta: “¿Ha personalizado o realizado adaptaciones a su silla de ruedas para sentirse más cómodo?", los usuarios relataron las modificaciones que le realizaron a su silla de ruedas para hacerla más cómoda. Sus respuestas fueron categorizadas según el tipo adaptación descrita. En la primera categoría "Asiento", los usuarios mencionaron que han adaptado el asiento de diversas formas, en la cuales la 
más predominante es un cojín convencional o de tipo dona. Incluso, los usuarios relataron que han usado tablas, sábanas y hasta una botella para hacer su asiento más confortable.

USUARIO 9: "- En el asiento... cuando me chupa para adentro le meto una botella de agua y ya me saca... ya agarré esa maña de meterle mi agua y ya me trae derechito"

En la segunda categoría, "Sistemas de seguridad” se mencionó la utilización de vendas y sábanas como un tipo de cinturón de seguridad.

USUARIO 3: "- Sí, me amarro con sábanas o con vendas. Le pongo un cojín en el asiento porque lastima el tubular de abajo y como yo tengo escaras... lastima mucho el tubo"

En la tercera categoría "Portaobjetos", los usuarios mencionaron la necesidad de adaptarle a la silla de ruedas accesorios de tipo bolsa para facilitar el trasporte de sus objetos personales. Por otro lado, los participantes hicieron énfasis en citar que dichas modificaciones se hacen con bastante ingenio debido a que el diseño de la silla de ruedas es poco personalizable.

USUARIO 1: "- Quiero ponerle un vaso, haz de cuenta... porque luego vamos al cine y no hay donde ponerlo y en la parte de abajo... quisiera una bolsa para llevar mi material porque soy diseñadora de moda y voy y compro mi material... entonces abajo quiero hacerle mi compartimento para mi mandado o para mis cosas"

Tabla 12

Categorías para la octava pregunta "¿Ha personalizado o realizado adaptaciones a su silla de ruedas para sentirse más cómodo?"

\begin{tabular}{ccc}
\hline $\mathbf{N}^{\circ}$ & Categorías & Frecuencia \\
\hline 1 & Asiento & 6 \\
\hline 2 & Sistema de seguridad & 2 \\
\hline 3 & Portaobjetos & 2 \\
\hline
\end{tabular}

Novena pregunta: “¿Cuáles reacciones emocionales cree usted que produce su silla de ruedas a las personas de su entorno?", todos los participantes consideraron que su silla de ruedas provoca reacciones emociones negativas en las personas de su entorno 
(amigos, vecinos, familiares, etc.). Las reacciones emociones más citadas por los participantes fueron las siguientes: lástima, rechazo, poca empatía y discriminación. A su vez, en sus respuestas se encontraron expresiones como "me hacen sentir menos", "siento que me critican y me juzgan", "me ven como una persona enferma". Debido a lo anterior, se planeó una sola categoría para esta pregunta.

USUARIO 3: "-Sienten lástima... conmiseración ...te hacen sentir menos."

USUARIO 4: "La gente te discrimina y te avienta. Ya hasta en el metro da miedo irte por la orilla. Creen que uno es el estorbo. Los elevadores, ya la gente los agarra y se enoja porque no cabemos".

\section{Tabla 13}

Categorías para la novena pregunta "¿Cuáles reacciones emocionales cree usted que produce su silla de ruedas a las personas de su entorno?"

\begin{tabular}{ccc}
\hline $\mathbf{N}^{\circ}$ & Categorías & Frecuencia \\
\hline 1 & Reacciones emocionales negativas & 10 \\
\hline
\end{tabular}

Decima pregunta: “¿Cuáles reacciones emocionales le produce a usted su silla de ruedas?". En esta pregunta, se encontraron respuestas de dos tipos, por ello, estas se clasificaron en dos categorías. En la primera categoría "Reacciones emociones positivas" lo usuarios manifestaron estar agradecidos con su silla de ruedas dado que reconocen que esta les otorga independencia. Algunos usuarios manifestaron reacciones emocionales positivas como bienestar, alegría y afecto.

USUARIO 2: "- Pues me siento bien, me transmite bienestar porque son mis piernas... es un medio de transporte para mí... es indispensable que este bien mi silla para yo poder hacer mis actividades y sobre todo siendo padre de familia, salgo a jugar con mi hija me la llevo al parque."

USUARIO 3: "- Me emociona porque para mí es indispensable."

La segunda categoría para la novena pregunta, fue denominada "Reacciones emocionales negativas" en la cual los usuarios mencionaron emociones tales como depresión, tristeza y decepción. Algunas de estas de estas respuestas de connotación 
negativa, estaban influenciadas por las reacciones emocionales de las personas de su entorno.

USUARIO 5: "-ES algo deprimente... hay muchas limitaciones en esta silla, me limita demasiado y el simple hecho de detenerte te causa algo de decepción..."

USUARIO 7: "- Me da depresión, porque para mí es la silla es como... la cadena de una mascota... me limita mucho"

\section{Tabla 14}

Categorías para la décima pregunta “¿Cuáles reacciones emocionales le produce a usted su silla de ruedas?"

\begin{tabular}{ccc}
\hline $\mathbf{N}^{\circ}$ & Categorías & Frecuencia \\
\hline 1 & Reacciones emocionales positivas & 6 \\
\hline 2 & Reacciones emocionales negativas & 4 \\
\hline
\end{tabular}

\subsection{Resultados cuantitativos}

\subsubsection{Evaluación de la satisfacción - QUEST 2.0}

En este apartado se presenta la información y los resultados obtenidos de la aplicación de cuestionario QUEST 2.0 (Quebec User Evaluation of Satisfaction with Assistive Technology). En este cuestionario se evaluó la satisfacción de los usuarios de silla de ruedas de propulsión manual en dos diferentes aspectos, el primero de ellos, la satisfacción con respecto a las características de la silla de ruedas (dimensiones, peso, facilidad de ajustar, estabilidad y seguridad, durabilidad, facilidad de uso, comodidad, efectividad y atracción visual). El segundo aspecto evaluado fue la satisfacción alusiva a los servicios asociados con la silla de ruedas (reparación, servicios profesionales y soporte permanente). Es importante mencionar que este último aspecto se evaluó de manera superficial ya que no tiene influencia en los objetivos de la presente investigación, por ello, estos resultados son expuestos a modo de información sin abordar sus detalles.

Por otro lado, la atracción visual no está contemplada como un factor a evaluar en la versión original del cuestionario QUEST 2.0. No obstante, partiendo de los 
resultados cualitativos en los cuales algunos usuarios mencionaron su inconformidad con la atracción visual de su silla de ruedas, se decidió incorporar este factor para ser evaluado en la cuantificación de la satisfacción. A lo anterior, también se suma que algunos estudios han evidenciado la importancia de la atracción visual en las ayudas técnicas. Según Ravneberg y Söderström (2017), se ha abordado en pocas ocasiones la manera de como las personas perciben la estética o apariencia de las ayudas técnicas. Sin embargo, a pesar de que los fabricantes enfatizan el diseño de las ayudas técnicas en cuestiones plenamente de utilidad, la estética está fuertemente relacionada con los gustos y disgustos de los usuarios y se ha reportado que en algunas ocasiones es un factor que ha sido motivo para el abandono de estas. Así, partiendo de la interpretación y percepción de usuarios de ayudas técnicas, se dice estos dispositivos forman parte del cuerpo y que revelan la identidad personal. Por ello, para esta investigación la atracción visual de la silla de ruedas fue considerada como otro ítem de estudio en la aplicación del cuestionario QUEST 2.0.

Como se mencionó en las condiciones de participación, no se consideró la colaboración de usuarios sin experiencia en el uso de silla de ruedas. Los participantes fueron cuestionados con respecto al tiempo de uso de la silla de ruedas y sus respuestas variaron de 2 a 45 años de uso de esta. Para lograr una mejor compresión de lo anterior, se presenta la Figura 10, en la cual se establecen 7 intervalos de tiempo de la muestra total de los participantes $(n=52)$. 


\section{Figura 10}

División de la muestra de población $(n=52)$ por tiempo de uso de la silla de ruedas.

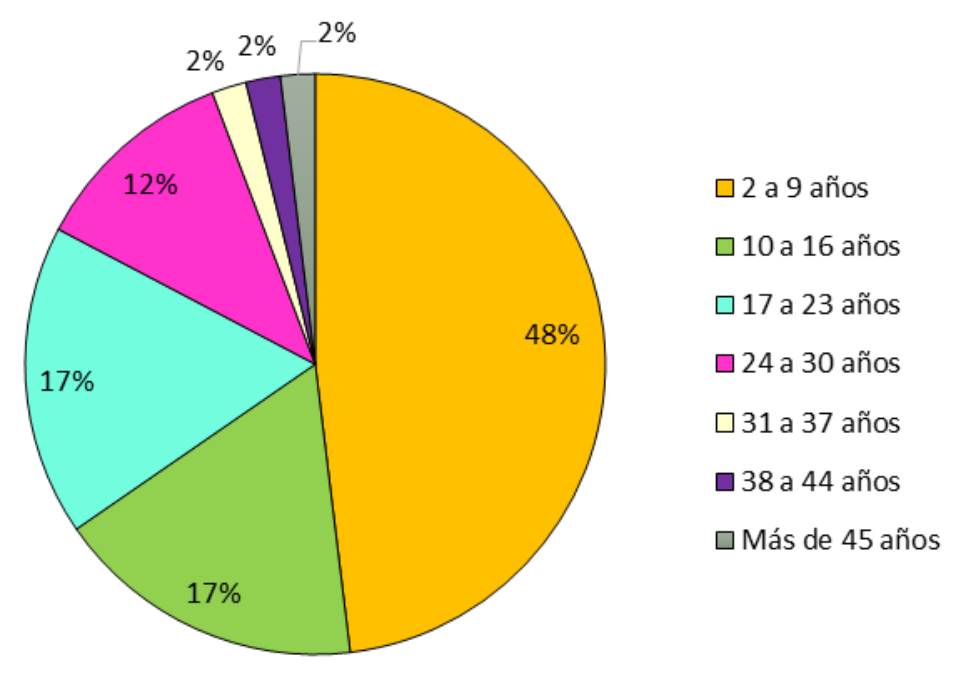

De lo mencionado anteriormente y en relación con la Figura 6, se deduce que todos los participantes poseen experiencia suficiente para proporcionar información de manera confiable en cuanto a su satisfacción y percepción ante la silla de ruedas de propulsión manual. Sin embargo, lo anterior hizo plantear algunas interrogantes con respecto a una posible correlación entre grado de satisfacción con la silla de ruedas de las personas con discapacidad en función de la experiencia con el manejo de esta. Dichas interrogantes pueden ser resueltas mediante la determinación cuantitativa de una posible correlación entre estos dos factores o variables. Las interrogantes fueron las siguientes:

- Si el tiempo de uso es mayor, ¿el usuario adquiere más experiencia y por lo tanto estará menos satisfecho con su silla de ruedas?

- Si el tiempo de uso es mayor, ¿el usuario adquiere más experiencia y por lo tanto estará más satisfecho con su silla de ruedas?

- Si el tiempo de uso es menor, ¿el usuario posee poca experiencia y debido a ello estará menos satisfecho con su silla de ruedas?

- Si el tiempo de uso es menor, ¿el usuario posee poca experiencia y por tal razón estará más satisfecho con su silla de ruedas? 
Los cuestionamientos formulados anteriormente, surgieron al inferir que una persona con mayor experiencia podría aportar información más confiable y en mayor cantidad en cuanto a su satisfacción con su silla de ruedas. De existir una correlación entre estas dos variables (tiempo de uso y grado de satisfacción), indicaría la presencia de subgrupos en los cuales la información tendría que ser tratada y analizada por separado con el propósito de encontrar similitudes entre estos. Para comprobar la existencia o no de una correlación entre las dos variables mencionadas, se llevó a cabo el cálculo del coeficiente de correlación de Pearson. Para esta investigación en particular, se determinaron 2 coeficientes de correlación de Pearson ya que se abordó la satisfacción de dos tipos de silla de ruedas de propulsión manual (de estructura plegable y de estructura rígida). Por lo tanto, se calculó un coeficiente de Pearson para cada tipo de silla anteriormente mencionado.

La obtención de dichos coeficientes se logró mediante la utilización del software Microsoft Excel en las dos muestras de población ( $n=26$ en cada muestra) y se determinó que no existe en ninguno de los casos una correlación entre las dos variables, es decir, que el tiempo de uso de la silla de ruedas no tiene una influencia directa en el grado de satisfacción de los usuarios. Los coeficientes de correlación de Pearson resultantes fueron los siguientes: para la silla de ruedas de estructura plegable generó un valor de 0.047 y para la silla de ruedas de estructura rígida arrojó un valor de -0.069 , por lo tanto, debido a que los dos valores fueron muy próximos a cero se afirma que no existe una correlación entre las variables.

Una vez se confirmó que no existe una posible correlación entre el tiempo de uso de la silla de ruedas y el grado de satisfacción de los usuarios se analizó la información de las dos muestras de estudio con el propósito de mostrar los resultados de manera general en los dos casos. Las siguientes tablas muestran dichos resultados. La segunda columna de cada una de las tablas muestra el valor promedio de las puntuaciones de las subescalas correspondientes a las características de la silla de ruedas y a los servicios relacionados con esta. A su vez, el valor indicado en la cuarta fila de esta columna hace referencia al promedio de las puntuaciones totales (característica de la silla de ruedas y servicios) proporcionadas por los 26 usuarios en cada caso. 


\section{Tabla 15}

Datos obtenidos de la aplicación del QUEST 2.0 para la silla de ruedas de propulsión manual de estructura plegable

\begin{tabular}{cccccccc}
\hline $\begin{array}{c}\text { QUEST 2.0 } \\
\begin{array}{c}\text { Silla de ruedas } \\
\text { de estructura } \\
\text { plegable }\end{array}\end{array}$ & Media & $\begin{array}{c}\text { Desviación } \\
\text { Estándar }\end{array}$ & $\begin{array}{c}\text { Puntuación con } \\
\text { Desviación } \\
\text { Estándar }\end{array}$ & $\begin{array}{c}\text { Puntuación } \\
\text { mínima }\end{array}$ & $\begin{array}{c}\text { Puntuación } \\
\text { máxima }\end{array}$ & Intervalo \\
\hline $\begin{array}{c}\text { Características } \\
\text { de la silla de } \\
\text { Ruedas }\end{array}$ & 3.06 & 0.66 & $2.40-3.72$ & 1.67 & 4.56 & 2.89 \\
\hline Servicios & 2.32 & 1 & $1.42-3.22$ & 1 & 4.67 & 3.67 \\
\hline Total & 2.88 & 0.60 & $2.28-3.47$ & 1.75 & 4.33 & 2.58 \\
\hline
\end{tabular}

\section{Tabla 16}

Datos obtenidos de la aplicación del QUEST 2.0 para la silla de ruedas de propulsión manual de estructura rígida

\begin{tabular}{ccccccc}
\hline $\begin{array}{c}\text { QUEST 2.0 } \\
\text { Silla de ruedas } \\
\text { con estructura } \\
\text { rígida }\end{array}$ & Media & $\begin{array}{c}\text { Desviación } \\
\text { Estándar }\end{array}$ & $\begin{array}{c}\text { Puntuación con } \\
\text { Desviación } \\
\text { Estándar }\end{array}$ & $\begin{array}{c}\text { Puntuación } \\
\text { mínima }\end{array}$ & $\begin{array}{c}\text { Puntuación } \\
\text { máxima }\end{array}$ & Intervalo \\
\hline $\begin{array}{c}\text { Características } \\
\text { de la silla de } \\
\text { ruedas }\end{array}$ & 4.21 & 0.57 & $3.64-4.78$ & 2.89 & 5.00 & 2.11 \\
\hline Servicios & 3.82 & 0.74 & $3.08-4.56$ & 2.33 & 5.00 & 2.67 \\
\hline Total & 4.13 & 0.52 & $3.60-4.65$ & 2.93 & 4.93 & 2.00 \\
\hline
\end{tabular}

De las anteriores tablas, se deduce que los usuarios están más satisfechos con la silla de ruedas de estructura rígida (media de 4.21) en comparación con la silla de ruedas de estructura plegable (media de 3.06). Teniendo en cuenta que, en una distribución normal, aproximadamente el $68 \%$ de los datos se encuentran en el rango de la media más o menos una desviación estándar $(\mu-1 \sigma \leq X \leq \mu+1 \sigma)$, se puede inferir que la silla de ruedas de estructura rígida posee un rango relativamente estrecho (3.64 - 4.78) donde sus valores son muy cercanos a los juicios de "satisfecho" (4) y "muy satisfecho" (5). Por el contrario, en el caso de la silla de ruedas de estructura plegable, se tiene un rango más amplio $(2.40$ - 3.72) en donde sus puntuaciones están más cercanas a las valoraciones de "no muy satisfecho" (2) y "satisfecho" (4). Sin embargo, tomando como valor de referencia el valor promedio o media de las 
características de la silla de ruedas, para el caso de la silla de ruedas de estructura rígida, su valor es 4.21 lo cual indica un valor de satisfacción cercano a 4 (satisfecho), no obstante, debe considerarse que se obtuvieron ponderaciones bajas (desde 2.89) lo cual mostró que este tipo de silla de ruedas presentó casos de insatisfacción.

Con relación a la silla de ruedas de estructura plegable, el valor promedio de las características del dispositivo fue de 3.06 lo cual indica un nivel de satisfacción cercano a 3 (más o menos satisfecho). Del mismo modo, para este tipo de silla de ruedas se obtuvieron valores mínimos de satisfacción desde 1.67, por lo cual se deduce que existen usuarios con niveles de satisfacción muy bajos.

Una vez que se indagó el nivel o grado de satisfacción de los usuarios con respecto a las características y servicios inherentes a la silla de ruedas, el QUEST 2.0 sugiere a los usuarios participantes seleccionar los 3 aspectos que consideran más importantes, dentro de los 12 aspectos evaluados. La tabla 17, muestra la lista de los factores más importantes considerados por los usuarios de los dos tipos de sillas de ruedas.

\section{Tabla 17}

Recurrencias de los aspectos evaluados en el QUEST 2.0 según la importancia indicada por los participantes.

\begin{tabular}{|c|c|c|c|}
\hline & \multirow{2}{*}{$\begin{array}{c}\text { Característica } \\
\text { de la silla de ruedas }\end{array}$} & \multicolumn{2}{|c|}{$\begin{array}{c}\text { Recurrencia } \\
{\left[\mathrm{N}^{\circ} \text { de personas }\right]}\end{array}$} \\
\hline & & $\begin{array}{c}\text { Silla de ruedas } \\
\text { estructura } \\
\text { plegable }\end{array}$ & $\begin{array}{l}\text { Silla de ruedas } \\
\text { estructura rígida }\end{array}$ \\
\hline 1 & Dimensiones & 6 & 9 \\
\hline 2 & Peso & 9 & 10 \\
\hline 3 & Facilidad para ajustar & 2 & 6 \\
\hline 4 & Estabilidad y seguridad & 14 & 9 \\
\hline 5 & Durabilidad & 9 & 11 \\
\hline 6 & Facilidad de uso & 7 & 10 \\
\hline 7 & Comodidad & 15 & 12 \\
\hline 8 & Efectividad & 2 & 3 \\
\hline 9 & Atracción visual & 7 & 0 \\
\hline \multirow{2}{*}{\multicolumn{2}{|c|}{$\begin{array}{c}\text { Servicios relacionados con la } \\
\text { silla de ruedas }\end{array}$}} & \multicolumn{2}{|c|}{$\begin{array}{c}\text { Recurrencia } \\
{\left[\mathrm{N}^{\circ} \text { de personas }\right]}\end{array}$} \\
\hline & & $\begin{array}{l}\text { Silla de ruedas } \\
\text { estructura }\end{array}$ & $\begin{array}{l}\text { Silla de ruedas } \\
\text { estructura rígida }\end{array}$ \\
\hline
\end{tabular}




\begin{tabular}{lccc}
\hline \multicolumn{4}{c}{ plegable } \\
\hline $\mathbf{1 0}$ & Reparación & 1 & 6 \\
\hline $\mathbf{1 1}$ & Servicios profesionales & 2 & 1 \\
\hline $\mathbf{1 2}$ & Acompañamiento continuo & 1 & 1 \\
\hline
\end{tabular}

De la Tabla 17, se puede deducir que, para los usuarios de la silla de ruedas de estructura plegable, los aspectos más importantes en el diseño de esta son la comodidad (15 recurrencias), la estabilidad y seguridad (14 recurrencias) y el peso y durabilidad (9 recurrencias en cada una de ellas). En el caso de la silla de ruedas de estructura rígida las características más importantes según los usuarios, es la comodidad (12 recurrencias), la durabilidad (11 recurrencias), el peso y la facilidad de uso (con 10 recurrencias en cada una de ellas). También, es importante resaltar que 7 personas usuarias de la silla de ruedas de estructura plegable indicaron la atracción visual como un factor importante en el diseño de esta, mientras que, en la silla de ruedas de estructura rígida, ningún usuario lo marcó como un aspecto relevante.

A continuación, se detallan los resultados de cada uno de los 9 aspectos relacionados con las características de la silla de ruedas en los cuales, se describen los valores promedio y algunos comentarios realizados por los mismos usuarios. Dichos comentarios brindaron un panorama de información para comprender más fácilmente el porqué de la ponderación resultante de cada factor evaluado.

4.2.1.1. Aspecto: Dimensiones. Los usuarios de la silla de ruedas de estructura rígida mostraron bastante satisfacción con respecto a sus sillas de ruedas pues el resultado promedio estuvo muy próximo al índice 4 (satisfecho). El valor promedio obtenido fue de 4.3 estando incluso por encima del valor promedio general de satisfacción de esta silla de ruedas (4.21). En el caso de la silla de ruedas de estructura plegable, la puntuación promedio estuvo cercana al índice 3 (más o menos satisfecho) ya que fue de 3.23. Algunos de los comentarios más recurrentes de los usuarios poco satisfechos en este aspecto de diseño se mencionan en la Tabla 18. 


\section{Tabla 18}

Comentarios recurrentes de los usuarios con respecto a las dimensiones de su silla de ruedas

\begin{tabular}{cccc}
\hline & Comentario & \multicolumn{2}{c}{$\begin{array}{c}\text { Tipo de } \\
\text { silla* }\end{array}$} \\
\cline { 3 - 4 } & A & B \\
\hline $\mathbf{1}$ & $\begin{array}{c}\text { Quisiera que fuera un poquito más } \\
\text { cerradita o angosta }\end{array}$ & $\mathrm{X}$ & \\
\hline $\mathbf{2}$ & Es muy voluminosa & $\mathrm{X}$ & \\
\hline $\mathbf{3}$ & $\begin{array}{c}\text { Me cuesta para acceder a las } \\
\text { puertas del metro }\end{array}$ & $\mathrm{X}$ & \\
\hline $\mathbf{4}$ & Es muy grande & $\mathrm{X}$ & \\
\hline $\mathbf{5}$ & $\begin{array}{c}\text { Es un poco ancha y eso la hace } \\
\text { inaccesible para lugares que son } \\
\text { angostos }\end{array}$ & & \\
\hline $\mathbf{6}$ & No es práctica & $\mathrm{X}$ & \\
\hline
\end{tabular}

\begin{tabular}{cccc}
\hline & Comentario & \multicolumn{2}{c}{$\begin{array}{c}\text { Tipo de } \\
\text { silla* }\end{array}$} \\
\cline { 3 - 4 } & & A & B \\
\hline $\mathbf{7}$ & $\begin{array}{c}\text { El asiento y los apoyabrazos son } \\
\text { muy grandes }\end{array}$ & $\mathrm{X}$ & \\
\hline $\mathbf{8}$ & La quisiera un poco más chica & & $\mathrm{X}$ \\
\hline $\mathbf{9}$ & Los apoyabrazos son muy altos & $\mathrm{X}$ & \\
\hline $\mathbf{1 0}$ & Se me hace muy alta & $\mathrm{X}$ & \\
\hline $\mathbf{1 1}$ & $\begin{array}{c}\text { Genera problemas para entrar a } \\
\text { Algunos lugares o usar trasporte } \\
\text { público }\end{array}$ & & $\mathrm{X}$ \\
\hline $\mathbf{1 2}$ & No está hecha a mi medida & $\mathrm{X}$ & \\
\hline
\end{tabular}

A: Silla de ruedas de propulsión manual de estructura plegable*

B: Silla de ruedas de propulsión manual de estructura rígida*

4.2.1.2. Aspecto: Peso. Con respecto al peso, los usuarios de ambos tipos de sillas de ruedas lo consideraron como el tercer factor más importante en el diseño de estas (Ver Tabla 17). En el caso de la silla de ruedas de estructura rígida, el valor promedio resultante fue de 4.08 estando próximo al índice 4 (satisfecho), sin embargo, como se mencionó anteriormente, el peso estuvo presente en las 3 características más relevantes para los usuarios. Para los usuarios de la silla de ruedas de estructura plegable, el valor promedio generado en esta característica fue de 2.46 , valor cercano al índice 2 (no muy satisfecho), siendo el valor promedio más bajo de todas las nueve características evaluadas. Algunos de los comentarios complementarios más recurrentes de los usuarios no satisfechos con respecto al peso de la silla de ruedas fueron los siguientes:

\section{Tabla 19}

Comentarios recurrentes de los usuarios con respecto al peso de su silla de ruedas
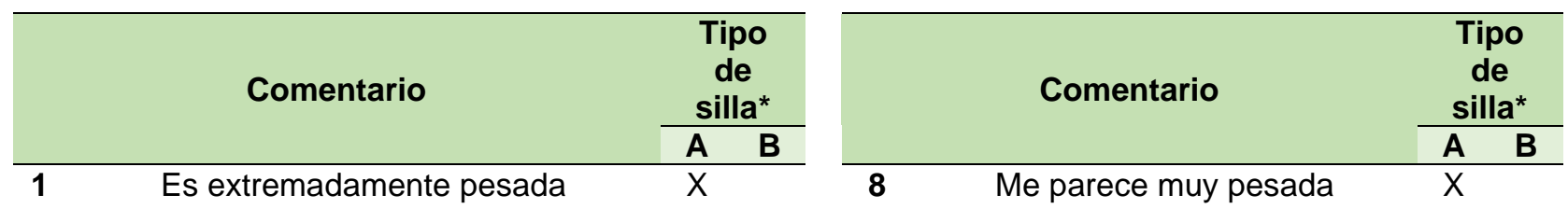


\begin{tabular}{ccc}
\hline 2 & $\begin{array}{c}\text { Un poco pesada a comparación de } \\
\text { nuevos modelos más ergonómicos y } \\
\text { ligeros }\end{array}$ & $\mathrm{X}$ \\
\hline $\mathbf{3}$ & $\begin{array}{c}\text { El tipo de material usado en la } \\
\text { fabricación podría ser más ligero, pero } \\
\text { sin perder resistencia }\end{array}$ & $\mathrm{X}$ \\
\hline $\mathbf{4}$ & Quisiera que fuera menos pesada & $\mathrm{X}$ \\
\hline $\mathbf{5}$ & Pesa demasiado & $\mathrm{X}$ \\
\hline & $\begin{array}{c}\text { No soy muy fuerte de mis brazos y } \\
\text { aún no la levantó del todo por mí } \\
\text { misma, sigo necesitando ayuda para } \\
\text { eso }\end{array}$ & $\mathrm{X}$ \\
\hline $\mathbf{7}$ & Hay sillas con menos peso & $\mathrm{X}$ \\
\hline
\end{tabular}

\begin{tabular}{|c|c|c|c|}
\hline 9 & $\begin{array}{c}\text { Es algo pesada para levantar y } \\
\text { guardarse }\end{array}$ & & $x$ \\
\hline 10 & $\begin{array}{l}\text { Si fueran más ligeras sería } \\
\text { mejor, pero interviene el precio }\end{array}$ & & $x$ \\
\hline 11 & $\begin{array}{l}\text { Las llantas me generan mucho } \\
\text { peso }\end{array}$ & $\mathrm{X}$ & \\
\hline 12 & Es muy pesada para mi fuerza & $X$ & \\
\hline 13 & $\begin{array}{l}\text { He tenido la oportunidad de } \\
\text { comparar el peso con otras de } \\
\text { conocidos y las de ellos son } \\
\text { más ligeras }\end{array}$ & & $x$ \\
\hline
\end{tabular}

A: Silla de ruedas de propulsión manual de estructura plegable*

B: Silla de ruedas de propulsión manual de estructura rígida*

4.2.1.3. Aspecto: Facilidad de ajustar. Los usuarios de la silla de ruedas de estructura rígida indicaron un valor promedio de 4.04 en la característica de facilidad de ajuste de los componentes de esta. Dicho valor promedio estuvo próximo al índice 4 (satisfecho). En el caso de la silla de ruedas de estructura plegable, el valor promedio de la satisfacción de los usuarios para este aspecto fue de 3.04, valor muy cercano al índice 3 (más o menos satisfecho). Los comentarios de insatisfacción de los usuarios en este aspecto de diseño están dirigidos a cuestiones de mantenimiento. Algunos de los comentarios fueron:

Tabla 20

Comentarios recurrentes de los usuarios con respecto a la facilidad de ajustar de su silla de ruedas

\begin{tabular}{|c|c|c|}
\hline & \multirow{2}{*}{ Comentario } & $\begin{array}{c}\text { Tipo de } \\
\text { silla* }^{*}\end{array}$ \\
\hline & & $\begin{array}{ll}\text { A } & \text { B }\end{array}$ \\
\hline 1 & $\begin{array}{c}\text { No siempre se cuenta con la } \\
\text { herramienta necesaria para } \\
\text { desmontar o ajustar alguna pieza }\end{array}$ & $x$ \\
\hline 2 & $\begin{array}{c}\text { Algunas piezas son difíciles de } \\
\text { cambiar }\end{array}$ & $x$ \\
\hline 3 & $\begin{array}{c}\text { Para mí es complicado cambiarle las } \\
\text { piezas }\end{array}$ & $x$ \\
\hline
\end{tabular}

\begin{tabular}{ccc}
\hline & Comentario & $\begin{array}{c}\text { Tipo de } \\
\text { silla* }\end{array}$ \\
\cline { 3 - 4 } & A & B \\
\hline 4 & $\begin{array}{c}\text { El mantenimiento es difícil, } \\
\text { hasta cambiar una rueda es } \\
\text { complicado }\end{array}$ & \\
\hline $\mathbf{5}$ & $\begin{array}{c}\text { Seria óptimo contar con ajustes } \\
\text { sencillos y no depender de } \\
\text { otros }\end{array}$ & $\mathrm{X}$ \\
\hline $\mathbf{6}$ & $\begin{array}{c}\text { Quisiera que fuera más fácil, a } \\
\text { veces es complicado }\end{array}$ & $\mathrm{X}$ \\
\hline
\end{tabular}

A: Silla de ruedas de propulsión manual de estructura plegable*

B: Silla de ruedas de propulsión manual de estructura rígida* 
2.1.1.4. Aspecto: Estabilidad y seguridad. En este aspecto, los usuarios de silla de ruedas de estructura rígida tuvieron un alto valor promedio ya que fue de 4.42 , cercano al índice de 4 (satisfecho). Para la silla de ruedas de estructura plegable, los usuarios de esta silla de ruedas mostraron un valor promedio de 3.11, próximo al índice 3 (más o menos satisfecho). Por otro lado, la estabilidad y seguridad fue el segundo factor más importante en la silla de ruedas de estructura plegable, considerado así por los mismos usuarios. Los comentarios de insatisfacción de los usuarios en general se relacionan con caídas o accidentes sufridos previamente. Algunos de estos comentarios fueron los siguientes:

\section{Tabla 21}

Comentarios recurrentes de los usuarios con respecto a la estabilidad y seguridad de su silla de ruedas

\begin{tabular}{|c|c|c|c|}
\hline & \multirow[t]{2}{*}{ Comentario } & \multicolumn{2}{|c|}{$\begin{array}{l}\text { Tipo } \\
\text { de } \\
\text { silla* }\end{array}$} \\
\hline & & A & B \\
\hline 1 & $\begin{array}{l}\text { Muy mala, me caí subiendo una } \\
\text { rampa }\end{array}$ & $x$ & \\
\hline 2 & Las llantas de resbalan con la lluvia & & $\mathrm{X}$ \\
\hline 3 & $\begin{array}{l}\text { No es segura para subir y bajar } \\
\text { rampas }\end{array}$ & $\mathrm{x}$ & \\
\hline 4 & $\begin{array}{c}\text { Si tuviera las llantas delanteras unas } \\
\text { poco más grandes que las normales, } \\
\text { sería más es más fácil pasar grietas o } \\
\text { pequeños desniveles y no sufrir } \\
\text { caídas }\end{array}$ & $x$ & \\
\hline 5 & $\begin{array}{c}\text { Es poco estable a la hora de } \\
\text { recargarse, tiende a volteaste hacia } \\
\text { atrás }\end{array}$ & $x$ & \\
\hline
\end{tabular}

\begin{tabular}{ccc}
\hline & Comentario & $\begin{array}{c}\text { Tipo } \\
\text { de } \\
\text { silla* }\end{array}$ \\
\cline { 3 - 3 } & A $\quad$ B \\
\hline $\mathbf{6}$ & $\begin{array}{c}\text { Tiene muy poca estabilidad } \\
\text { porque las ruedas están en } \\
\text { vertical }\end{array}$ & $\mathrm{X}$ \\
\hline $\mathbf{7}$ & $\begin{array}{c}\text { Me siento poco segura al } \\
\text { manejarla }\end{array}$ & $\mathrm{X}$ \\
\hline $\mathbf{8}$ & Se voltea cuando paso un tope & $\mathrm{X}$ \\
\hline & $\begin{array}{c}\text { En bajadas se deslizan las } \\
\text { Ilantas y es muy dura, se atora } \\
\text { con un mínimo desnivel de la } \\
\text { calle }\end{array}$ & $\mathrm{X}$ \\
\hline & $\begin{array}{c}\text { La mía no es muy estable y se } \\
\text { le sale la llanta }\end{array}$ & $\mathrm{X}$ \\
\hline $\mathbf{1 0}$ & \\
\hline
\end{tabular}

A: Silla de ruedas de propulsión manual de estructura plegable*

B: Silla de ruedas de propulsión manual de estructura rígida*

2.1.1.5. Aspecto: Durabilidad. La durabilidad, fue un factor relevante ya que estuvo señalado en los tres factores más importantes por los usuarios de ambos tipos de sillas de ruedas. En el caso de la de silla de ruedas de estructura rígida fue considerado por los usuarios el segundo factor más importante y obtuvo una 4.12, es decir próximo al indicador 4 (satisfecho). Los usuarios de la silla de ruedas de 
estructura plegable indicaron a la durabilidad como el tercer factor más importante en sus sillas de ruedas, a su vez, el valor promedio resultante en este aspecto fue de 3.08 , cercano al indicador 3 (más o menos satisfecho). Algunos de los comentarios complementarios realizados por usuarios no satisfechos con la durabilidad de la silla de ruedas, fueron los siguientes:

\section{Tabla 22}

Comentarios recurrentes de los usuarios con respecto a la durabilidad de su silla de ruedas

\begin{tabular}{|c|c|c|c|}
\hline & \multirow[t]{2}{*}{ Comentario } & \multicolumn{2}{|c|}{$\begin{array}{c}\text { Tipo de } \\
\text { silla* }^{*}\end{array}$} \\
\hline & & A & B \\
\hline 1 & Las llantas se desgastan muy rápido & & $\mathrm{X}$ \\
\hline 2 & Ya me acabé las llantas & $\mathrm{X}$ & \\
\hline 3 & $\begin{array}{c}\text { Se desgastan muy rápido los } \\
\text { componentes por el uso excesivo } \\
\text { que se le da }\end{array}$ & $\mathrm{X}$ & \\
\hline 4 & $\begin{array}{l}\text { Las llantas se desgastan por la falta } \\
\text { de pavimentación y mantenimiento } \\
\text { al de piso por donde se transita }\end{array}$ & & $X$ \\
\hline 5 & $\begin{array}{l}\text { Algunos componentes se desgastan } \\
\text { muy rápido y no hay repuestos con } \\
\text { el proveedor }\end{array}$ & $\mathrm{X}$ & \\
\hline 6 & $\begin{array}{l}\text { Casi no duran las piezas y es un } \\
\text { poco difícil encontrar las piezas de } \\
\text { las sillas }\end{array}$ & $X$ & \\
\hline
\end{tabular}

\begin{tabular}{|c|c|c|c|}
\hline \multirow{2}{*}{\multicolumn{2}{|c|}{ Comentario }} & \multicolumn{2}{|c|}{$\begin{array}{c}\text { Tipo de } \\
\text { silla* }\end{array}$} \\
\hline & & & B \\
\hline 7 & $\begin{array}{l}\text { He tenido que soldarla varias } \\
\text { veces }\end{array}$ & $x$ & \\
\hline 8 & $\begin{array}{c}\text { Como el asiento es de hule se } \\
\text { rompe seguido }\end{array}$ & $x$ & \\
\hline 9 & $\begin{array}{l}\text { Las barreras arquitectónicas } \\
\text { hacen que los baleros se } \\
\text { maltraten y las llantas se aflojen }\end{array}$ & & $x$ \\
\hline 10 & $\begin{array}{c}\text { El asiento dura muy poco, } \\
\text { debería ser de hule ya que yo lo } \\
\text { lavo seguido y tengo que } \\
\text { esperar mucho para que se } \\
\text { seque }\end{array}$ & $x$ & \\
\hline 11 & $\begin{array}{c}\text { Aunque le doy cuidados y } \\
\text { limpieza constante, se me oxidó } \\
\text { más pronto de lo que pensaba }\end{array}$ & $\mathrm{X}$ & \\
\hline 12 & $\begin{array}{c}\text { Las llantas truenan y están } \\
\text { desniveladas }\end{array}$ & & $x$ \\
\hline
\end{tabular}

A: Silla de ruedas de propulsión manual de estructura plegable* B: Silla de ruedas de propulsión manual de estructura rígida*

2.1.1.6. Aspecto: Facilidad de uso. La facilidad de uso fue elegida por los usuarios de silla de ruedas de estructura rígida como el tercer factor más importante. En este tipo de silla de ruedas, la facilidad de uso tuvo un valor promedio de satisfacción de 4.5, próximo al indicador 4 (satisfecho), sin embargo, este valor estuvo por encima del valor promedio general de satisfacción (4.21) para esta silla de ruedas. Por otra parte, para la silla de ruedas de estructura plegable, el valor promedio de satisfacción fue de 3.27, cercano al índice 3 (más o menos satisfecho). Algunos de los comentarios complementarios por parte de los usuarios poco satisfechos con esta característica de su silla de ruedas, fueron los siguientes: 
Tabla 23

Comentarios recurrentes de los usuarios con respecto a la facilidad de su silla de ruedas

\begin{tabular}{lccc}
\hline & Comentario & \multicolumn{2}{c}{$\begin{array}{c}\text { Tipo de } \\
\text { silla* }\end{array}$} \\
\cline { 3 - 4 } & A & B \\
\hline $\mathbf{1}$ & No puedo dar el giro fácilmente & $\mathrm{X}$ & \\
\hline $\mathbf{2}$ & $\begin{array}{c}\text { Quisiera que se me facilitara más el } \\
\text { movimiento }\end{array}$ & $\mathrm{X}$ & \\
\hline $\mathbf{3}$ & Es complejo manejarla & $\mathrm{X}$ \\
\hline $\mathbf{4}$ & No es fácil & \\
\hline $\mathbf{5}$ & $\begin{array}{c}\text { No es muy fácil, pero vamos } \\
\text { echándole ganas }\end{array}$ & $\mathrm{X}$ \\
\hline $\mathbf{6}$ & $\begin{array}{c}\text { Si no tuviera apoyabrazos y el } \\
\text { respaldo alto sería más fácil de usar }\end{array}$ & $\mathrm{X}$ & \\
\hline
\end{tabular}

\begin{tabular}{cccc}
\hline & Comentario & \multicolumn{2}{c}{$\begin{array}{c}\text { Tipo de } \\
\text { silla* }\end{array}$} \\
\cline { 3 - 4 } & & A & B \\
\hline $\mathbf{7}$ & Es de difícil manejo & X & \\
\hline \multirow{8}{8}{} & $\begin{array}{c}\text { No estoy segura en manejarla, } \\
\text { me da mucho miedo desde que } \\
\text { me caí }\end{array}$ & $\mathrm{X}$ & \\
\hline $\mathbf{9}$ & $\begin{array}{c}\text { Después de 15 años me adapte } \\
\text { a ella }\end{array}$ & $\mathrm{X}$ \\
\hline $\mathbf{1 0}$ & Los cursos me han ayudado & $\mathrm{X}$ \\
\hline $\mathbf{1 1}$ & $\begin{array}{c}\text { Después del primer curso ha } \\
\text { sido más fácil }\end{array}$ & $\mathrm{X}$ \\
\hline
\end{tabular}

A: Silla de ruedas de propulsión manual de estructura plegable*

$\mathrm{B}$ : Silla de ruedas de propulsión manual de estructura rígida*

2.1.1.7. Aspecto: Comodidad. La comodidad fue el primero de los tres factores más importantes, considerado así por los usuarios de ambos tipos de silla de ruedas. Para la silla de ruedas de estructura rígida, el valor promedio de satisfacción con la comodidad fue de 3.85, el más bajo de los 9 aspectos evaluados, aun así, estuvo próximo al índice 4 (satisfecho). En el caso de la silla de ruedas de estructura plegable, el promedio de satisfacción fue de 2.88, valor próximo al índice 3 (más o menos satisfecho). Algunos comentarios realizados por los usuarios poco satisfechos con la comodidad de sus sillas de ruedas fueron los siguientes:

Tabla 24

Comentarios recurrentes de los usuarios con respecto a la comodidad de su silla de ruedas

\begin{tabular}{cccc}
\hline & Comentario & $\begin{array}{c}\text { Tipo de } \\
\text { silla* }\end{array}$ \\
\cline { 3 - 4 } & A & B \\
\hline $\mathbf{1}$ & $\begin{array}{c}\text { Se requiere de cojín anti-escaras, } \\
\text { es incómodo }\end{array}$ & $\mathrm{X}$ \\
\hline $\mathbf{2}$ & $\begin{array}{c}\text { Podría ser mejor con algún } \\
\text { componente extra como un cojín o } \\
\text { respaldo ergonómico }\end{array}$ & $\mathrm{X}$ \\
\hline $\mathbf{3}$ & $\begin{array}{c}\text { Le pondría un descansapiés más } \\
\text { completo }\end{array}$ & $\mathrm{X}$ & \\
\hline $\mathbf{4}$ & Me gustaría que los asientos no & & $\mathrm{X}$ \\
\hline
\end{tabular}

\begin{tabular}{cccc}
\hline & Comentario & \multicolumn{2}{c}{$\begin{array}{c}\text { Tipo de } \\
\text { silla* }\end{array}$} \\
\cline { 3 - 4 } & A & B \\
\hline $\mathbf{1 0}$ & Hay que hacerle adaptaciones & $\mathrm{X}$ & \\
\hline $\mathbf{1 1}$ & $\begin{array}{c}\text { Las bandas del asiento son } \\
\text { incomodas y están muy } \\
\text { separadas }\end{array}$ & & $\mathrm{X}$ \\
\hline $\mathbf{1 2}$ & $\begin{array}{c}\text { Después de varias horas de } \\
\text { uso, te cansa la espalda }\end{array}$ & $\mathrm{X}$ \\
\hline $\mathbf{1 3}$ & Me lastiman las barras debajo & $\mathrm{X}$ & \\
\hline
\end{tabular}




\begin{tabular}{ccc}
\hline \multicolumn{3}{c}{ fueran planos } \\
\hline $\mathbf{5}$ & $\begin{array}{c}\text { El asiento y el respaldo como son } \\
\text { de lona se calientan mucho }\end{array}$ & $\mathrm{X}$ \\
\hline $\mathbf{6}$ & $\begin{array}{c}\text { Necesito ponerle cobijas, } \\
\text { almohadas o una dona para que el } \\
\text { asiento no lastime }\end{array}$ & $\mathrm{X}$ \\
\hline $\mathbf{7}$ & $\begin{array}{c}\text { Podría ser más cómoda, debido a } \\
\text { que la posición de mis piernas no es } \\
\text { tan satisfactoria }\end{array}$ & $\mathrm{X}$ \\
\hline $\mathbf{8}$ & $\begin{array}{c}\text { El asiento y los apoyabrazos son } \\
\text { muy incomodos }\end{array}$ & $\mathrm{X}$ \\
\hline & $\begin{array}{l}\text { La lona del asiento se va } \\
\text { desgarrando y eso me produce } \\
\text { rozamiento y escaras y eso mismo } \\
\text { pasa con la lona del respaldo, se } \\
\text { desgarra y me produce dolor }\end{array}$ & $\mathrm{X}$ \\
\hline
\end{tabular}

\begin{tabular}{ccc}
\hline \multicolumn{3}{c}{ del asiento } \\
\hline 14 & $\begin{array}{c}\text { Al no ser a mi medida, es } \\
\text { incómoda }\end{array}$ & $\mathrm{X}$ \\
\hline 15 & $\begin{array}{c}\text { El asiento es una simple lona, } \\
\text { no tiene esponja }\end{array}$ & $\mathrm{X}$ \\
\hline 16 & $\begin{array}{c}\text { La silla me mantiene en una } \\
\text { posición incómoda }\end{array}$ & $\mathrm{X}$ \\
\hline 17 & $\begin{array}{c}\text { El asiento se pandea y el } \\
\text { respaldo también y eso te } \\
\text { incomoda }\end{array}$ & $\mathrm{X}$ \\
\hline
\end{tabular}

A: Silla de ruedas de propulsión manual de estructura plegable*

B: Silla de ruedas de propulsión manual de estructura rígida*

2.1.1.8. Aspecto: Efectividad. La efectividad obtuvo un valor promedio de satisfacción de 4.31 para la silla de ruedas de estructura rígida, estando cerca al índice 4 (satisfecho) y por encima del valor de satisfacción general para este tipo de silla (4.21). Para la silla de ruedas de estructura plegable, el valor promedio de satisfacción resultante en la efectiva fue de 3.35, cercano al índice 3 (más o menos satisfecho) y siendo levemente superior al valor promedio general de satisfacción para esta silla de ruedas (3.06). Algunos de los comentarios realizados por los usuarios poco satisfechos con la efectividad de su silla fueron los siguientes:

\section{Tabla 25}

Comentarios recurrentes de los usuarios con respecto a la efectividad de su silla de ruedas

\begin{tabular}{|c|c|c|}
\hline & \multirow{2}{*}{ Comentario } & $\begin{array}{l}\text { Tipo de } \\
\text { silla* }^{*}\end{array}$ \\
\hline & & A $\quad$ B \\
\hline 1 & $\begin{array}{c}\text { Es muy lenta, pero creo que es así } \\
\text { por lo pesada }\end{array}$ & $X$ \\
\hline 2 & $\begin{array}{c}\text { No hay movilidad al } 100 \% \text { debido al } \\
\text { peso }\end{array}$ & $X$ \\
\hline
\end{tabular}

Es complicado ya que no es fácil

3 utilizarla en todo terreno por su peso $X$ y la forma de cómo está hecha

Me gustaría una silla de material

4 más ligero y más cómoda", "Por ser tan dura es muy cansado y lento

\begin{tabular}{|c|c|c|c|}
\hline \multirow{2}{*}{\multicolumn{2}{|c|}{ Comentario }} & \multicolumn{2}{|c|}{$\begin{array}{l}\text { Tipo de } \\
\text { silla* }^{*}\end{array}$} \\
\hline & & $\mathbf{A}$ & B \\
\hline 5 & Quisiera poder moverme más & & $x$ \\
\hline 6 & $\begin{array}{c}\text { No me permite tener una vida } \\
\text { normal }\end{array}$ & $\mathrm{X}$ & \\
\hline 7 & $\begin{array}{l}\text { Es difícil andar en cualquier silla } \\
\text { de ruedas en la Ciudad de } \\
\text { México, por cuestión de } \\
\text { accesibilidad y el terreno suele } \\
\text { ser difícil para andar }\end{array}$ & $\mathrm{X}$ & \\
\hline
\end{tabular}


A: Silla de ruedas de propulsión manual de estructura plegable*

B: Silla de ruedas de propulsión manual de estructura rígida*

2.1.1.9. Aspecto: Atracción visual. En la silla de ruedas de estructura plegable, no hubo un solo usuario que marcara este aspecto como un factor importante. El valor promedio de satisfacción para la atracción visual en el tipo de silla mencionado fue de 4.27, valor cercano al índice 4 (satisfecho) y levemente superior al valor promedio general de satisfacción para esta silla (4.21). Para la silla de ruedas de estructura plegable, el valor promedio de satisfacción en este aspecto fue de 3.12, valor próximo al índice 3 (más o menos satisfecho) y ligeramente superior valor promedio general de satisfacción para esta silla (3.06). Como se citó anteriormente, aunque ningún usuario de la silla de ruedas de estructura rígida marco la atracción visual como un factor importante y en caso de la silla de ruedas de estructura plegable solo 7 usuarios lo hicieron, sí se generaron algunos comentarios complementarios con respecto a este aspecto. Dichos comentarios fueron los siguientes:

Tabla 26

Comentarios recurrentes de los usuarios con respecto a la atracción visual de su silla de ruedas

\begin{tabular}{ccc}
\hline & Comentario & $\begin{array}{c}\text { Tipo de } \\
\text { silla* }\end{array}$ \\
\cline { 3 - 4 } & A & B \\
\hline 1 & Me gustaría que fuera cromada & X \\
\hline 2 & $\begin{array}{c}\text { Se ve muy aseñorada, como para } \\
\text { viejitos }\end{array}$ & $\mathrm{X}$ \\
\hline 3 & $\begin{array}{c}\text { Me gustaría unos rines más ligeros } \\
\text { y visualmente más lindos }\end{array}$ & $\mathrm{X}$ \\
\hline 4 & $\begin{array}{c}\text { Normal, le falta mejorar en ese } \\
\text { aspecto }\end{array}$ & $\mathrm{X}$ \\
\hline
\end{tabular}

\begin{tabular}{cccc}
\hline & \multirow{2}{*}{ Comentario } & $\begin{array}{c}\text { Tipo de } \\
\text { silla* }\end{array}$ \\
\cline { 3 - 4 } & & $\mathrm{A}$ & $\mathrm{B}$ \\
\hline 5 & $\begin{array}{c}\text { Se ve como para viejitos, como } \\
\text { muy oculta }\end{array}$ & $\mathrm{X}$ & \\
\hline 6 & $\begin{array}{c}\text { Al compararla con otras, no es } \\
\text { tan bonita }\end{array}$ & & $\mathrm{X}$ \\
\hline 7 & La hacen para cuestión médica & $\mathrm{X}$ & \\
\hline 8 & Es muy sombría & $\mathrm{X}$ \\
\hline
\end{tabular}

A: Silla de ruedas de propulsión manual de estructura plegable*

B: Silla de ruedas de propulsión manual de estructura rígida*

\subsubsection{Cuantificación de la percepción - Escala de Diferencial Semántico}


Como parte de la investigación cuantitativa, se aplicó la escala de Diferencial Semántico con el propósito de cuantificar la percepción de la silla de ruedas por parte de los usuarios de esta. Los resultados de este instrumento se muestran en la Figura 11 , en la cual se evidencia el valor número en cada uno de los factores evaluados por área o dimensión de diseño. Estos se resultados se mostraron en la tabla anteriormente mencionada para los dos tipos de silla de ruedas (estructura plegable y estructura rígida).

Para el caso de la silla de ruedas de estructura plegable, se obtuvo el mismo valor $(-0.23)$ en los dos factores evaluados de la dimensión de atracción visual. En esta misma dimensión, para la silla de ruedas de estructura rígida el par de adjetivos Moderna/Anticuada tuvo un valor levemente inferior (2.27) al par de adjetivos Atractiva/No atractiva (2.38).

En la dimensión práctica, para el caso de la silla de ruedas de estructura plegable, los factores con los valores de percepción más bajo fueron los pares de adjetivos Rápida/Lenta (-0.92), Fácil de transportar/Difícil de transportar (-0.31) y Personalizable/No Personalizable (-0.15).

Específicamente para la silla de ruedas de ruedas de estructura rígida, en la dimensión práctica los valores con la percepción más baja se ubicaron en los pares de adjetivos Fácil mantenimiento/Difícil mantenimiento (1.92), Personalizable/No personalizable (2.19) y Rápida/Lenta (2.23).

Por último, en la dimensión simbólica de la silla de ruedas de estructura plegable los valores de percepción más bajos se registraron los pares de adjetivos Innovadora/Tradicional (-0.54), Inclusiva/Excluyente (0.0) y con un mismo valor (0.15) en Sociable/Introvertida E independiente/Dependiente. Para la silla de rueda de estructura rígida, en esta última dimensión, los índices de percepción más bajos se presentaron en los pares de adjetivos Innovadora/Tradicional (1.18), Sociable/Introvertida (2.23) e Inclusiva/Excluyente (2.27). 
Figura 11

Resultados de la Escala de Diferencial Semántico

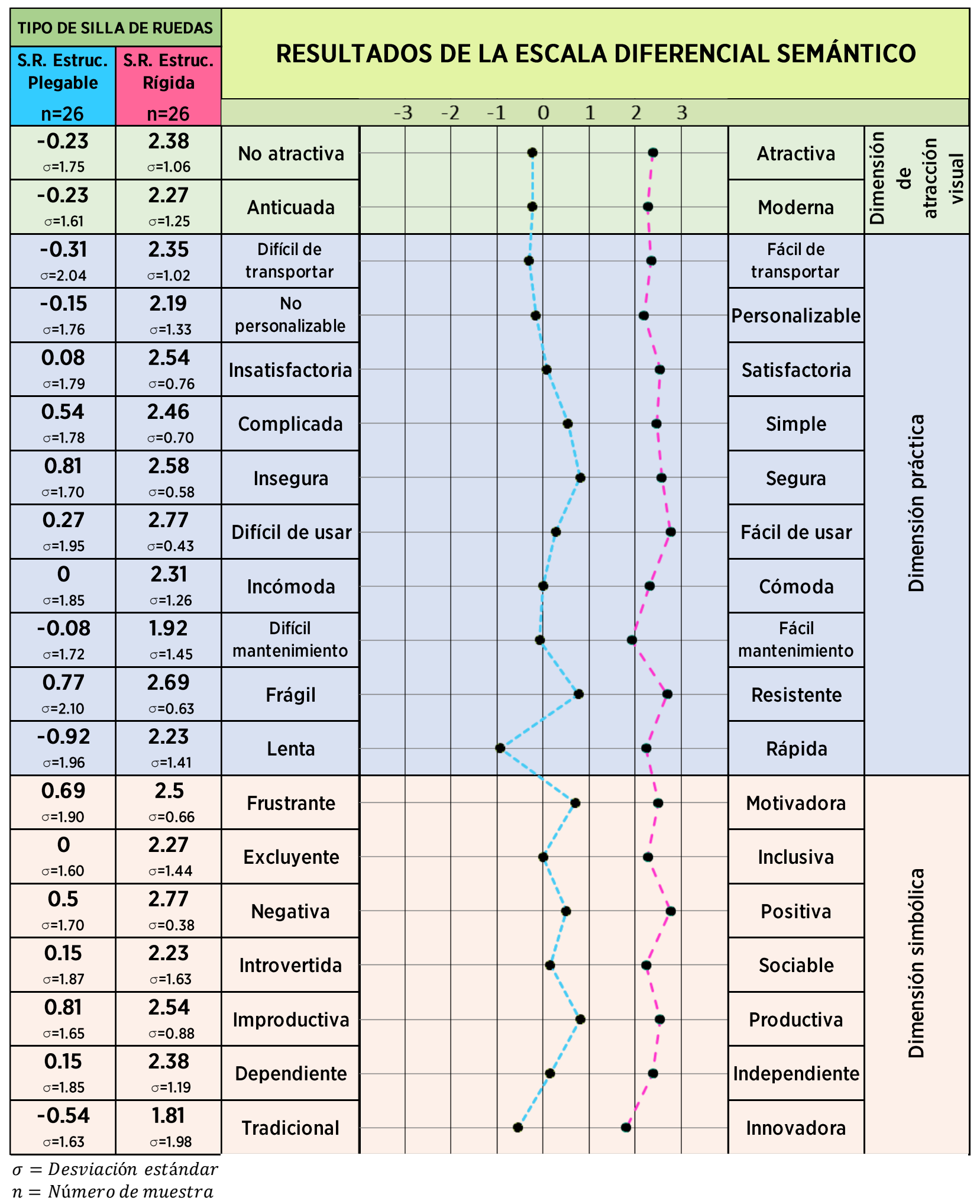




\subsection{Análisis y discusión de los resultados}

En primera instancia, el tamaño de la muestra para la investigación cualitativa fue reducido ya que esta parte de la investigación no tenía intenciones probabilísticas y además fue considerada de tipo exploratorio. De esta manera, el tamaño de la muestra no fue importante en términos numéricos puesto que se tuvo el propósito de abordar de manera profunda y cualitativa la opinión de los usuarios. Por esto, consideró que una muestra de diez participantes era adecuada para ayudar entender el fenómeno de estudio y responder a la pregunta de investigación planteada.

Con respecto a los resultados referentes a la usabilidad, en la entrevista se tuvo como resultado una respuesta generalizada en cuanto a la capacitación en el manejo de la silla de ruedas. Todos los usuarios manifestaron no haber recibido ningún tipo de entrenamiento por parte de alguna entidad. Estos resultados son similares a los encontrados por Carneiro (2018) y Lanutti (2019), en los cuales mencionaron que el entrenamiento para el uso de la silla de ruedas es un hecho poco probable, aun cuando los usuarios consideran el entrenamiento como un factor importante. La falta de entrenamiento puede influir en la satisfacción de los usuarios con su silla de ruedas y en la forma en como estos la perciben. Esto se puede inferir debido a los hallazgos de la investigación de Caro y Cruz (2020), donde se afirma que la falta de capacitación en el manejo de la silla de ruedas, afecta directamente el desempeño ocupacional de las personas con discapacidad, reduciendo su independencia y perjudicando su participación social. Asimismo, Štefanac et al. (2018) mencionó que los usuarios de sillas de ruedas que reciben entrenamiento en el manejo de esta, se sienten más seguros al hacer uso del dispositivo. A pesar de lo anterior, en los resultados de esta investigación, la satisfacción de los usuarios en la silla de ruedas de estructura plegable en relación con la facilidad de uso no fue tan baja comparada con los otros factores, sin embargo, los usuarios mencionaron algunos comentarios negativos al respecto. Dichos comentarios se pudieron apreciar en la Tabla 23.

Por otra parte, el peso fue una característica física de la silla de ruedas que causó mayor insatisfacción en los usuarios. Se pudo apreciar en los resultados de QUEST 2.0 que en los dos tipos de silla de ruedas el peso fue un factor con baja satisfacción y considerado por los usuarios como una característica importante en el diseño. De igual 
forma, en los resultados para la silla de ruedas de estructura plegable, es probable que la insatisfacción del peso tenga relación con la manera en cómo esta es percibida, ya que en los resultados de la escala de Diferencial Semántico se evidenció que es asimilada como lenta y difícil de transportar. Estos resultados coinciden con los hallazgos del estudio de Marchiori et al. (2015), en el cual también el peso fue una característica de la silla de ruedas que mostró gran insatisfacción en los usuarios de las mismas.

Igualmente, en los resultados de QUEST 2.0, la comodidad fue uno de los ítems con una puntuación de satisfacción poco favorable en los dos tipos de sillas de ruedas. Para el tipo de silla de ruedas de estructura plegable, lo anterior tiene una fuerte relación con los resultados de la entrevista. En esta, los usuarios relataron que su insatisfacción estaba asociada con las características físicas de la silla de ruedas, mencionando que algunas partes de esta son percibidas como incomodas en su diseño, materiales empleados y funcionalidad. Las partes de la silla de ruedas que más se citaron como incómodas fueron el asiento, el respaldo, los apoyabrazos y los descansapiés. El asiento fue el componente de la silla de ruedas mayormente citado y catalogado como incómodo ya que gran parte de los usuarios han tenido que realizar diversas modificaciones para adaptarlo a sus necesidades; estas adecuaciones tienen como propósito mejorar su funcionalidad o mitigar el dolor ocasionado por el desgaste de los materiales. Lo anterior, también fue evidenciado en la investigación de HerreraSaray et al. (2013), donde relató que los usuarios realizan modificaciones creativas en las sillas de ruedas para satisfacer necesidades cotidianas.

Con respecto a dichas modificaciones creativas, también se evidenció lo mencionado en el estudio de Saray et al. (2013), el cual afirma que estas se desarrollan en función de la existencia de dolor en los usuarios de silla de ruedas o del ámbito social y laboral en el cual se desenvuelven estos usuarios. Para llevar a cabo dichas adaptaciones, la personalización juega un papel importante en el diseño de la silla de ruedas, ya que en esta investigación los usuarios manifestaron haber realizado modificaciones o tener intensiones de hacerlas debido a cierta insatisfacción con el diseño de esta. A su vez, en los resultados de la escala de Diferencial Semántico para la silla de ruedas de estructura rígida, la personalización fue uno de los adjetivos con 
menor índice de percepción. Esto indicó que la personalización es una característica para mejorar el diseño de la silla de ruedas de estructura rígida y como consecuencia se podrían alterar de manera positiva las emociones que se involucran en la relación usuario-producto. Lo anterior, debido a que la personalización ofrece al usuario la posibilidad de sentir la silla de ruedas como una extensión de su cuerpo y de proyectar su personalidad con dicha ayuda técnica (Costa, 2012). A la hora de considerar la personalización en el proceso de diseño, Maës (2016), menciona que esta característica favorece la interacción entre el usuario y su silla de ruedas.

Otros resultados a considerar son los relacionados a la experiencia del usuario $(U X)$. En estos, la atracción visual es una característica importante para analizar, ya que pareció no ser un factor relevante en la entrevista realizada para el caso de la silla de ruedas de estructura plegable. En esta entrevista solo dos usuarios mencionaron su inconformidad con la atracción visual de su silla de ruedas. Asimismo, en los resultados de la evaluación de satisfacción QUEST 2.0 en los dos tipos de sillas de ruedas, la atracción visual obtuvo valores medios de satisfacción con respecto a las demás características evaluadas. Sin embargo, en los hallazgos de la escala Diferencial Semántico, los pares de adjetivos de la dimensión de atracción visual tuvieron índices bajos de percepción en los dos tipos de silla de ruedas. Lo anterior, podría indicar que, aunque los usuarios tienen una percepción negativa de la atracción visual de su silla de ruedas, atraviesan por un proceso de resignación o conformismo en el cual, terminan adaptándose y soportando los defectos de su ayuda técnica. Este fenómeno también fue evidenciado por Marchiori et al. (2015), el cual lo denominó "accomodation" refiriéndose a un proceso cognitivo que modifica en los usuarios la forma de pensar y de ver las cosas, teniendo como consecuencia la aceptación de las fallas de la silla de ruedas. Štefanac (2019), también observó este hallazgo y mencionó que "accomodation" es un efecto que altera los procesos cognitivos y de razonamiento del usuario, lo cual hace que terminen aceptando las fallas y deficiencias de su silla de ruedas. Es importante destacar que los dos estudios mencionados anteriormente evidenciaron el efecto "accomodation" al evaluar únicamente características relacionadas con la usabilidad de la silla de ruedas, sin embargo, en esta investigación surge la hipótesis que este mismo efecto ocurre en factores relacionados con la 
experiencia del usuario ( $U X)$, como la atracción visual o apariencia de la silla de ruedas. Lo anterior, ya que se observó que los usuarios no reportan valores muy bajos de satisfacción con respecto a la atracción visual, sin embargo, si se reportaron valores bajos de percepción en este aspecto evaluado.

Específicamente en la silla de ruedas de estructura plegable, se observó en los resultados de la entrevista otro factor relacionado con la experiencia del usuario. Dicho factor es el estigma social ya que los usuarios sienten que su silla de ruedas provoca reacciones emocionales negativas en las personas de su entorno (familiares, vecinos, amigos, etc.). Algunas de las respuestas emocionales mencionadas por los usuarios fueron los conceptos de lástima, rechazo, poca empatía y discriminación. Lo anterior, también se evidenció en las investigaciones de Lanutti (2019) y Carneiro (2018). Para este último, el estigma o prejuicio se debe a que la silla de ruedas es frecuentemente asociada a la falta de capacidad y considerada como un elemento limitante e inconveniente.

Por último, los usuarios manifestaron en la entrevista que su silla de ruedas provoca en ellos más reacciones emocionales de carácter positivo que negativo, tales como el agradecimiento, la independencia y el bienestar. Sin embargo, algunos usuarios mencionaron que su silla de ruedas les genera reacciones emocionales negativas tales como tristeza, depresión y decepción. Estas, parecen estar fuertemente relacionadas con el estigma social mencionado anteriormente, ya que están influenciadas por las reacciones emocionales negativas de las personas de su entorno (familiares, amigos, vecinos, etc.). Con este resultado, surge la hipótesis de que el estigma social afecta considerablemente las emociones del usuario con su silla de ruedas y, en consecuencia, también se ve afectada de manera negativa la experiencia del usuario y la usabilidad.

\subsection{Definición de los requerimientos de Diseño}

Los requerimientos de diseño se determinaron con base en la información recolectada de los tres instrumentos utilizados (entrevista, QUEST 2.0 y la escala de Diferencial Semántico). Con relación a los resultados del QUEST 2.0 (Quebec User Evaluation of 
Satisfaction with Assistive Technology) se tomaron en cuenta las características con los valores más bajos de satisfacción y aquellas características consideradas como las más importantes por los usuarios. En la Tabla 26, se puede observar en orden ascendente las ponderaciones de satisfacción resultantes de la aplicación de dicho cuestionario para cada tipo de silla de ruedas.

\section{Tabla 27}

Ponderaciones de satisfacción resultantes de la aplicación del QUEST 2.0

\begin{tabular}{|c|c|c|c|}
\hline \multicolumn{2}{|c|}{$\begin{array}{c}\text { Silla de ruedas de propulsión manual de } \\
\text { estructura plegable }\end{array}$} & \multicolumn{2}{|c|}{$\begin{array}{c}\text { Silla de ruedas de propulsión manual de } \\
\text { estructura rígida }\end{array}$} \\
\hline Característica & $\begin{array}{l}\text { Ponderación de } \\
\text { satisfacción } \\
\text { resultante }\end{array}$ & $\begin{array}{l}\text { Ponderación de } \\
\text { satisfacción } \\
\text { resultante }\end{array}$ & Característica \\
\hline Peso & 2.46 & 3.85 & Comodidad \\
\hline Comodidad & 2.88 & 4.04 & Facilidad de ajustar \\
\hline Facilidad de ajustar & 3.04 & 4.08 & Peso \\
\hline Durabilidad & 3.08 & 4.12 & Durabilidad \\
\hline Estabilidad y seguridad & 3.11 & 4.27 & Atracción visual \\
\hline Atracción visual & 3.12 & 4.30 & Dimensiones \\
\hline Dimensiones & 3.23 & 4.31 & Efectividad \\
\hline Facilidad de uso & 3.27 & 4.42 & Estabilidad y seguridad \\
\hline Efectividad & 3.35 & 4.5 & Facilidad de uso \\
\hline
\end{tabular}

Del mismo modo, en la Tabla 27 se muestran las características consideras como las más importantes por los mismos usuarios de los dos tipos de silla de ruedas. En el Tabla 17 se mencionaron las recurrencias por cada una de estas características.

Tabla 28

Características consideradas más importantes por los usuarios de silla de ruedas

\begin{tabular}{cccc}
\hline \multicolumn{2}{c}{$\begin{array}{c}\text { Silla de ruedas de propulsión manual de } \\
\text { estructura plegable }\end{array}$} & $\begin{array}{c}\text { Silla de ruedas de propulsión manual de } \\
\text { estructura rígida }\end{array}$ \\
\hline $\begin{array}{c}\text { Grado de importancia } \\
\text { según los usuarios }\end{array}$ & Característica & Característica & $\begin{array}{c}\text { Grado de importancia } \\
\text { según los usuarios }\end{array}$ \\
\hline 1 & Comodidad & Comodidad & 1 \\
\hline 2 & Estabilidad y Seguridad & Durabilidad & 2 \\
\hline 3 & Facilidad de uso & Facilidad de uso & 3 \\
\cline { 2 - 3 } & Peso & Peso & 3 \\
\hline
\end{tabular}


Por otro lado, en la Tabla 28 y basados en los resultados de la escala de Diferencial Semántico, se pueden evidenciar los 5 pares de adjetivos con los menores índices de percepción en los dos tipos de sillas de ruedas.

\section{Tabla 29}

Pares de adjetivos con los menores índices de percepción

\begin{tabular}{|c|c|c|c|}
\hline \multicolumn{2}{|c|}{$\begin{array}{c}\text { Silla de ruedas de propulsión manual de } \\
\text { estructura plegable }\end{array}$} & \multicolumn{2}{|c|}{$\begin{array}{c}\text { Silla de ruedas de propulsión manual de } \\
\text { estructura rígida }\end{array}$} \\
\hline Característica & $\begin{array}{l}\text { Índice de percepción } \\
\text { resultante }\end{array}$ & $\begin{array}{l}\text { Índice de percepción } \\
\text { resultante }\end{array}$ & Característica \\
\hline Lenta / Rápida & -0.92 & 1.81 & $\begin{array}{l}\text { Tradicional / } \\
\text { innovadora }\end{array}$ \\
\hline $\begin{array}{l}\text { Tradicional / } \\
\text { innovadora }\end{array}$ & -0.54 & 1.92 & $\begin{array}{l}\text { Difícil mantenimiento / } \\
\text { Fácil mantenimiento }\end{array}$ \\
\hline $\begin{array}{l}\text { Difícil de transportar / } \\
\text { Fácil de transportar }\end{array}$ & -0.31 & 2.19 & $\begin{array}{l}\text { Personalizable / No } \\
\text { personalizable }\end{array}$ \\
\hline Atractiva / No atractiva & \multirow{2}{*}{-0.23} & 2.23 & Introvertida / Sociable \\
\hline Anticuada / Moderna & & 2.27 & Anticuada / Moderna \\
\hline
\end{tabular}

Los resultados cuantitativos de los dos instrumentos anteriores se pudieron contrastar con la información cualitativa de la entrevista a los usuarios de la silla de ruedas de estructura plegable. Entre los hallazgos, se encontró que la mayor insatisfacción de los usuarios con respecto a su silla de ruedas está relacionada con los factores físicos de la misma, tales como el respaldo, el asiento, los apoyabrazos, los descansapiés y los materiales empleados. Con el propósito de visualizar de manera integral los factores que se contemplaron para realizar las adecuaciones a la silla de ruedas de propulsión manual, la Tabla 29, sintetiza parte de esta información y en ella se plantean los requerimientos de diseño. 
Tabla 30

Requerimientos de diseño planteados para la investigación

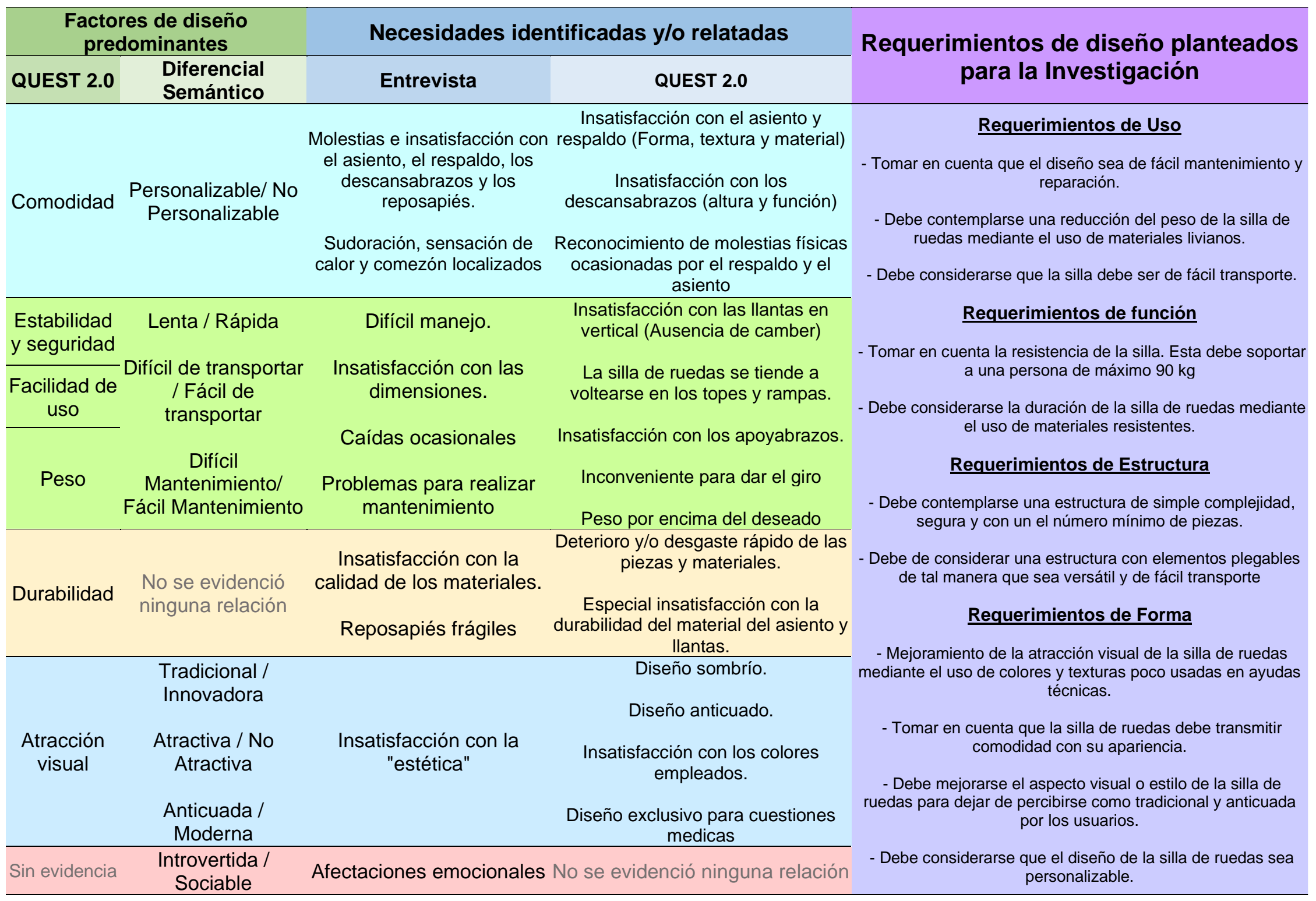




\section{DESARROLLO Y SIMULACIÓN DE ESFUERZOS PARA EL MODELO PROPUESTO}

\subsection{Desarrollo del diseño propuesto}

Una vez establecidas las necesidades y planteados los requerimientos de diseño, se precedió a determinar cuáles componentes se deberían diseñar y cuales irían a permanecer en su versión estándar. Por cuestiones de mantenimiento y accesibilidad a las refacciones, se decidió que las llantas, las ruedas delanteras y los frenos se implementarían a la nueva propuesta en sus formas y diseños habituales y/o convencionales.

En primera medida se decidió por comenzar en la propuesta de diseño del marco o estructura de la silla de ruedas. Durante el proceso de diseño, surgieron diferentes ideas en las cuales se contemplaron aspectos técnicos, funcionales, de atracción visual. Algunas de estas ideas se muestran en la Figura 12, donde se pueden apreciar ciertos bocetos. Sin embargo, al tener en cuenta los resultados del cuestionario QUEST 2.0, en los cuales la silla de ruedas de estructura rígida, la característica con el segundo índice de satisfacción más alto fue la seguridad y estabilidad del dispositivo, se determinó que la estructura del diseño propuesto debería ser similar al tipo de silla mencionado anteriormente. A su vez, en dicha estructura se deberá contemplar elementos que faciliten su transporte, su guardado y que transmita al usuario funcionalidad y versatilidad. Para ello, se tomaron en cuenta las recomendaciones de la Organización Mundial de la Salud (2008), en las cuales se sugiere que en el diseño de una silla de ruedas se debe considerar la característica de fácil transporte, por lo tanto, recomiendan tres formas o mecanismos para lograrlo: marco plegable, ruedas desmontables y respaldo plegable hacia adelante. En la propuesta de diseño para la investigación, se decidió implementar en la estructura de la silla de ruedas los tres mecanismos sugeridos por la OMS. Lo anterior, debido a que algunos usuarios de la silla de ruedas de estructura plegable manifestaron su satisfacción con esta característica de la silla de ruedas. Por otro lado, los usuarios de la silla de ruedas de estructura rígida estaban a gusto con la estabilidad que les proporcionaba este tipo 
estructura, sin embargo, deseaban que esta fuera un poco más fácil a la hora de transportarse.

\section{Figura 12}

Ideas / bocetos para la propuesta de la silla de ruedas

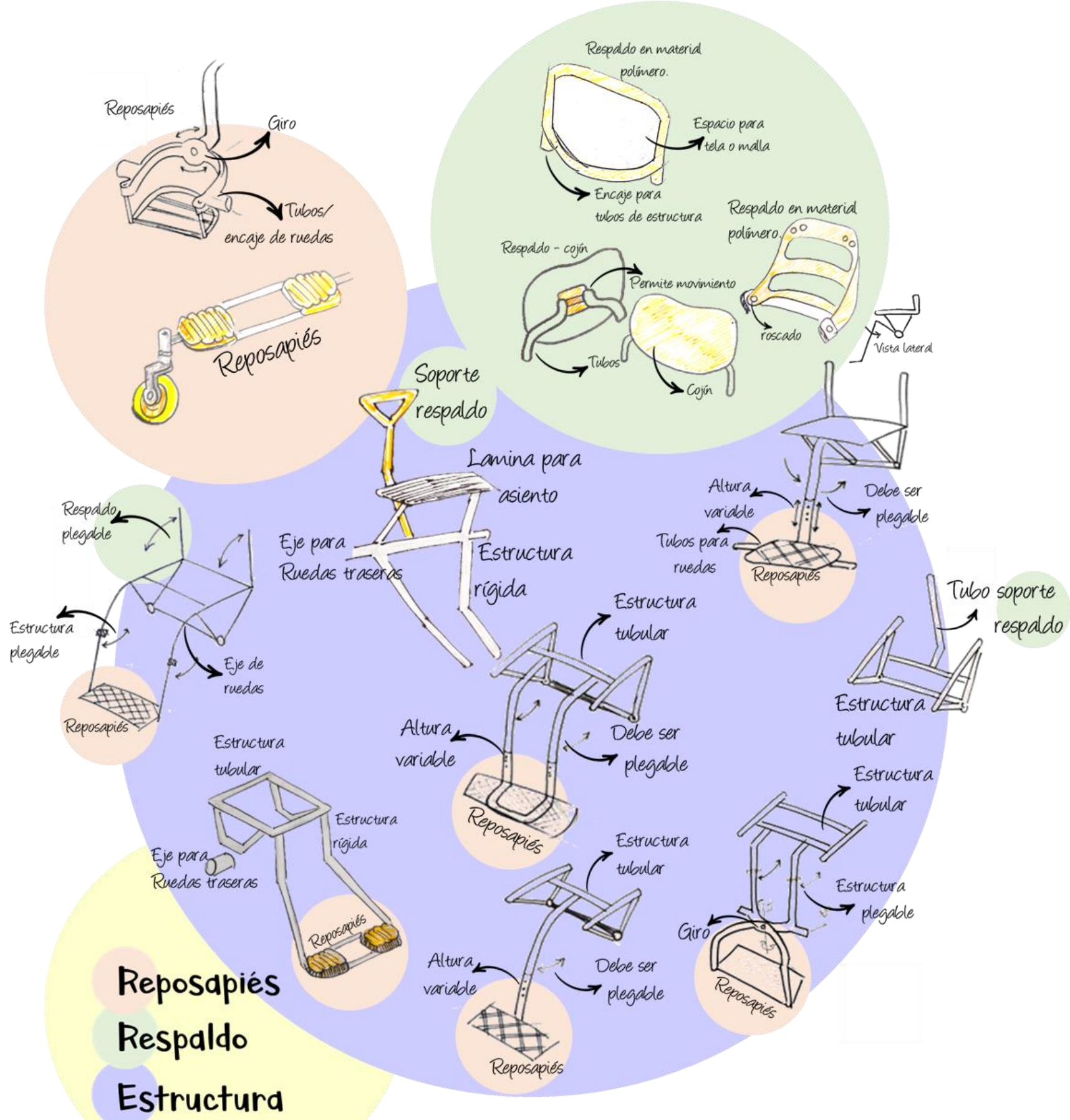


En la propuesta de diseño con respecto al plegado de la estructura se sugiere el uso de mecanismos existentes en el mercado, los cuales los cuales van a permitir un fácil mantenimiento y un costo asequible. Debido a lo anterior, se optó usar un mecanismo comercial empleado en el bastidor de las bicicletas del marco plegable, este se puede observar en la Figura 13.

Figura 13

Mecanismo Q-Lock Handlepost (bloqueo rápido)

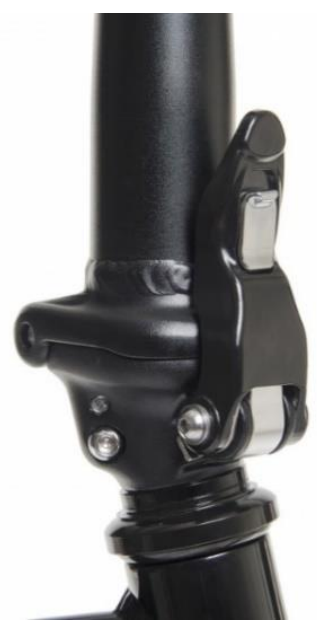

Nota: Tomado de Q-Lock ${ }^{\mathrm{TM}}$ Handlepost, por Tern, 2021, https://www.ternbicycles.com/no/tech/471/q-lock-handlepost

Por otro lado, con respecto al asiento se consideró realizar un cambio en el material empleado debido a la insatisfacción de los usuarios con el material comúnmente utilizado, y partiendo de las necesidades identificadas se optó por la implementación de un material rígido como los polímeros. Con el propósito de lograr un asiento cómodo y de mejor percepción por el usuario, se decidió implementar la forma de la silla Panton ${ }^{12}$. Con relación al respaldo, por razones similares de insatisfacción con los materiales empleados habitualmente, de optó por el uso de un

12 La silla Panton fue creada por el arquitecto diseñador danés Verner Panton en la década de los 60. Se caracteriza principalmente por ser fabricada en una sola pieza de polímeros (poliuretano o polipropileno), ser apilable, apta para cualquier ambiente y ergonómicamente cómoda y ligera (MartínTrueba, 2017, p. 23) 
material polímero y debido al problema de los usuarios en cuanto a la sudoración excesiva y sensación de comezón se decidió incorporar a esta pieza un material textil.

Mencionado lo anterior, se presenta la propuesta final en la Figura 14 y en la Figura 15 se muestra el plegado de la estructura de esta. La estructura propuesta presenta un diseño similar a las sillas de ruedas actuales, pero brinda versatilidad al ser desmontable y de fácil transporte. Las llantas, son desmontables gracias al mecanismo de quick release o desenganche rápido. En cuanto a los descansapiés se decidió mantener la forma de aquellos usados habitualmente con la opción de poder graduar la altura dependiendo de la estatura o de las medidas antropométricas del usuario. Debido a la gran insatisfacción del usuario con respecto a la funcionalidad de los reposabrazos, para esta propuesta, estos no se tomaron en cuenta con el propósito de transmitirle al usuario una sensación de libertad y comodidad.

\section{Figura 14}

Propuesta final de la silla de ruedas de propulsión manual

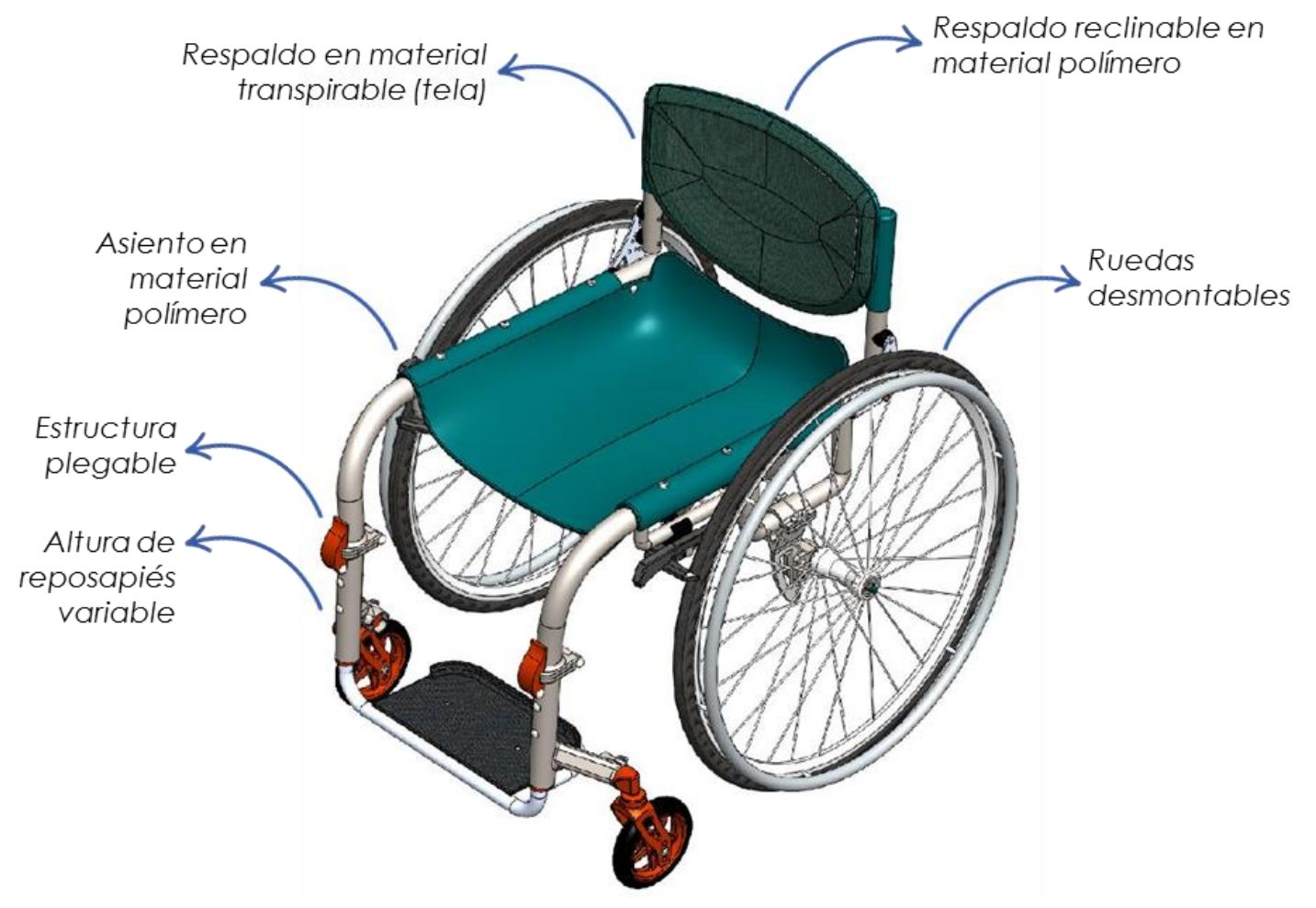




\section{Figura 15}

Plegado de la silla de ruedas de propulsión manual propuesta

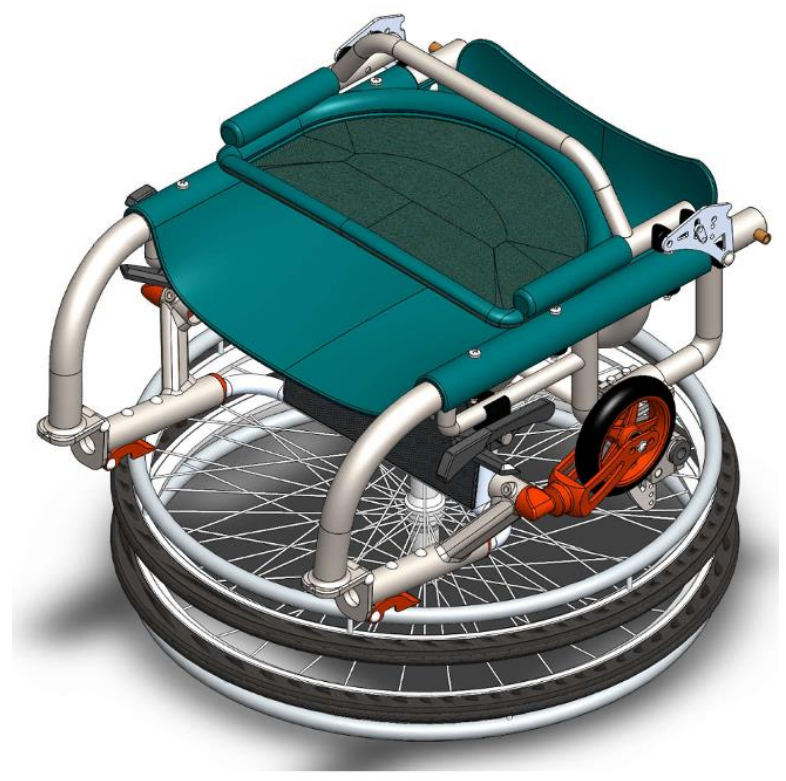

Figura 16

Vista lateral y frontal del diseño propuesto simulado con figura humana.
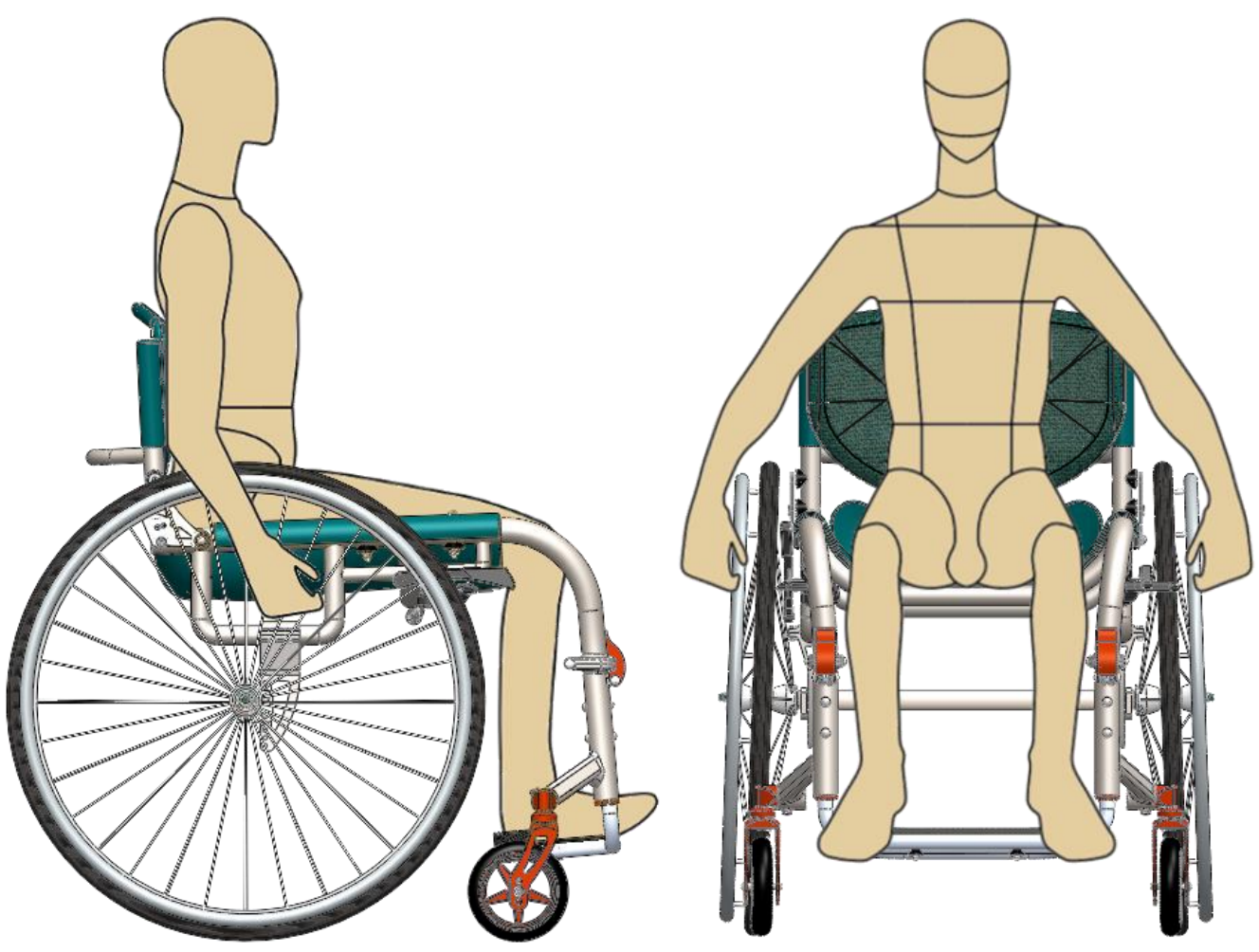
Finalmente, en la Figura 16 se aprecian las dos vistas principales del diseño propuesto, cada una simulada con una figura humana y en la Figura 17, se detallan las medidas principales de este diseño. Para la obtención de dichas medidas, se contó con los datos proporcionados en los libros de Prado-León et al. (2007) y Panero y Zelnik (1996).

\section{Figura 17}

Vista lateral y frontal de la propuesta de diseño con sus principales medidas
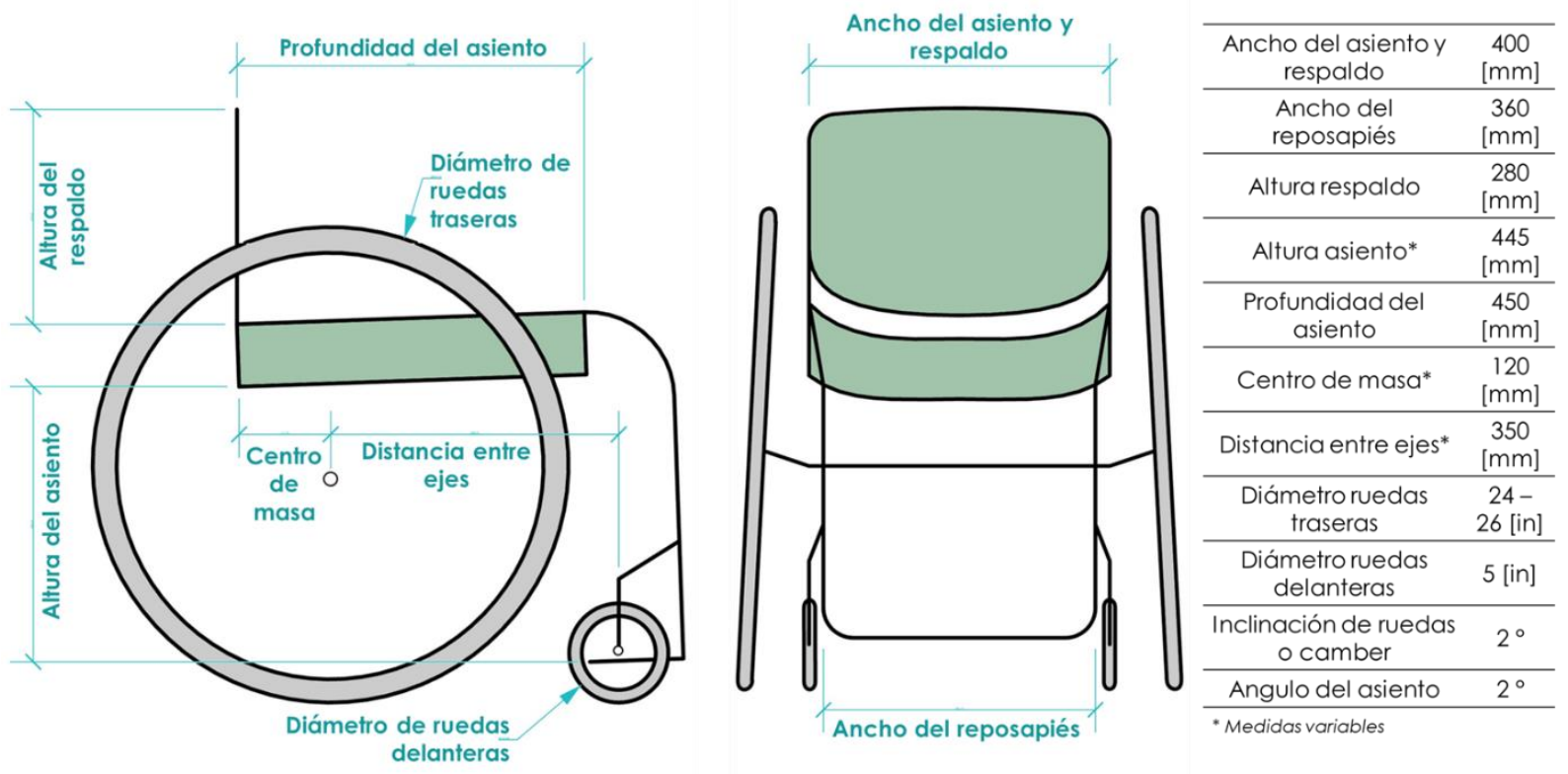

\subsection{Simulación de esfuerzos}

En el diseño y desarrollo de productos, la simulación de esfuerzos o simulación numérica es una herramienta de gran importancia que brinda la posibilidad de constatar la resistencia del modelo, sin la necesidad de construir un prototipo. Dicha simulación de esfuerzos se lleva a cabo mediante el Método de Elementos Finitos, que es una forma de evaluar la resistencia mecánica de un sistema o producto. Este método con frecuencia es empleado en ingeniera estructural, sin embargo, es de gran ayuda en el análisis de tensiones y deformaciones de sólidos con geometrías variadas tal como la silla de ruedas y sus componentes (Lopes et al., 2019). 
Durante la investigación, de la propuesta de la silla de ruedas se verificó la resistencia mecánica de los componentes que fueron modificados o rediseñados mediante el uso del software SolidWorks. Para la información de las propiedades mecánicas de los materiales se empleó la base de datos del software CES EduPack ${ }^{13}$. En la aplicación de cargas y en la consideración del valor mínimo de factor de seguridad, se tuvo en cuenta lo estipulado por la norma ISO 7176-814.

\subsubsection{Asiento}

En el caso del asiento, se contempló el uso de un material polímero para moldeo por inyección. El material considerado fue el polipropileno debido a importantes características como su bajo costo, su ductilidad y su baja densidad. En cuanto a su rigidez, esta es mayor a la de otros materiales y puede ser reforzada o mejorada mediante la adición de fibra de vidrio o talco a su composición. Asimismo, se moldea con gran facilidad y posee mejor apariencia ya que permite la transparencia y acepta una gama de colores más vivos. Entre sus diversos usos, se encuentran aplicaciones en la ingeniería, el mobiliario y las estructura para sillas (Ashby et al., 2011). Las propiedades mecánicas del material seleccionado se pueden ver en la Tabla 30.

13 CES EduPack ${ }^{T M}$ es un software especializado en materiales para la ciencia, ingeniería, manufactura y diseño. La base de datos ofrecida por CES EduPack ${ }^{T M}$ proporciona información técnica, económica y medioambiental de los materiales. A su vez, esta base de datos abarca un gran número de áreas tales como el ecodiseño, polímeros, biomateriales, desarrollo sostenible, aeronáutica, arquitectura, entre otras (Ansys, 2021). Recuperado el 02 de abril de 2021 de https://www.ansys.com/products/materials/granta-edupack

${ }^{14}$ La norma ISO 7176-8 establece los requisitos y procedimientos para la verificación de la estructura de la silla de ruedas mediante ensayos de carga estática, de impacto y fatiga. Dichos requisitos y procedimientos aplican para silla de ruedas que soportan un peso menor o igual a 100 [kg] (Marques et al., 2020). 


\section{Tabla 31}

Propiedades mecánicas de polipropileno

\begin{tabular}{ccc}
\hline \multicolumn{3}{c}{$\begin{array}{c}\text { Propiedades mecánicas de Polipropileno con 20\% de } \\
\text { Fibra de vidrio en su composición }\end{array}$} \\
\hline 1 & Módulo elástico (módulo de Young) & $2.97[\mathrm{Gpa}]$ \\
\hline 2 & Coeficiente de Poisson & 0.369 \\
\hline 3 & Módulo cortante & $1.075[\mathrm{GPa}]$ \\
\hline 4 & Límite de tracción & $45.4[\mathrm{Mpa}]$ \\
\hline 5 & Límite de compresión & $43.35[\mathrm{Mpa}]$ \\
\hline 6 & Limite elástico & $48.15[\mathrm{Mpa}]$ \\
\hline 7 & Densidad & $1040[\mathrm{~kg} / \mathrm{m} 3]$ \\
\hline
\end{tabular}

Nota. Valores promedio obtenidos de la base de datos de CES EduPack 2019

En cuanto a la fuerza aplicada, se contempló en los requerimientos que la silla de ruedas debería ser resistente al peso máximo de 90 [kg]. La norma ISO 7176-8, establece que una silla de ruedas diseñada para soportar pesos entre 75 a 100 [kg], las pruebas de carga estáticas deben ser realizadas con una fuerza de 1000 [N], lo equivalente a $100[\mathrm{~kg}]$. Los resultados del análisis de esfuerzos para el asiento se expusieron en las siguientes Figura 18, Figura 19 y Figura 20.

\section{Figura 18}

Simulación de tensiones para el asiento analizado en SolidWorks

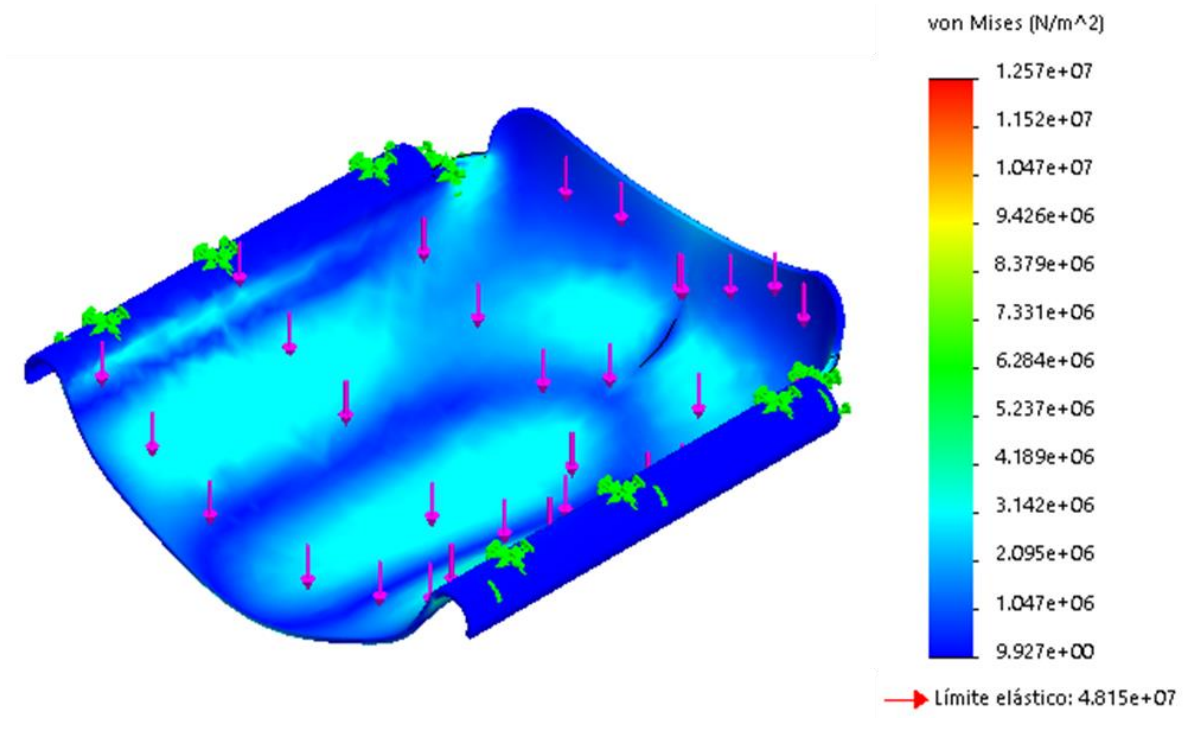




\section{Figura 19}

Simulación de desplazamientos para el asiento analizado en SolidWorks

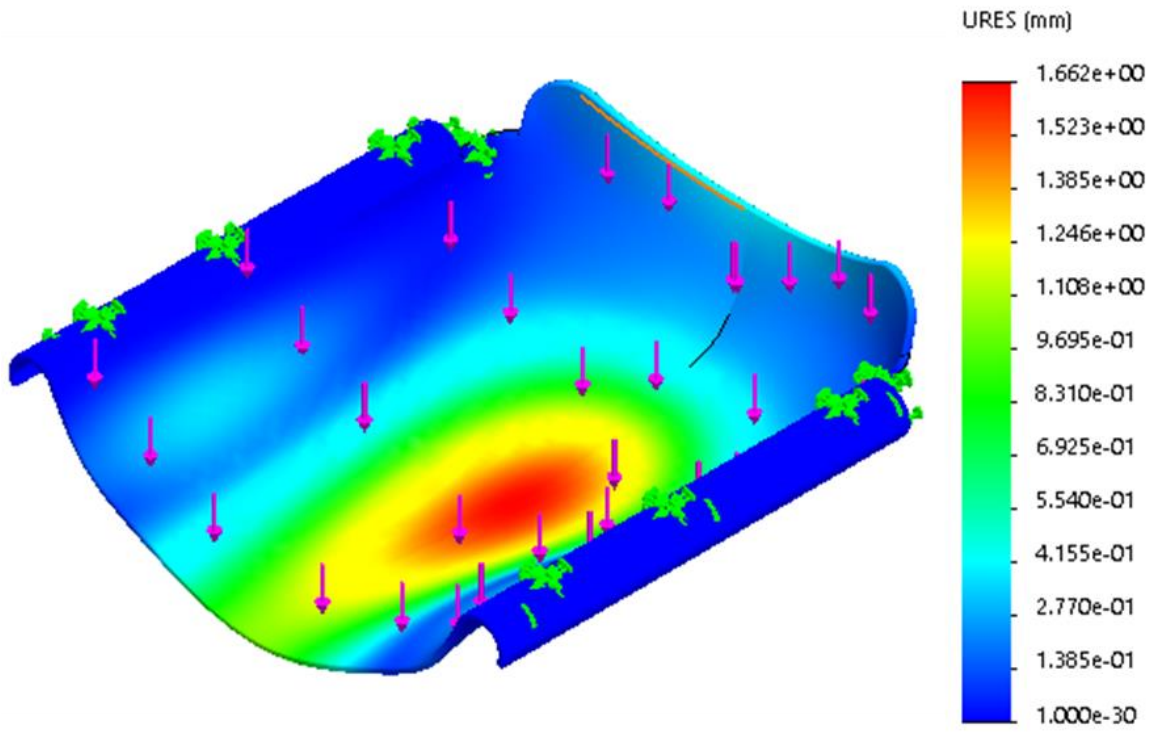

Figura 20

Factor de seguridad resultante en el asiento analizado en SolidWorks

FDS

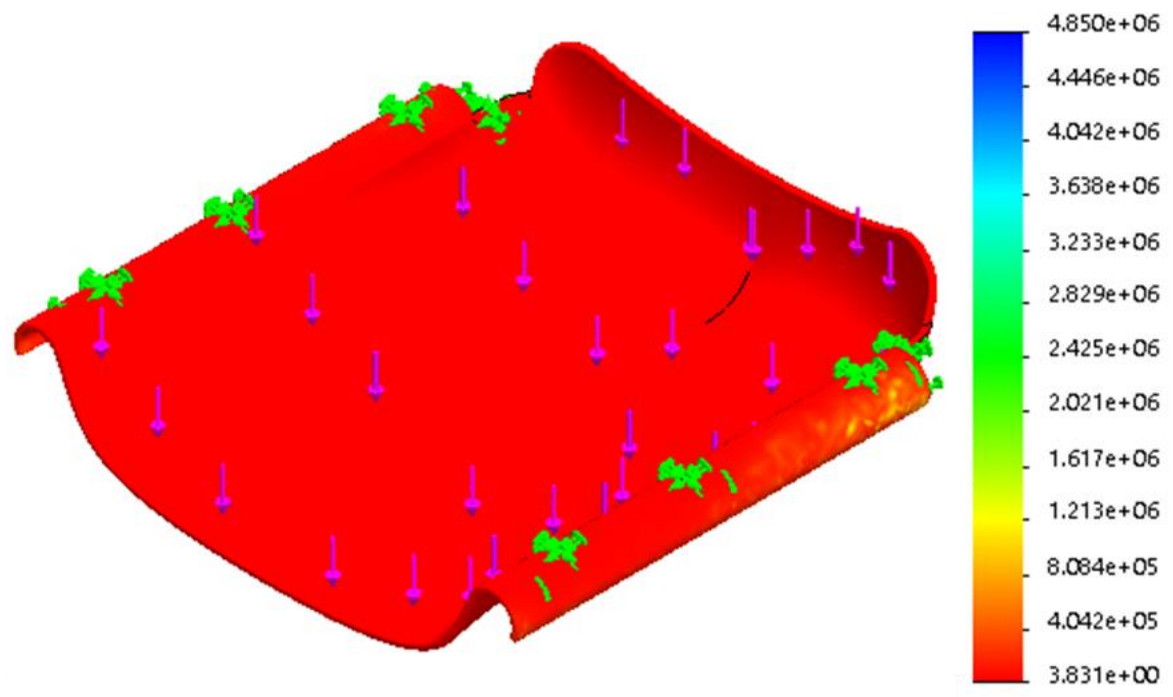


En la simulación de esfuerzos para el asiento, se obtuvo como resultado una tensión máxima de $1.257 \times 10^{7}[\mathrm{~Pa}]$, sin embargo, esta no sobrepasó el límite elástico del polipropileno $\left(4.81 \times 10^{7}[\mathrm{~Pa}]\right)$. A su vez, esta fuerza ocasionó un desplazamiento máximo de $1.66[\mathrm{~mm}]$ y un factor de seguridad mínimo de 3.8. En lo referente al factor de seguridad, la Norma ISO 7176-8 sugiere que dicho factor sea mayor o igual a 1.5 (Chacon-Cifuentes et al., 2020). En el caso del asiento, se pudo evidenciar que el factor de seguridad resultante fue de 3.8 , lo cual cumple con el requerimiento de la norma.

\subsubsection{Respaldo}

El material usado para la simulación del respaldo fue también el polipropileno empleado en el asiento (Ver Tabla 30). En alusión a la fuerza aplicada, se consideró el $20 \%$ de la carga máxima (1000 [N]), es decir $200[\mathrm{~N}]$, lo equivalente a $20[\mathrm{~kg}]$. Dicha carga fue aplicada en dirección perpendicular a la superficie. Los resultados de la simulación de esfuerzos para el respaldo se pueden apreciar en la Figura 21, Figura 22 y Figura 23.

\section{Figura 21}

Simulación de tensiones para el respaldo analizado en SolidWorks

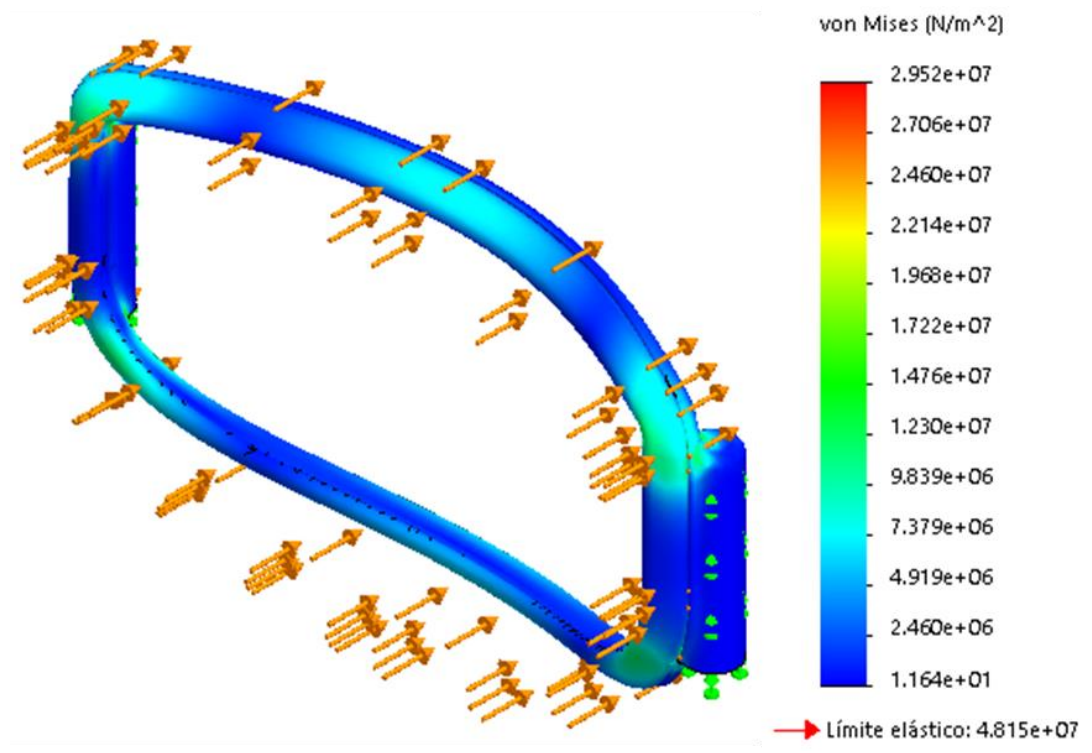




\section{Figura 22}

Simulación de desplazamientos para el respaldo analizado en SolidWorks
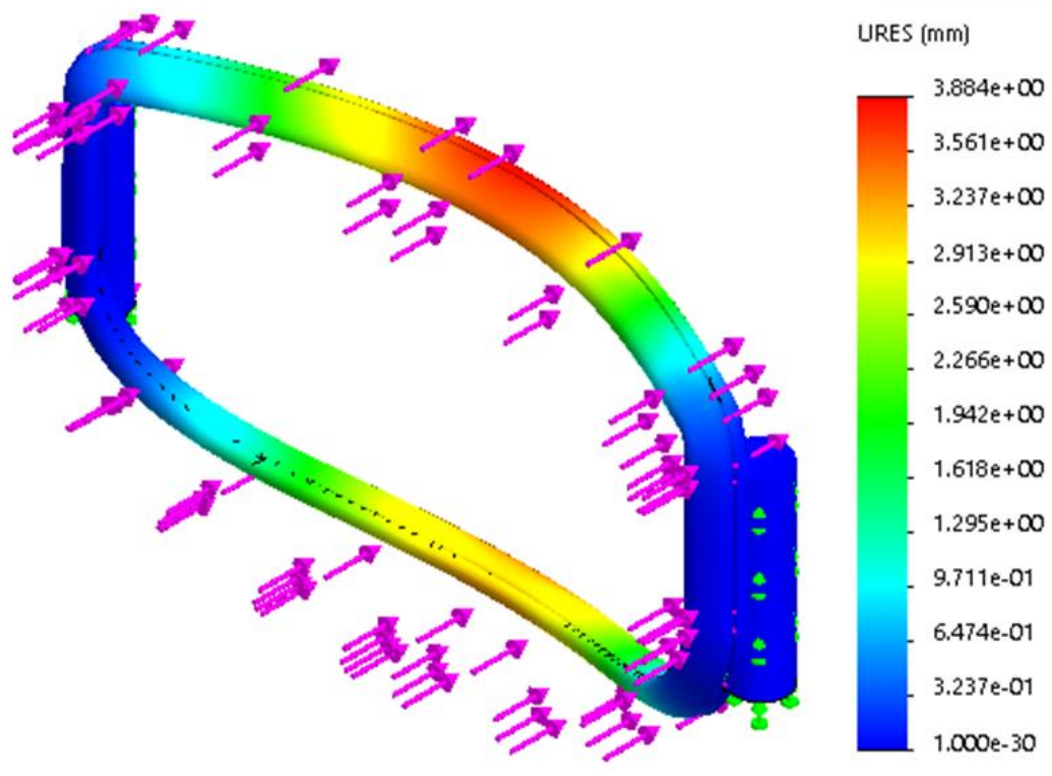

\section{Figura 23}

Factor de seguridad resultante en el respaldo analizado en SolidWorks

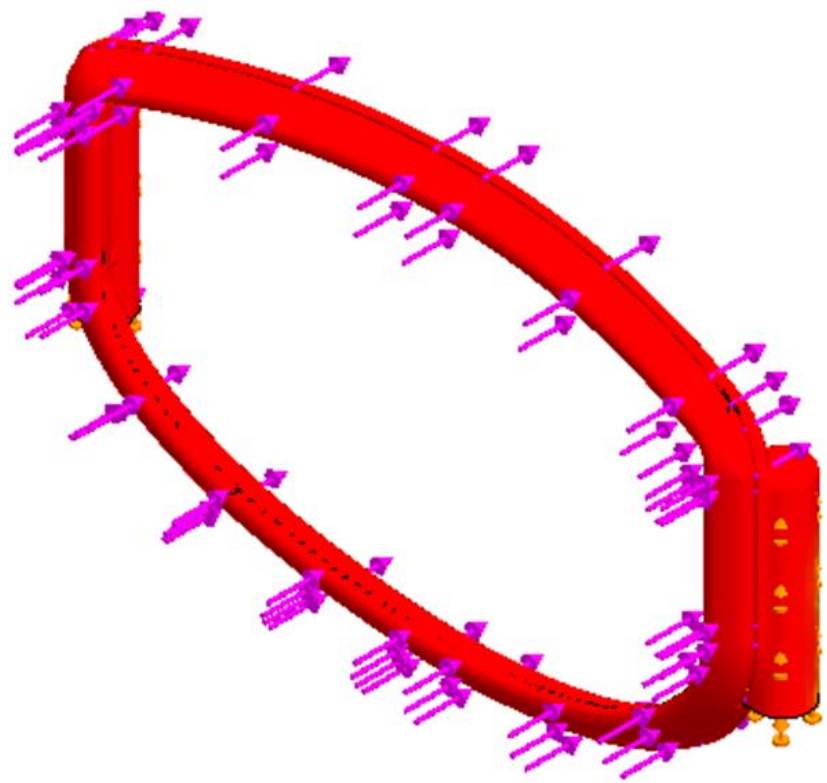

FDS

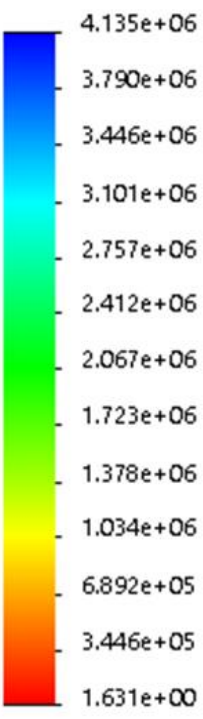


El análisis de esfuerzos realizado al respaldo dio como resultado una tensión máxima de $2.952 \times 10^{7}[\mathrm{~Pa}]$ la cual no superó el límite elástico del polipropileno empleado $\left(4.815 \times 10^{7}[\mathrm{~Pa}]\right)$. En cuanto al desplazamiento máximo provocado por la fuerza proporcionada se obtuvo como resultante un valor de $3.88[\mathrm{~mm}]$ y un factor de seguridad mínimo de 1.63, el cual supera al valor estipulado por la norma ISO 7176-8.

\subsubsection{Estructura superior}

En el caso de la estructura o marco, como material se consideró emplear para la simulación el acero AISI 1020. Lo anterior debido a que se considera un material de bajo costo y con características mecánicas apropiadas, gran disponibilidad en el mercado y buenas propiedades de soldabilidad (Leal y Silva, 2018). Las propiedades mecánicas de este acero se pueden observar en la Tabla 31. Por otro lado, para la estructura se tomó en cuenta el tamaño de los diámetros estandarizados del acero y se modeló de tal manera que cumpliera con el diámetro y espesor de un tubo de 1 [pul] de diámetro nominal de cedula 30. Las medidas correspondientes se pueden detallar en la Figura 24.

Con respecto a la fuerza aplicada, se consideró una fuerza de la misma magnitud que se aplicó en el siento, es decir 1000 [N] lo equivalente a 100 [kg]. Los resultados de la simulación de esfuerzos para la estructura arrojaron una tensión máxima de $1.48 \times 10^{8}[\mathrm{~Pa}]$ la cual no supera el límite elástico del acero empleado en la simulación $\left(3.5 \times 10^{8}[\mathrm{~Pa}]\right)$. En los demás resultados, se obtuvo un desplazamiento con un valor máximo de 0.44 [mm] y un factor de seguridad mínimo de 2.3 que cumple con el requisito de la norma mencionada anteriormente. Dichos resultados se pueden observar en la Figura 25, Figura 26 y Figura 27.

Tabla 32

Propiedades mecánicas del Acero AISI 1020

\begin{tabular}{ccc}
\hline & Propiedades mecánicas del Acero AISI 1020 \\
\hline $\mathbf{1}$ & Módulo elástico (módulo de Young) & $215[\mathrm{Gpa}]$ \\
\hline $\mathbf{2}$ & Coeficiente de Poisson & 0.295 \\
\hline $\mathbf{3}$ & Módulo cortante & $84[\mathrm{GPa}]$ \\
\hline $\mathbf{4}$ & Límite de tracción & $490[\mathrm{Mpa}]$ \\
\hline $\mathbf{5}$ & Límite de compresión & $350[\mathrm{Mpa}]$ \\
\hline $\mathbf{6}$ & Limite elástico & $350[\mathrm{Mpa}]$ \\
\hline $\mathbf{7}$ & Densidad & $7900\left[\mathrm{~kg} / \mathrm{m}^{3}\right]$ \\
\hline
\end{tabular}

Nota. Valores promedio obtenidos de la base de datos de CES EduPack 2019 


\section{Figura 24}

Diámetros estandarizados de los aceros, cedula 30

TUBO CÉDULA 30

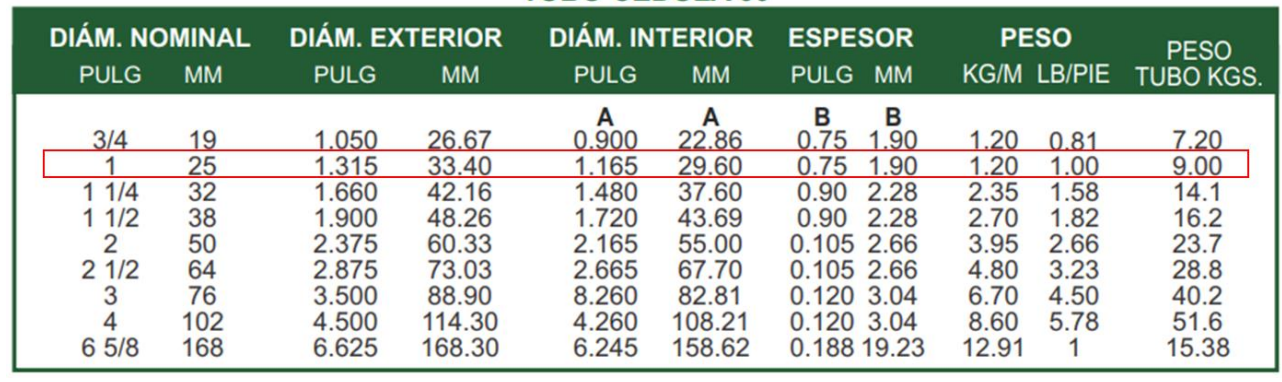

Nota: Tomado de Catálogo de productos Kalish Acero (P.120), 2020, por Kalish, https://www.kalischacero.com/catalogo/Kalisch_Acero_Catalogo.pdf

\section{Figura 25}

Simulación de tensiones para la estructura superior analizado en SolidWorks

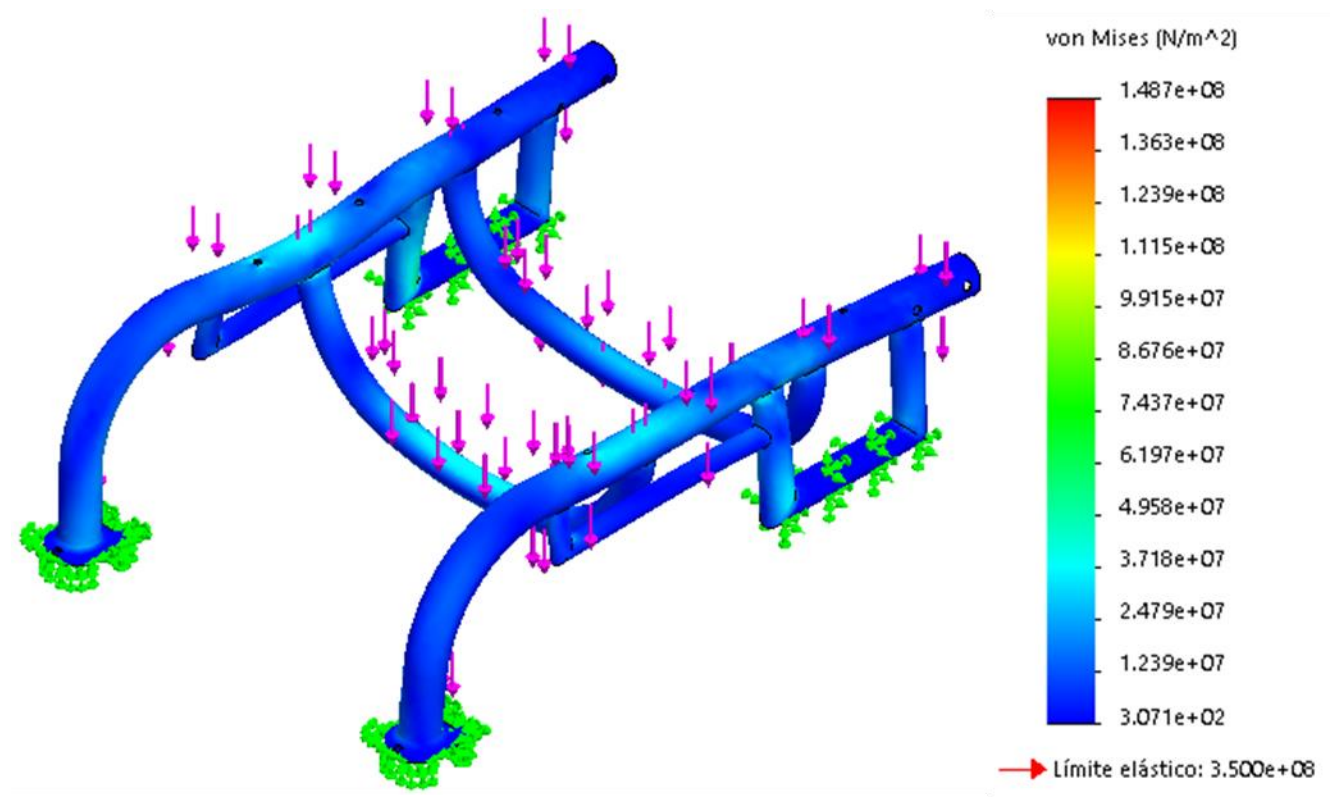




\section{Figura 26}

Simulación de desplazamientos para la estructura analizado en SolidWorks
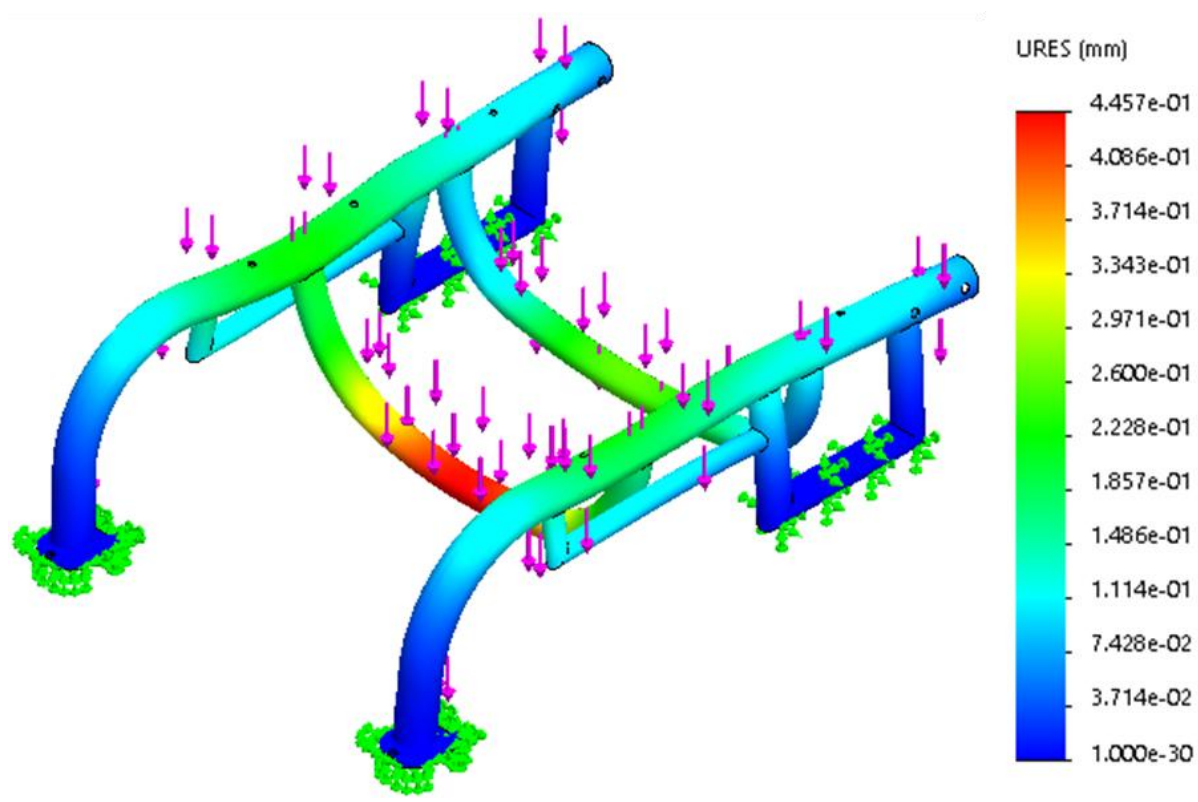

\section{Figura 27}

Factor de seguridad resultante para la estructura analizado en SolidWorks
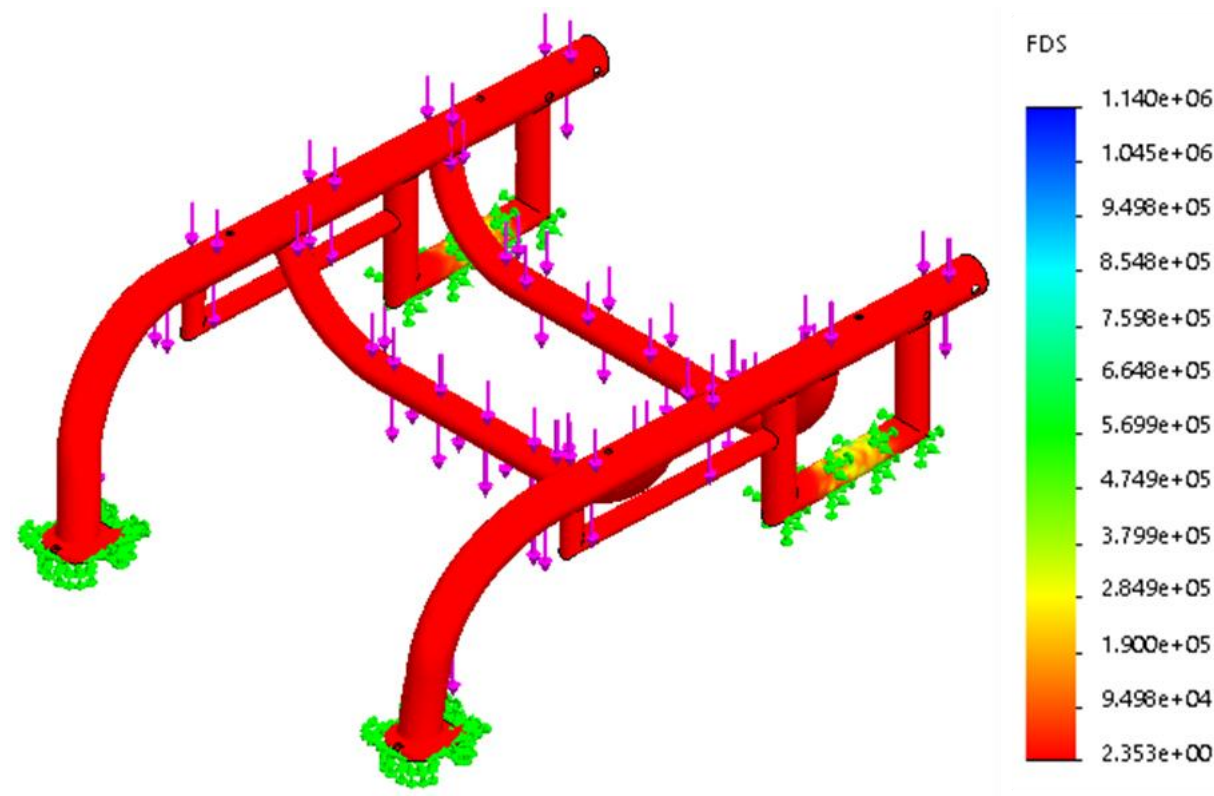


\subsubsection{Pieza inferior de la estructura}

El material empleado para la simulación en esta pieza fue el acero AISI 1020, el mismo material usado en la estructura superior del cual sus propiedades mecánicas se describen en la Tabla 31. En este caso, para determinar la fuerza ejercida sobre la pieza, fue indispensable su cálculo mediante la realización de un diagrama de cuerpo libre de la estructura superior. En la Figura 28, se muestra el diagrama de cuerpo libre y su respectivo cálculo realizado para de definir la fuerza que actúa sobre el componente. La fuerza de $500[\mathrm{~N}]$ fue determinada por la división matemática de la carga total (1000 [N]) en los dos lados de la silla de ruedas. La fuerza $F_{1}$ fue calculada por la sumatoria de momentos en el punto $A$, igual a cero $\left(\Sigma M_{A}=0\right)$. Dicha fuerza, debido a la ley de acción y reacción es la misma que actúa sobre la pieza inferior de la estructura, cambiando solo su sentido.

\section{Figura 28}

Diagrama de cuerpo libre de la estructura superior

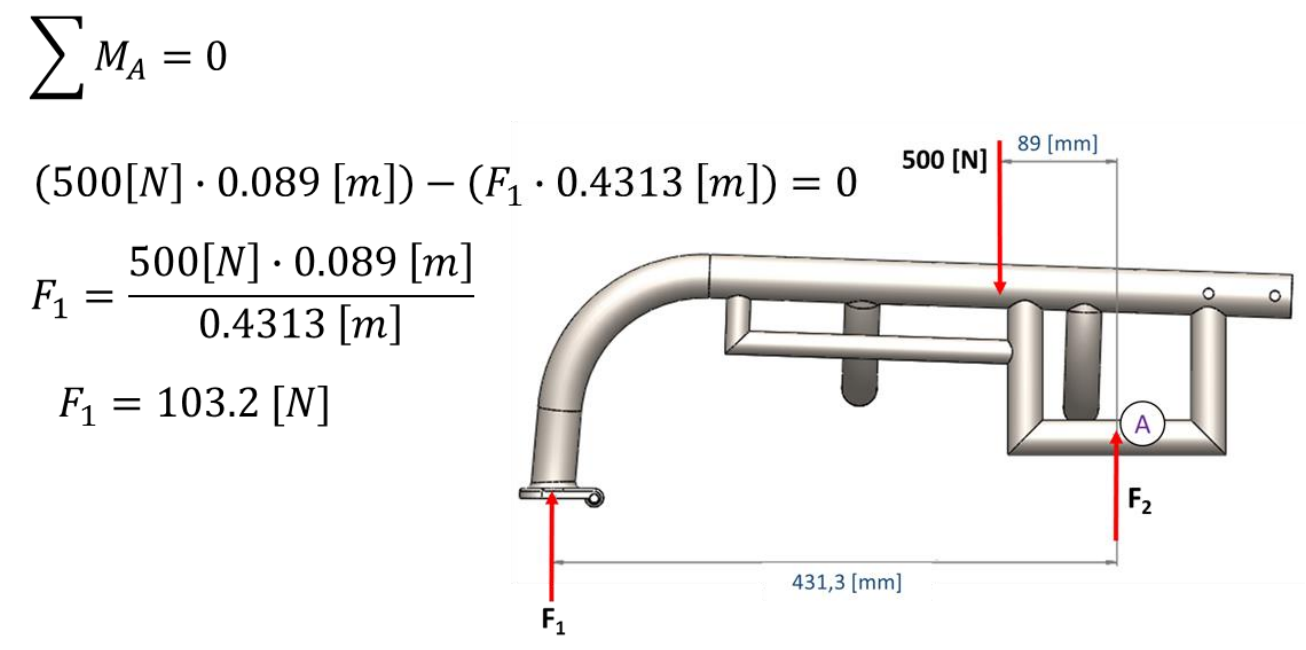

Los resultados de la simulación de esfuerzos para la pieza inferior de la estructura se muestran en la Figura 29, Figura 30 y Figura 31. En estos resultados, se aprecia que la tensión máxima ejercida por la fuerza de $103.2[\mathrm{~N}]$ fue de $7.5912 \times 10^{6}[\mathrm{~Pa}$ ], la cual no supera el límite elástico del acero AISI 1020. Por otro lado, se obtuvo un desplazamiento máximo de 0.00084 [mm], es decir un desplazamiento con un valor despreciable o nulo. El factor de seguridad mínimo resultante fue de 46, lo cual cumplió con el valor establecido por la norma ISO 7176-8 (mayor o igual a 1.5). 


\section{Figura 29}

Simulación de tensiones para la pieza inferior de la estructura analizado en SolidWorks

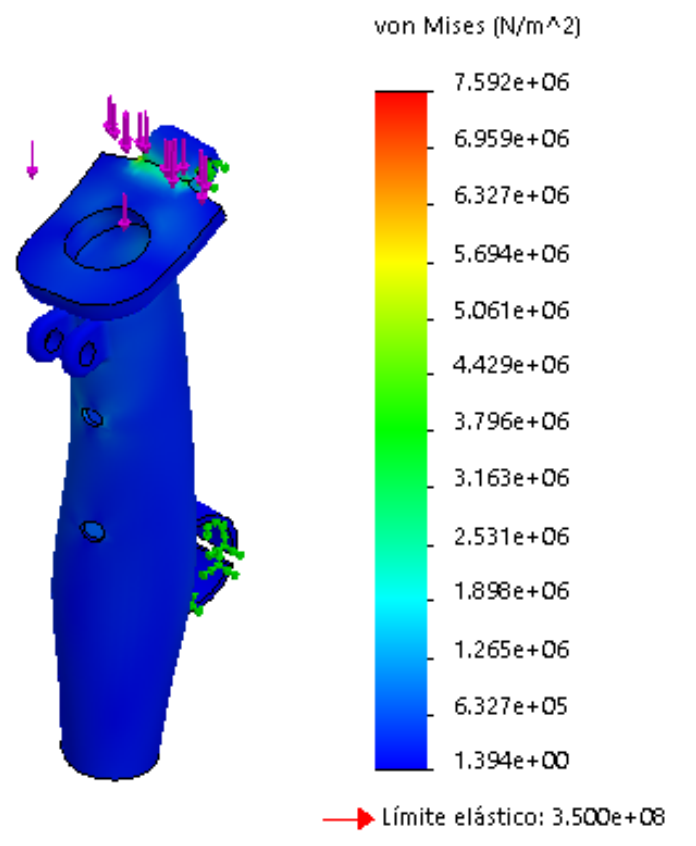

\section{Figura 30}

Simulación de desplazamientos para la pieza inferior de la estructura analizado en SolidWorks

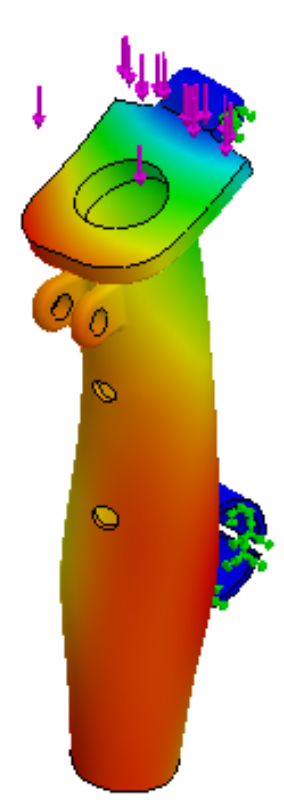

\section{Figura 31}

Factor de seguridad resultante en la pieza inferior de la estructura analizado en SolidWorks

FDS
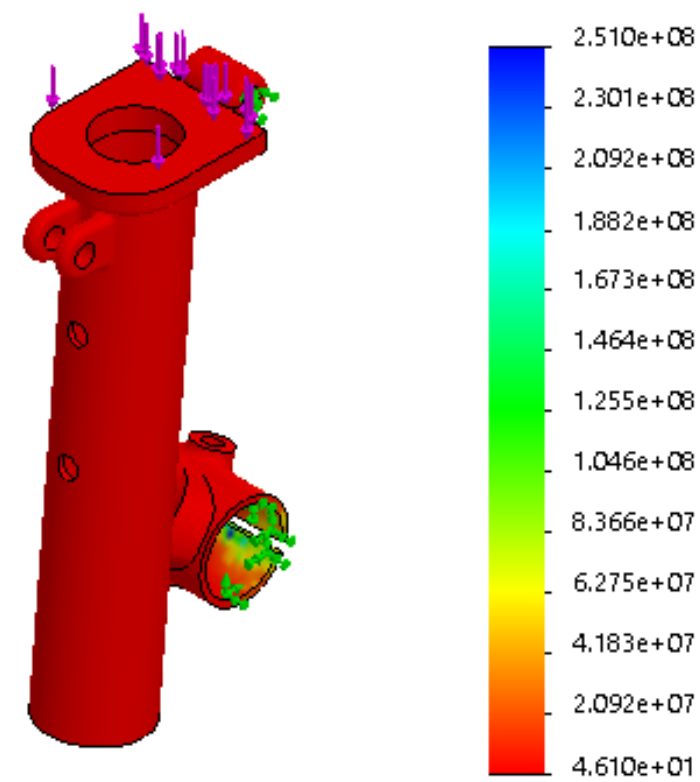


\section{EVALUACIÓN EMOCIONAL}

Esta evaluación se llevó a cabo mediante la Rueda Emocional de Ginebra o GEW por sus siglas en inglés (Geneva Emotion Wheel). Esta es un instrumento diseñado con el propósito de medir o evaluar las reacciones emocionales que pueden surgir de cualquier tipo de interacción con objetos, situaciones y/o eventos (McGinn y Kelly, 2018). Esta herramienta es un cuestionario compuesto por palabras pares que representan 20 familias de emociones y están dispuestas en forma de rueda o círculo. Cada par de palabras o familia de emociones consta de cinco círculos de diferentes tamaños, organizados de manera creciente los cuales simbolizan la intensidad de la emoción. Además, los encuestados poseen la opción de expresar alguna otra emoción que no se encuentre estipulada en el cuestionario o de manifestar que no sienten ninguna emoción en la interacción con el producto o situación (Carneiro, 2018). La Rueda Emocional de Ginebra, puede apreciarse en la Figura 32.

\section{Figura 32}

Rueda Emocional de Ginebra

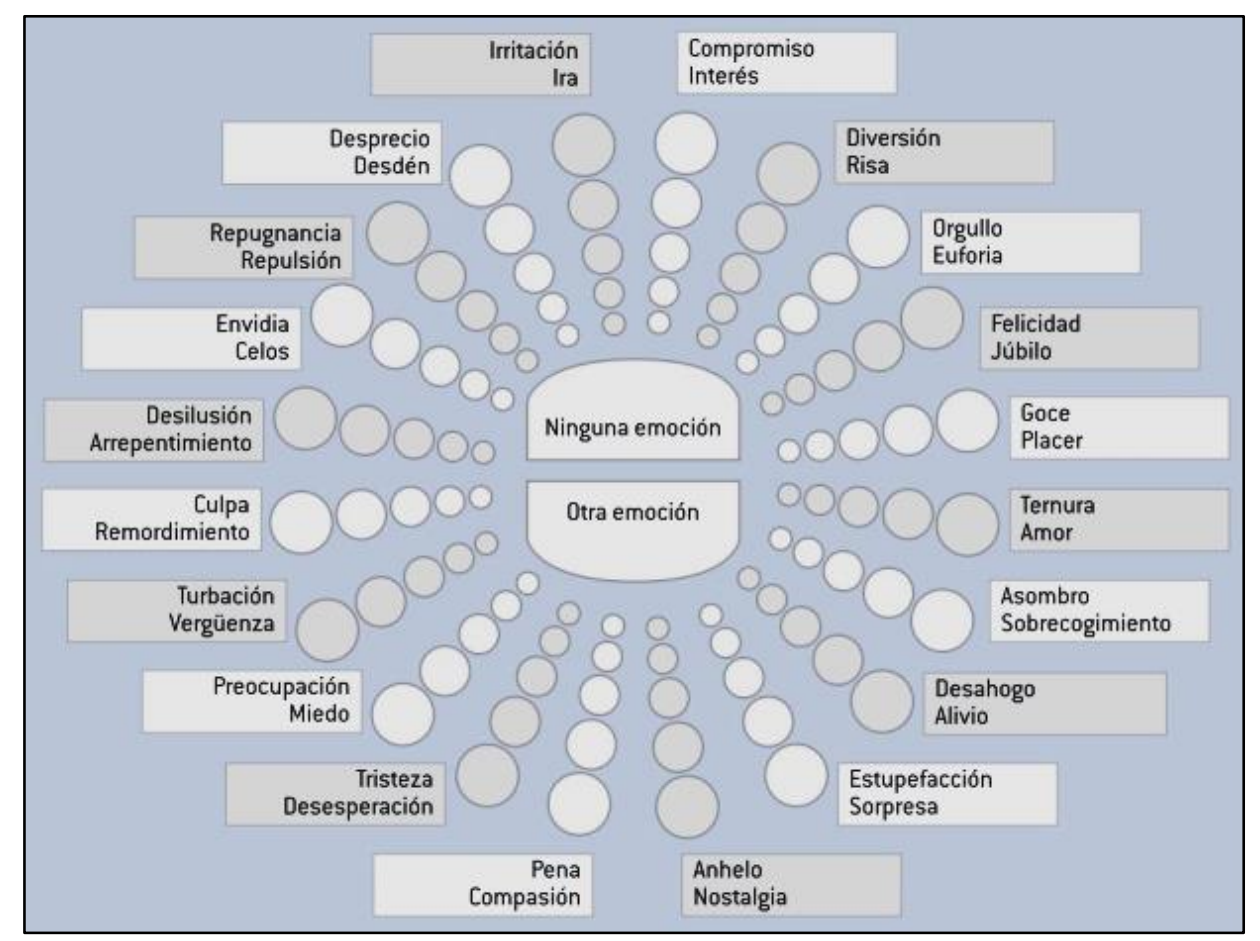

Nota. Tomado del Programa del Diploma del IB Oxford: IB Teoría del Conocimiento Libro del Alumno (Edición en español), por (Dombrowski et al., 2015, p. 166), Oxford University Press. 
En cuanto al uso de la Rueda de Ginebra en la evaluación de las reacciones emocionales producidas por la interacción con silla de ruedas, se puede mencionar dos estudios de referencia. El primero de ellos, Mokdad et al (2017), fue una investigación en la cual se abordaron las reacciones emocionales de personas con discapacidad motriz hacia su silla de ruedas en una muestra de población en Argelia, teniendo como variables el género y el tipo de discapacidad. La segunda investigación, Carneiro et al. (2019), profundizó sobre las diferentes reacciones emocionales producidas por dos tipos de sillas de ruedas en personas con y sin discapacidad motriz en Portugal.

\subsection{Muestra de población para la evaluación del diseño}

La muestra estuvo integrada por 26 usuarios de silla de ruedas, 10 de ellos usuarios de silla de ruedas de estructura plegable y 16 usuarios de silla de ruedas de estructura rígida. Los requisitos de participación para esta fase de la investigación fueron los siguientes: a) ser usuario de silla de rueda de propulsión manual (de estructura plegable o rígida), b) no poseer discapacidad cognitiva y, c) tener más de 18 años. La distribución de los usuarios participantes por género y edad se describe en la Tabla 33.

\section{Tabla 33}

Distribución y edades promedio de la muestra de participantes en la evaluación emocional

\begin{tabular}{|c|c|c|c|c|}
\hline Tipo de silla de ruedas & \multicolumn{3}{|c|}{$\begin{array}{c}\text { Distribución de los participantes por } \\
\text { género }\end{array}$} & $\begin{array}{l}\text { Edad promedio } \\
\qquad(\bar{X})\end{array}$ \\
\hline \multirow{2}{*}{$\begin{array}{l}\text { Silla de ruedas de estructura } \\
\text { plegable }\end{array}$} & \multirow{2}{*}{$n=10$} & Hombres & 6 & 35.6 \\
\hline & & Mujeres & 4 & 36 \\
\hline \multirow{2}{*}{$\begin{array}{c}\text { Silla de ruedas de estructura } \\
\text { rígida }\end{array}$} & \multirow{2}{*}{$n=16$} & Hombres & 8 & 44.4 \\
\hline & & Mujeres & 8 & 47.13 \\
\hline
\end{tabular}




\subsection{Instrumento de la evaluación - Rueda Emocional de Ginebra (Geneva Emotion Wheel)}

En la medición de las respuestas emocionales debido a la interacción visual con las sillas de ruedas, se empleó la Rueda Emocional de Ginebra en su versión 2.0 (Ver Figura 32). Dicho instrumento es considerado una herramienta de medición válida y confiable, ya que se ha utilizado en diversas investigaciones (Mokdak, 2017). La Rueda Emocional de Ginebra está conformada por 20 pares de emociones dispuestas en forma circular en la cual, la persona que es evaluada indica la intensidad emocional que le provoca al interactuar con el objeto o entorno (Rebelo, 2019).

\subsection{Configuración experimental de la Evaluación emocional}

La evaluación emocional se llevó a cabo con tres modelos de silla de ruedas, la de estructura plegable, la de estructura rígida y la silla de ruedas diseñada a partir de las valoraciones de la satisfacción y la percepción de los usuarios. Según lo propuesto por Bertoncello y Gomes (2002), las tres sillas de ruedas clasifican en la categoría de sillas de ruedas de propulsión manual y de baja complejidad tecnológica.

Para el estudio, dichas sillas de ruedas fueron modeladas en SolidWorks y mediante este mismo software se realizó un video correspondiente a cada una de ellas. Los videos realizados mostraron cada modelo con dos giros de $360^{\circ}$ en los cuales los usuarios pudieron observar su diseño y cada uno de sus elementos. Asimismo, con el propósito de mantener un ambiente neutral y de no alterar las emociones ni causar cualquier tipo de predisposición en lo usuarios, en dichos videos se excluyeron todo tipo de melodías y no se especificaron las características técnicas de las sillas de ruedas.

\subsection{Procedimiento de la Evaluación Emocional}

Debido a la emergencia sanitaria ocasionada por la pandemia de la enfermedad del coronavirus COVID-19, la evaluación emocional del diseño propuesto se limitó estrictamente a los medios digitales llevándose a cabo mediante una modalidad virtual. Para lo anterior, en la realización del cuestionario se empleó la plataforma Google Forms y para la exhibición de los videos se usó YouTube. Con respecto a la búsqueda de personas voluntarias y con discapacidad motriz, se contó con la colaboración de 
FINDEDIS (Fundación para la Inclusión y Desarrollo de Personas con Discapacidad) de la Ciudad de México.

El formato de respuesta empleado para la evaluación emocional del diseño propuesto fue el de calificación forzada de todas las emociones estipuladas en la rueda, en la cual el usuario debe marcar la intensidad emocional de cada una de las emociones planteadas y esta puede ir de 0 (cero) siendo una intensidad nula a 5 (cinco) que representa una intensidad máxima. A su vez, se realiza una pregunta de carácter opcional donde el usuario puede mencionar otra emoción que no se encuentre en la rueda y que surgió en la interacción con el producto.

Por otro lado, es importante mencionar que los usuarios evaluaron el tipo de silla que usan y la silla de ruedas con el modelo propuesto, es decir, cada individuo evaluó dos tipos sillas de ruedas. La primera en ser evaluada fue la silla de la cual son usuarios y la segunda fue la silla con el modelo propuesto. De lo anterior, es importante destacar que, en el modelo propuesto solo fue evaluada la experiencia del usuario por medio de la percepción visual, en cambio, para las sillas de ruedas de propulsión manual de estructura rígida y de estructura plegable, la evaluación se vio influenciada por la experiencia del usuario y por el uso, ya que, en estos dos casos los usuarios tuvieron la oportunidad de usar previamente el producto.

\subsection{Procesamiento de datos de la Evaluación Emocional}

En análisis de los datos de la evaluación emocional se llevó a cabo mediante el software Microsoft Excel, en el cual los datos fueron organizados según el tipo de silla de ruedas que usaba la persona evaluada. Una vez que se organizaron los datos se llevó a cabo la obtención de valores promedio y la realización de las gráficas radiales.

\subsection{Resultados de la Evaluación Emocional}

Los resultados de la evaluación mediante la Rueda Emocional de Ginebra en los usuarios de la silla de ruedas de estructura plegable mostraron que las intensidades emocionales con relación a este tipo de silla de ruedas fueron inferiores en las emociones positivas con respecto al modelo propuesto. En cuanto a las emociones negativas, las reacciones emocionales de la silla de ruedas de estructura plegable 
fueron superiores a las del modelo de silla de ruedas propuesto excepto, en las emociones envidia/celos. Los valores promedios resultantes de la evaluación en los usuarios de silla de ruedas de estructura plegable se pueden detallar de manera gráfica en la Figura 33.

Con respecto a los resultados de la evaluación emocional de silla de ruedas de estructura rígida, en la mayoría de las emociones positivas se obtuvieron valores de intensidad levemente inferiores a los del modelo de silla de ruedas propuesto. Sin embargo, en todas las emociones negativas en los dos modelos de silla de rueda se obtuvieron valores de intensidad muy bajos y próximos entre sí, en los cuales sus diferencias pueden considerarse despreciables. Estos resultados se muestran en la Figura 34 .

\section{Figura 33}

Resultados de la evaluación emocional para los usuarios de la silla de ruedas de estructura plegable

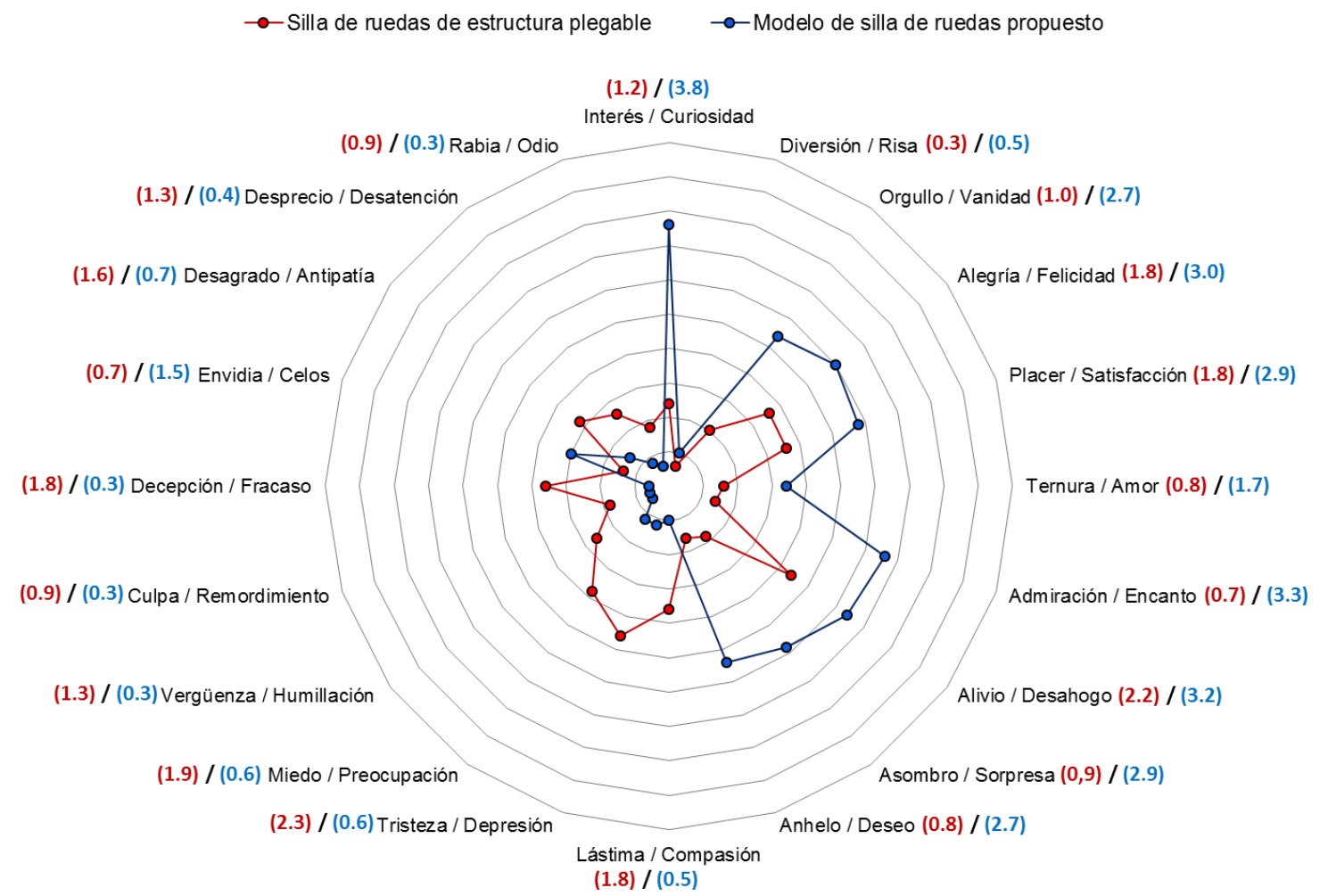




\section{Figura 34}

Resultados de la evaluación emocional para los usuarios de la silla de ruedas de estructura rígida.

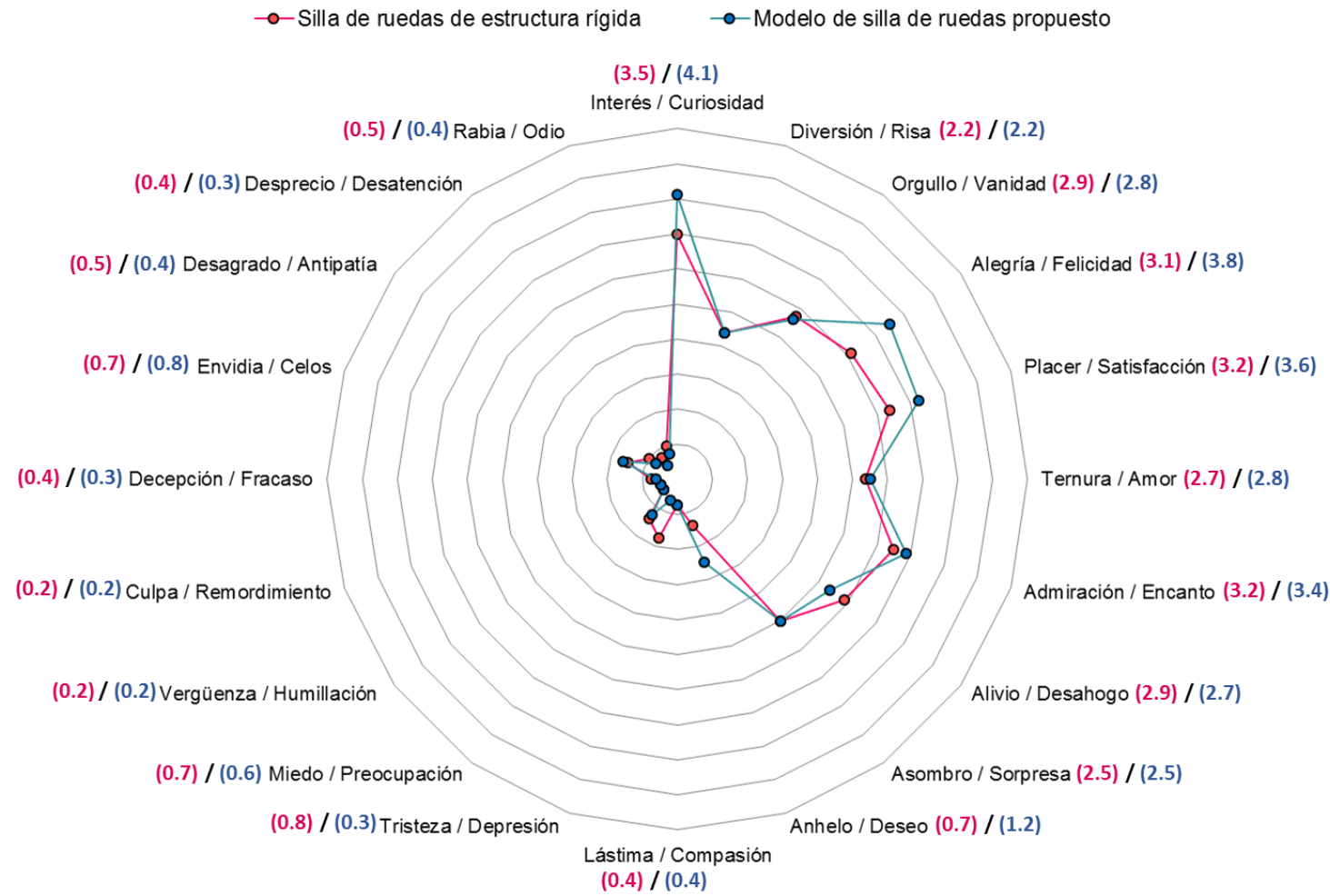

\subsection{Discusión de la evaluación emocional}

Teniendo en cuenta los resultados de la evaluación emocional de la silla de ruedas de estructura plegable, se evidenció que esta desató intensidades emocionales bajas en las emociones positivas e intensidades emocionales relativamente altas en las emociones negativas. Estos valores, presentaron diferencias considerables con los resultados del modelo de la silla de ruedas propuesto en esta investigación, ya que en esta se obtuvieron respuestas de emociones favorables en las emociones positivas, y respuestas emocionales muy bajas en las emociones negativas. Además, se debe mencionar que la diferencia más significativa en los resultados de los dos tipos de silla de ruedas citados anteriormente se encontró en el par de emociones interés / curiosidad. El anterior hallazgo coincide con los resultados obtenidos por Rebelo (2019) en los cuales, menciona que es posible despertar un mayor interés de las personas usuarias de sillas de ruedas, implementando diseños modernos ya que una silla de 
ruedas con un diseño de características innovadoras o fuera de lo convencional, evoca reacciones emocionales más positivas que los diseños tradicionales.

Asimismo, los resultados de la evaluación emocional de la silla de ruedas de estructura plegable concuerdan con los hallazgos obtenidos por Mokdad (2017) en los cuales, las intensidades emocionales fueron predominantes en las emociones negativas. Mokdad (2017), hace alusión a que dichas respuestas emocionales negativas pueden ser la consecuencia de problemas sociales como los prejuicios, la discriminación y el estigma social a la discapacidad. Sin embargo, con los hallazgos de Rebelo (2019) y los resultados de esta investigación se puede mencionar que las respuestas emocionales negativas también están relacionadas al tipo de diseño y a la atracción visual de la silla de ruedas, ya que los mismos usuarios de la silla de ruedas de estructura plegable, manifestaron respuestas emocionales favorables en el modelo propuesto. De lo anterior también se puede afirmar debido a que los usuarios de la silla de ruedas de estructura rígida mostraron reacciones emocionales muy bajas en las emociones negativas y favorables en las emociones positivas. Dichas reacciones emocionales positivas en este tipo de silla de ruedas aumentaron leve y favorablemente en el modelo de silla de ruedas propuesto, lo cual indica que las respuestas emocionales tienen una relación directa con la atracción visual, el tipo de diseño y las características físicas de la silla de ruedas. 


\section{CONCLUSIONES Y CONSIDERACIONES FINALES}

En este apartado, se hace una reflexión general en la que se abordan detalles del problema de investigación, de los objetivos planteados, de la metodología empleada, de los instrumentos usados en la recolección de la información y de los resultados obtenidos. Con respecto a la determinación de los requerimientos de diseño de la silla de ruedas de propulsión manual a partir de la satisfacción y percepción de los usuarios y teniendo en cuenta los resultados de la evaluación emocional, se puede mencionar que es un proceso fundamental en la mejoría de las ayudas técnicas. Es decir, que la opinión y participación de los usuarios en el diseño y desarrollo en este tipo de productos es de gran importancia, ya que repercute directamente en la satisfacción y percepción de estos. Al implementar este tipo de estrategias en la gestión del diseño, se demostró que es posible obtener resultados favorablemente perceptibles y cuantificables, lo cual indica que mediante esta metodología se puede obtener diseños de ayudas técnicas con mejores índices de satisfacción y percepción, que logren cumplir las expectativas de los usuarios.

En relación con los instrumentos utilizados, la entrevista estructurada, fue la herramienta que proporcionó la parte cualitativa en la investigación. En esta, se obtuvo información relacionada con la usabilidad y con la experiencia del usuario de la silla de ruedas de propulsión manual. También, fue un medio complementario ya que, basados en los resultados obtenidos de esta, se integró el factor de atracción visual para ser evaluado en la parte cuantitativa de la investigación. En los resultados de la entrevista, se evidenció que las preguntas que evaluaban cuestiones de usabilidad fueron contestadas con razonamientos enfocados a las características físicas de la silla de ruedas, tal como se observó en la literatura proveniente de previas investigaciones. Por otro lado, en aquellas preguntas que tenían como propósito profundizar en la experiencia del usuario (UX), se obtuvieron respuestas en las cuales estos manifestaron ciertas emociones. Sin embargo, dichas emociones en la mayoría de los casos estuvieron influenciadas por las características físicas de la silla de ruedas y las barreras en el espacio arquitectónico. La parte cualitativa de esta investigación lleva a plantear que, en las sillas de ruedas, las características de su diseño marcan una relación entre la usabilidad y la experiencia del usuario. No obstante, es importante 
mencionar que en esta ayuda técnica y para esta pesquisa, los resultados tendieron a mostrar que una mala usabilidad se asocia a una mala experiencia del usuario. Estos resultados son discordantes con los hallazgos de investigaciones previas, por ello, se sugiere plantear nuevos estudios con nuevas perspectivas y metodologías que logren explicar dichas diferencias y que puedan definir una relación más clara entre la usabilidad de la silla de ruedas y la experiencia del usuario (UX).

Respecto al cuestionario QUEST 2.0, este fue una herramienta muy útil el cual afirma su amplio uso en investigaciones con propósitos similares. Sin embargo, para esta investigación no se aplicó dicho cuestionario en su formato original, debido a que se agregó la atracción visual como un factor para evaluar las características físicas de la silla de ruedas. Lo anterior se debió a dos razones principales, la primera, porque se consideraron hallazgos de previas investigaciones en las cuales, los usuarios manifestaron cierta insatisfacción con la atracción visual de algunas ayudas técnicas. La segunda razón, se relaciona con los resultados de la entrevista estructurada aplicada en esta investigación, en la que algunos participantes mencionaron su inconformidad con la apariencia de la silla de ruedas. A partir de lo anterior, se puede deducir que el QUEST 2.0 es una herramienta de fácil adaptación y no necesariamente debe ser usada en su versión original, sino que brinda una estructura flexible que se ajusta a los propósitos particulares de cualquier investigación que busque cuantificar la satisfacción de los usuarios en cualquier ayuda técnica.

Los resultados obtenidos en el QUEST 2.0, indicaron que la silla de ruedas de estructura rígida obtuvo un valor final de satisfacción promedio de 4.21 y la silla de ruedas de estructura plegable un valor resultante fue de 3.06; a pesar de ser valores tan distantes el uno con respecto al otro, en ambos casos se registraron usuarios con cierta insatisfacción que se pudo observar en la sección de comentarios. Con estos, fue evidente conocer y entender que en ambos diseños de sillas de ruedas existen necesidades y problemas de usabilidad y de ergonomía no contemplados en el proceso de diseño de estas. La evaluación individual de cada uno de los factores considerados en el cuestionario reveló que el peso y la comodidad son las características que ocasionan mayor insatisfacción en los dos tipos de silla de ruedas. Asimismo, los dos factores anteriormente mencionados al igual que el factor durabilidad fueron los tres 
factores considerados de mayor importancia, considerados así por los mismos usuarios. Esto lleva a la reflexión, que independientemente del tipo de silla de ruedas y de sus características físicas, los usuarios presentan insatisfacción en las mismas singularidades del diseño y a su vez, comparten la misma opinión en cuantas aquellas características que deben de ser consideradas en el proceso de diseño y desarrollo de estas. Sin embargo, se requiere continuar explorando mediante estudios comparativos similares a este que ratifiquen o no los resultados obtenidos en esta investigación.

Mencionando los niveles de satisfacción de la silla de ruedas, se considera que las metodologías tal como la que se llevó a cabo en esta investigación en donde la satisfacción se abordó desde un enfoque mixto (cuantitativo y cualitativo), deben emplearse para el planteamiento de los requerimientos de diseño de las ayudas técnicas ya que se llevan a cabo mediante un enfoque del Diseño Centrado en el Usuario valorando la opinión, las preocupaciones y las necesidades reales de este. Lo anterior, con el propósito de mejorar los diseños existentes, y su vez, proponer nuevas soluciones que se adecuen a las expectativas del usuario logrando así, mejores índices de satisfacción. Otra razón por la cual dichas metodologías de este tipo deben ser llevadas a cabo, se debe a las sugerencias encontradas en la literatura y a los resultados de un gran número de estudios recientes, los cuales hacen un llamado a todos los involucrados en el diseño de este tipo de productos, para incorporar la opinión del usuario en diferentes y nuevas formas de abordar el diseño de estos. Teniendo en cuenta la considerable diferencia entre los niveles finales de satisfacción de los dos tipos de silla de ruedas, se propone un posible estudio futuro para obtener la cuantificación de la satisfacción en usuarios de los dos tipos de sillas de ruedas que no hayan adquirido la silla de ruedas mediante una donación, ya que esto pudo influir y ocasionar un sesgo en los resultados debido a que se interpone el sentimiento de agradecimiento. Esto se propone porque se descubrió en las respuestas de la entrevista estructurada realizada en esta investigación, que existe un predominio del sentimiento de agradecimiento en todos los usuarios.

Por otro lado, se aplicó la Escala de Diferencial Semántico como una herramienta para la cuantificación de la percepción. Esta demostró ser una herramienta de fácil y útil aplicación ya que permitió, relacionar la percepción con tres dimensiones del diseño 
(dimensión de la atracción visual, dimensión práctica y dimensión simbólica) en las cuales se contemplaron diversos atributos para el diseño. Los resultados de la escala de Diferencial Semántico dejaron en evidencia una relación entre la apariencia y la percepción negativa para el caso de la silla de ruedas de estructura plegable debido a que en los pares de atributos Atractivo/No atractivo y Moderno/Anticuado de la dimensión de atracción visual, obtuvieron puntajes bajos en comparación a los demás atributos evaluados. Esto se complementa y se confirma con los resultados obtenidos en los otros instrumentos empleados, en donde los usuarios manifestaron que el diseño, los materiales y la forma de este tipo de silla de ruedas están asociados con la enfermedad, la vejez, la discriminación y la infelicidad. Con respecto a los resultados de la silla de ruedas de estructura rígida, en la dimensión de atracción visual, esta no fue percibida de manera notablemente negativa, lo cual concuerda con las hipótesis de investigaciones previas donde se afirma que la apariencia de la silla de ruedas impacta en la forma de cómo esta es percibida, y cómo esto contribuye en el aumento o disminución del estigma social que padecen los usuarios de dicha ayuda técnica. Sin embargo, a pesar de lo anterior en la dimensión simbólica, el par de atributos con Tradicional/Innovador fue aquel que presentó el menor índice de percepción en la silla de ruedas de estructura rígida dejando al descubierto la necesidad de una posible mejora en su diseño.

De igual forma en la dimensión práctica, el par de atributos Lento/Rápido fue uno de los cuales tuvo un bajo índice de percepción en los dos tipos de silla de ruedas. Con esto, se afirma que la percepción está fuertemente influenciada por la experiencia del usuario y la usabilidad ya que el peso, fue un factor con niveles bajos de satisfacción en el cuestionario QUEST 2.0 y citado en varias ocasiones de forma negativa en la entrevista estructurada. Basados en los resultados de la dimensión práctica y su relación con la usabilidad, se sugiere como posibles estudios futuros contemplar como variable de estudio en la cuantificación de la percepción, el nivel de experiencia en el uso de la silla de ruedas y a su vez, tomar en cuenta si se tuvo o no entrenamiento para el uso de esta. Lo anterior, debido a que todos los usuarios de silla de ruedas de estructura plegable no tuvieron entrenamiento en el manejo de esta en comparación con los usuarios de silla de ruedas de estructura rígida que pasaron por un curso de 
entrenamiento, por lo tanto, existe la posibilidad de que esto pudo alterar los índices de percepción en la dimensión práctica generando así una gran diferencia entre los índices de percepción de los dos tipos de silla de ruedas.

Una vez que se identificaron los requerimientos de diseño, se procedió a modelar la propuesta de silla de ruedas de propulsión manual la cual se sometió a una simulación de esfuerzos mediante herramientas CAD/CAE. Del mismo modo, este modelo propuesto fue sometido a una evaluación emocional con el propósito de comprobar la eficacia de una metodología mixta en el diseño y desarrollo de ayudas técnicas. Dicha evaluación emocional se llevó a cabo por medio de la Rueda Emocional de Ginebra, y teniendo en cuenta los resultados de este instrumento, se puede afirmar que con el modelo propuesto se obtuvieron reacciones emocionales favorables con respecto a la silla de ruedas de estructura rígida y a la de estructura plegable, esto a su vez valida la metodología empleada para mejorar el diseño de ayudas técnicas. Asimismo, se plantea la hipótesis de que pequeños cambios realizados en el diseño de dichos productos, los cuales modifiquen y beneficien a la atracción visual, mejorarán la percepción de este ya que ocasiona respuestas emocionales positivas. A su vez, el uso de este instrumento sugiere o da lugar a que los diseñadores de productos para personas con discapacidad se planteen nuevas investigaciones y metodologías en las cuales se consideren las emociones como un factor de diseño que aporte información y se relacione con la usabilidad y la experiencia del usuario (UX).

Como un posible estudio futuros que aporte continuidad a esta investigación, se plantea la realización de un estudio donde se evalúe el uso de la silla de ruedas propuesta, para ello, es necesario construirla de tal forma que el usuario pueda manipular la silla de ruedas y sus mecanismos. Del mismo modo, se propone una investigación en la cual, una vez construido el prototipo de la silla de ruedas, se evalúe la percepción y satisfacción del usuario, usándola en espacios púbicos como las universidades. Lo anterior, con la intención de incorporar al diseño de las ayudas técnicas ciertos requerimientos que involucren los problemas de accesibilidad que presentan estos espacios.

Finalmente, la investigación buscó demostrar y aportar a la literatura actual la importancia de incorporar la satisfacción y percepción en el diseño y desarrollo de 
productos, especialmente en aquellos que tienen como propósito mejorar la calidad de vida de las personas con discapacidad. A su vez, el presente estudio demostró que mediante este tipo de metodologías se mejoran dichos productos, logrando que estos provoquen reacciones emocionales positivas. Lo anterior, lleva a reflexionar que un cambio de perspectiva metodológica en el diseño de ayudas técnicas puede influenciar de manera favorable en la autoestima de la persona con discapacidad. 


\section{REFERENCIAS}

- $\quad$ Abreu e Lima, C. E., Nascimento, G. R., Fontana, L. G., Colla, V., Rustik, A., Becker Júnior, R. C., y Cecconello Machado, A. A. (2016). Projeto de uma cadeira de rodas utilizando metodologia projetual. Revista de Extensão da Universidade de Cruz Alta, 8(1), 152-168. http://revistaeletronica.unicruz.edu.br/index.php/Cataventos/article/view/4037/857

- $\quad$ Alcantud Marín, F., y Soto Pérez, F. J. (2003). Tecnologías de ayuda en personas con trastornos de comunicación. Nau Llibres.

- Almenara, M. (2018). Modelo teórico-práctico para la implementación del diseño centrado en el usuario en el desarrollo, la validación y la aceptación de los productos de apoyo para personas con enfermedades de origen neurológico. [Doctorado]. Universidad Autónoma de Barcelona.

- Ansys. (2021). Ansys Granta EduPack. https://www.ansys.com/products/materials/granta-edupack

- $\quad$ Ashby, M., Johnson, K., Marques, A. S., Tinoco, Á., y Roberto, M. M. (2011). Materiais e Design: Arte e Ciência da seleção de materiais no de Produto. http://www.sciencedirect.com/science/book/9788535238426

- Bane, H. M., Sheafer, V., y Rispin, K. (2019). Face and content validity for the Wheelchair Satisfaction Questionnaire. Disability and Rehabilitation: Assistive Technology, 1-5. https://doi.org/10.1080/17483107.2019.1684579

- $\quad$ Bertoncello, I., y Gomes, L. V. N. (2002). Análise diacrônica e sincrônica da cadeira de rodas mecanomanual. Production, 12(1), 72-82. https://doi.org/10.1590/S010365132002000100007

- Boiani, J. A. (2018). Design e Tecnologia Assistiva: Avaliação da mobilidade, satisfação e semântica de andador para idosos. [Maestría]. Universidade Estadual Paulista.

- $\quad$ Bonsiepe, G. (1999). Del objeto a la interface. Mutaciones del diseno. Ediciones Infinito.

- Cabero-Almenara, J., Fernandez-Batanero, J. M., y Córdoba-Perez, M. (2016). Conocimiento de las TIC aplicadas a las personas con discapacidades. Construcción de un instrumento de diagnóstico. magis, Revista Internacional de Investigación en Educación, 8(17), 157-176. https://doi.org/10.11144/Javeriana.m8-17.ctap 
- Carneiro, L., Rebelo, F., Filgueiras, E., y Noriega, P. (2015). Usability and User Experience of Technical Aids for People with Disabilities? A Preliminary Study with a Wheelchair. Procedia Manufacturing, 6068-6074. https://doi.org/10.1016/j.promfg.2015.07.736

- $\quad$ Carneiro, L., Rebelo, F., y Noriega, P. (2019). Different wheelchairs designs influence emotional reactions from users and non-users? Advances in Ergonomics in Design. AHFE 2018. Advances in Intelligent Systems and Computing., 777, 572-580. https://doi.org/10.1007/978-3-319-94706-8_60

- Carneiro, L. T. (2018). O impacto do Design da Cadeira de Rodas na Experiência de Utilização e na Perceção do Estigma [Doctorado]. Universidad de Lisboa.

- $\quad$ Caro, C. C., y Cruz, D. M. C. da. (2020). Treinamento de habilidades com cadeiras de rodas manuais: Uma revisão integrativa da literatura. Cadernos Brasileiros de Terapia Ocupacional, 28(2), 661-681. https://doi.org/10.4322/2526-8910.ctoAR1863

- Carrasco-Zannini Rincón, J., Montellano Tolosa, C., Moore, J., Scolari, C. A., Stolarski, A., Tapia Mendoza, A., Álvarez Tamayo, D., Ceja Bravo, A., Del Valle Romero, C., Garcia Melgarejo, M., Hernández González, M., Morales Campos, A., Rivera Díaz, L. A., Rodríguez Alvarez, F., Romero González, M., Sánchez Ramos, M. E., y Torres Rios, J. (2009). El diseño y sus usuarios: De la forma a la interacción. Encuadre.

- $\quad$ Chacon-Cifuentes, P., Zuleta, A. A., Sevilla, G., Valencia-Escobar, A., Correa-Bedoya, E., y Echeverria-Echeverria, F. (2020). Human Factors in All-Terrain Wheelchair Design for Rural Population. En T. Ahram y C. Falcão (Eds.), Advances in Usability and User Experience (Vol. 972, pp. 899-910). Springer International Publishing. https://doi.org/10.1007/978-3-03019135-1_88

- Cook, A. M., y Polgar, J. M. (2014). Assistive Technologies- E-Book: Principles and Practice. Elsevier Health Sciences.

- Costa, P. C. da R. (2012). O Design de Costumização das Cadeiras de Rodas [Doctorado]. Universidade Técnica de Lisboa.

- Crepaldi, C., y Santos, C. T. dos. (2018). Abordagens metodológicas do design emocional: Uma revisão bibliográfica sistemática. Human Factors in Design, 7(14), 74-94. https://doi.org/10.5965/2316796307142018074 
- $\quad$ da Silva, J. C. R. P., Paschoarelli, L. C., Friso, V. R., y da Silva, J. C. P. (2019). The Development of an Online Questionnaire for End Users About the Visual Perception of Informational Ergonomics and Its Attributes in Graphic Brands. En T. Z. Ahram y C. Falcão (Eds.), Advances in Usability, User Experience and Assistive Technology (Vol. 794, pp. 615622). Springer International Publishing. https://doi.org/10.1007/978-3-319-94947-5_62

- $\quad$ Dombrowski, E., Rotenberg, L., y Bick, M. (2015). Programa del Diploma del IB Oxford: IB Teoría del Conocimiento Libro del Alumno (Edición en español). Oxford University Press.

- Domingues, I., Pinheiro, Silveira, J., Francisco, P., Jutai, J., y Martins, A. (2019). Psychosocial Impact of Powered Wheelchair, Users' Satisfaction and Their Relation to Social Participation. Technologies, 7(4), 73. https://doi.org/10.3390/technologies7040073

- $\quad$ Ebrahimi, A., Kazemi, A., y Ebrahimi, A. (2016). Review Paper: Wheelchair Design and Its Influence on Physical Activity and Quality of Life Among Disabled Individuals. Iranian Rehabilitation Journal, 14(2), 85-92. https://doi.org/10.18869/nrip.irj.14.2.85

- Gómez-Beleño, G. E., y López-Muñoz, J. S. (2016). Tecnología de asistencia para la inclusión educativa de personas con parálisis cerebral: Una revisión crítica de la literatura. Rehabilitación, 50(2), 87-94. https://doi.org/10.1016/j.rh.2016.01.001

- Herrera, A. (2016). Triz como una herramienta en el diseño conceptual de una silla de ruedas innovadora [Maestría]. Universidad Nacional Autonoma de México.

- Herrera-Saray, P., Peláez-Ballestas, I., Ramos-Lira, L., Sánchez-Monroy, D., y BurgosVargas, R. (2013). Problemas con el uso de sillas de ruedas y otras ayudas técnicas y barreras sociales a las que se enfrentan las personas que las utilizan. Estudio cualitativo desde la perspectiva de la ergonomía en personas discapacitadas por enfermedades reumáticas y otras condiciones. Reumatología Clínica, 9(1), 24-30. https://doi.org/10.1016/j.reuma.2012.05.010

- Holdschip, R. (2015). Design \& Semântica: Investigação de técnicas estatísticas para auxílio no projeto de produto. [Maestría]. Universidade Estadual Paulista.

- INEGI. (2017). La discapacidad en México, datos al 2014: Versión 2017. Instituto Nacional de Estadística y Geografía. http://internet.contenidos.inegi.org.mx/contenidos/Productos/prod_serv/contenidos/espanol/bvin egi/productos/nueva_estruc/702825094409.pdf 
- INEGI. (2020a). Censo de Población y Vivienda 2020: Resultados complementarios. https://www.inegi.org.mx/contenidos/programas/ccpv/2020/doc/Censo2020_Resultados_comple mentarios_EUM.pdf

- INEGI. (2020b). Panorama sociodemográfico de México: Censo de Población y Vivienda 2020.

https://www.inegi.org.mx/contenidos/productos/prod_serv/contenidos/espanol/bvinegi/productos /nueva_estruc/702825197711.pdf

- $\quad$ INEGI. (2021). Así se contó México.

https://www.inegi.org.mx/contenidos/productos/prod_serv/contenidos/espanol/bvinegi/productos /nueva_estruc/702825007046.pdf

- International Society for Prosthetics and Orthotics, United States Agency for International Development, y World Health Organization. (2006). Report of a Consensus Conference on Wheelchairs for Developing Countries.

- Lancioni, G., Sigafoos, J., O'Reilly, M., y Singh, N. (2013). Assistive technology: Interventions for individuals with severe/profound and multiple disabilities. Springer.

- Lanutti, J. N. de L. (2019). Compreensão dos aspectos emocionais em diferentes Cadeiras de Rodas: Uma contribuição para o Design Ergonômico e Inclusivo [Doctorado]. Universidade Estadual Paulista.

- $\quad$ Lanutti, J. N. L., Medola, F. O., Gonçalves, D. D., da Silva, L. M., Nicholl, A. R. J., y Paschoarelli, L. C. (2015). The Significance of Manual Wheelchairs: A Comparative Study on Male and Female Users. Procedia Manufacturing, 3, 6079-6085. https://doi.org/10.1016/j.promfg.2015.07.752

- $\quad$ Leal, L. E. A. M., y Silva, R. R. da. (2018). Desenvolvimento de uma handbike de baixo custo. Revista Tecnológica da Universidade Santa Úrsula, 1(1), 100-113.

- $\quad$ Lida, I., y Buarque, L. (2016). Ergonomia: Projeto e produção. Blucher.

- Lima Barroso, B. (2018). Adaptação transcultural do modelo prática baseada em evidência na Tecnologia Assistiva para a língua portuguesa (Brasil) [Doctorado]. Universidade de São Paulo.

- $\quad$ Linhares, R., y Pereira, K. (2017). A discussion about the design utility through the emotional focus. Revista Poliedro, 1, 101-111. 
- $\quad$ Löbach, B. (2001). Design industrial: Bases para a configuração dos produtos industriais (1a ed.). Edgard Blücher.

Lopes, F. L., de Amorim, H. A., y Kunkel, M. E. (2019). Structural Analysis with Finite Element Method of a Child Electric Wheelchair Built with PVC and Arduino. En R. Costa-Felix, J. C. Machado, y A. V. Alvarenga (Eds.), XXVI Brazilian Congress on Biomedical Engineering (Vol. 70/1, pp. 717-721). Springer Singapore. https://doi.org/10.1007/978-981-13-2119-1_110

Maës, L. (2016). Sillas de ruedas. EMC - Kinesiterapia - Medicina Física, 37(3), 1-9. https://doi.org/10.1016/S1293-2965(16)78904-3

- $\quad$ Magnusson, L., y Ahlström, G. (2017). Patients' Satisfaction with Lower-limb Prosthetic and Orthotic Devices and Service delivery in Sierra Leone and Malawi. BMC Health Services Research, 17(1), 102-113. https://doi.org/10.1186/s12913-017-2044-3

- $\quad$ Magnusson, L., Ahlström, G., Ramstrand, N., y Fransson, E. (2013). Malawian prosthetic and orthotic users' mobility and satisfaction with their lower limb assistive device. Journal of Rehabilitation Medicine, 45(4), 385-391. https://doi.org/10.2340/16501977-1117

- $\quad$ Mallin, S. S. V., y Carvalho, H. G. de. (2015). Assistive Technology and User-Centered Design: Emotion as Element for Innovation. Procedia Manufacturing, 3, 5570-5578. https://doi.org/10.1016/j.promfg.2015.07.738

- Manzano-Hernandez, P., Trotta, M. G., Aceves-Gonzalez, C., Rossa-Sierra, A., y Cortes-Chavez, F. (2020). User Attitudes Towards Wheelchairs: A Mexican Case Study with Special Focus on Vulnerable Wheelchair Users and Wheelchair Assistants. En G. Di Bucchianico (Ed.), Advances in Design for Inclusion (Vol. 954, pp. 282-291). Springer International Publishing. https://doi.org/10.1007/978-3-030-20444-0_27

- Marchiori, C., Bensmail, D., Gagnon, D., y Pradon, D. (2015). Manual wheelchair satisfaction among long-term users and caregivers: A French study. The Journal of Rehabilitation Research and Development, 52(2), 181-192. https://doi.org/10.1682/JRRD.2014.04.0092

- Marín, M., Muccio, L., Lanutti, J., Orci, F., y Paschoarelli, L. C. (2015, octubre). Avaliação de percepção estética, simbólica e de uso de cadeiras de rodas manuais. Fourth International Conference on Integration of Design, Engineering and Management for innovation, Florianópolis, Brasil. 
- $\quad$ Marín-Vásquez, M. (2017). Avaliação de percepção de produtos destinados às pessoas com capacidades específicas (usuários de cadeiras de rodas): Tecnologia Assistiva e Design Ergonômico [Maestría]. Universidade Estadual Paulista.

Marques, L. S., Magalhães, R. R., de Lima, D. A., Tsuchida, J. E., Fuzzato, D. C., y de Andrade, E. T. (2020). Finite element analysis of a commercial wheelchair. Disability and Rehabilitation: Assistive Technology, 1-12. https://doi.org/10.1080/17483107.2020.1749893

- $\quad$ Martín-Trueba, T. (2017). La Bauhaus: Diseños tipológicos mobiliario (sillas y sillones) y su aplicabilidad social en el mundo del cine y la publicidad [Maestría, Universidad de las Palmas de Gran Canaria]. http://hdl.handle.net/10553/23011

- Mattozo, T. (2016). Tecnologia assistiva: Identificação dos requisitos do produto de órteses para membros inferiores_Uma visão a partir das percepções dos usuários. [Maestría]. Universidade Federal de Santa Catarina.

- McGinn, C., y Kelly, K. (2018). Using the Geneva Emotion Wheel to Classify the Expression of Emotion on Robots. Companion of the 2018 ACM/IEEE International Conference on Human-Robot Interaction, 191-192. https://doi.org/10.1145/3173386.3177058

- Medola, F., Gama, S., Elui, V., Paschoarelli, L., y Fortulan, C. (2014, julio 19). Users' Perceptions on Mobility, Comfort and Usability of Manual Wheelchairs. 5th International Conference on Applied Human Factors and Ergonomics AHFE 2014, Kraków, Poland.

- Merino, G. S. A. D. (2016). GODP- Guia de orientação para Desenvolvimento de Projetos: Uma metodologia de Design Centrado no Usuário. Ngd/UFSC. http://www.ngd.ufsc.br

- $\quad$ Mokdad, M., Mebarki, B., Bouabdellah, L., y Mokdad, I. (2017). Emotional Responses of the Disabled Towards Wheelchairs. En W. Chung y C. S. Shin (Eds.), Advances in Affective and Pleasurable Design (Vol. 585, pp. 86-96). Springer International Publishing. https://doi.org/10.1007/978-3-319-60495-4_10

- Mora Barrera, C. A. (2010). Validación de la versión en español de la evaluación de Quebec de usuarios con tecnología de asistencia (Quest 2.0) [Especialización]. Universidad Nacional de Colombia.

- $\quad$ Norman, D. A. (2008). Design emocional: Por que adoramos (ou detestamos) os objetos do dia-a-dia. Rocco. 
- $\quad$ Olmedo Torre, N., Ivern Cacho, J., y Perez Poch, A. (2016). Diseño mecánico de una silla de ruedas con superación de obstáculos. DYNA INGENIERIA E INDUSTRIA, 91(1), 161165. https://doi.org/10.6036/7669

- Organización Mundial de la Salud. (2008). Guidelines on the provision of manual wheelchairs in less-resourced settings.

- Organización Mundial de la Salud (Ed.). (2011a). Informe mundial sobre la discapacidad. World Health Organization.

- $\quad$ Organización Mundial de la Salud. (2011b). Joint position paper on the provision of mobility devices in less-resourced settings: A step towards implementation of the Convention on the Rights of Persons with Disabilities (CRPD) related to personal mobility. https://www.who.int/disabilities/publications/technology/jpp_final.pdf

- $\quad$ Organización Mundial de la Salud. (2014). Opening the GATE for Assistive Health Technology: Shifting the paradigm. https://www.who.int/phi/implementation/assistive_technology/concept_note.pdf

- Organización Mundial de la Salud. (2017). Mejora del acceso a la tecnología de asistencia: Informe del general (EB142/21). https://apps.who.int/iris/handle/10665/274141

- Organización Mundial de la Salud. (2018). Tecnologia de Asistencia. https://www.who.int/es/news-room/fact-sheets/detail/assistive-technology

- $\quad$ Organización Panamericana de la Salud. (2006). Discapacidad: Lo que todos debemos saber. Biblioteca Sede OPS.

- $\quad$ Panero, J., y Zelnik, M. (1996). Las dimensiones humanas en los espacios interiores (Septima edición). Ediciones G. Giii.

- $\quad$ Pichler, R. F., y Merino, G. S. (2017). Assistive technology projects with user-centered approach: Diagrams of product-user-context interactions. Revista Educação Gráfica, 12(3), 192-212.

- $\quad$ Prado-Leon, L. R., Avila-Chaurand, R., y Gonzalez-Munoz, E. L. (2007). Dimensiones antropometricas de poblacion latinoamerica (2. Aufl). Universidad.

- Ravneberg, B., y Söderström, S. (2017). Disability, society and assistive technology. Routledge, Taylor \& Francis Group. 
- $\quad$ Requejo, P. S., Furumasu, J., y Mulroy, S. J. (2015). Evidence-Based Strategies for Preserving Mobility for Elderly and Aging Manual Wheelchair Users: Topics in Geriatric Rehabilitation, 31(1), 26-41. https://doi.org/10.1097/TGR.0000000000000042

Rossi, M. C., Orsi Medola, F., Augusto Costa, F., Soares, L., Delsim, J. C., Mercaldi Rafani, S., Carril Elui, V. M., y da Silva Santana, C. (2010). Satisfação do usuário de tecnologia assistiva. Fisioterapia Brasil, 11(4), 304-308.

Saffer, D. (2010). Designing for Interaction: Creating Innovative Applications and Devices. New Riders.

- Salmerón, L., Fajardo, I., y Cañas, J. (2004). Sobre la relación entre la ergonomía y psicología cognitiva. Anuario de Psicología de la Universidad de Barcelona, 35(4), 507-519.

- Scolari, C. A. (2021). Las Leyes de la interfaz: Diseño, Ecología, Evolución, Tecnología. Gedisa Editorial.

- Secomand, F. (2015). O artefato irredutível: Em busca de novos ideais para o design de interfaces. Revista Ergodesign \& $\mathrm{HCl}, 3(1), 22-29$.

- Silva, W. (2019). SINTO, LOGO EXISTO: validação de um modelo para análise do design emocional [Tesis de Doctorado, Universidade Federal de Pernambuco]. https://repositorio.ufpe.br/handle/123456789/34024

- Silva, W., y Cavalcanti, V. (2015, septiembre). Modelo de Análise do Design emocional aplicado ao desenvolvimento de produtos de moda. $11^{\circ}$ Colóquio de Moda, $8^{a}$ Edição Internacional, Curitiba, Brasil.

- Soares, J., Fontes, A., Ferrarini, C., Borras, M., y Braatz, D. (2017). Tecnologia Assistiva: Revisão de aspectos relacionados ao tema. Revista Espacios, 38(13), 8-23.

- S Stefanac, S., Grabovac, I., y Fristedt, S. (2018). Wheelchair Users' Satisfaction with the Prescribed Wheelchairs and Wheelchair Services in Croatia. Collegium antropologicum Journal of the Croatian Anthropological Society, 42(3), 101-112.

- Sumner, E., O'Connell, C., y MacAlpine, B. (2017). Wheelchair donation in a lowresources setting: Utilization, challenges and benefits of wheelchairs provided through a specialized seating programme in Haiti. Journal of Rehabilitation Medicine, 49(2), 178-184. https://doi.org/10.2340/16501977-2186

- Sutradhar, A., Sunny, Md. S. H., Mandal, M., y Ahmed, R. (2017). Design and construction of an automatic electric wheelchair: An economic approach for Bangladesh. 2017 
3rd International Conference on Electrical Information and Communication Technology (EICT), 1-5. https://doi.org/10.1109/EICT.2017.8275159

- Urquieta-Salomón, J., Figueroa, y Hernández-Prado, B. (2008). El gasto público en salud relacionado con la población de discapacidad. Un análisis en población sobre México. Salud pública de México, 50(2), 136-146.

- $\quad$ Visagie, S., Mlambo, T., Van der Veen, J., Nhunzvi, C., Tigere, D., y Scheffler, E. (2015). Is any wheelchair better than no wheelchair? A Zimbabwean perspective. African Journal of Disability, 4(1). https://doi.org/10.4102/ajod.v4i1.201

- $\quad$ Williams, E., Hurwitz, E., Obaga, I., Onguti, B., Rivera, A., Sy, T. R. L., Kirby, R. L., Noon, J., Tanuku, D., Gichangi, A., y Bazant, E. (2017). Perspectives of basic wheelchair users on improving their access to wheelchair services in Kenya and Philippines: A qualitative study. BMC International Health and Human Rights, 17(1), 22. https://doi.org/10.1186/s12914-0170130-6

- Zolotova, M., y Giambattista, A. (2019). Designing Cognitive Ergonomics Features of Medical Devices. Aspects of Cognitive Interaction. The Design Journal, 22(sup1), 463-474. https://doi.org/10.1080/14606925.2019.1595432 


\title{
9. ANEXOS
}

\section{ANEXO A. Consentimiento Informado}

\author{
Universidad \\ Autónoma \\ Metropolitana \\ Casa abierta al tiempo Azcapotzalco
}

Ciudad de México, de de 2019

\section{CONSENTIMIENTO INFORMADO}

Por este medio, me permito comunicar a usted que el alumno José David Rojas Anaya, inscrito en la Maestría de Diseño y Desarrollo de Productos, del sistema de Posgrados de la División de Ciencias y Artes para el Diseño, de la Universidad Autónoma Metropolitana, Unidad Azcapotzalco; requiere llevar a cabo la realización de esta encuesta y entrevista para su proyecto de investigación titulado "Rediseño de la silla de ruedas convencional a partir de la percepción y satisfacción de los usuarios con discapacidad motriz". Dicho trabajo está siendo dirigido por la Mtra. Areli García González.

Para lo anterior, se solicita de su CONSENTIMIENTO, quien voluntaria y conscientemente da su autorización para llevar a cabo a su nombre las encuestas, entrevistas y registro fotográfico necesario para la recolección de la información de este proyecto. Asimismo, acepta que recibió una explicación clara y completa de los propósitos académicos de esta investigación. La información obtenida se usará con estricta CONFIDENCIALIDAD y sólo con fines académicos y divulgación en foros, congresos, exposiciones, presentaciones públicas, a través de medios electrónicos y/o impresos.

Yo, declaro hacer sido informado y voluntariamente acepto participar en el proyecto de investigación anteriormente mencionado.

Firma del participante

Jose David Rojas Anaya

Responsable de la investigación

Mtra. Areli García González

Directora de la investigación 


\section{ANEXO B. Cuestionario QUEST 2.0, versión en español}

\section{Evaluación de la Satisfacción del Usuario con Tecnología de Aparatos Auxiliares. Encuesta Québec}

\section{QUEST (Versión 2.0) en español}

Fecha:

Nombre o pseudónimo del usuario:

Edad: $\quad$ Género: ( ) Mujer ( ) Hombre

Tipo o modelo de silla:

Hace cuánto tiempo usa la silla de ruedas:

Patología o causa:

Régimen de seguridad social: ( ) Privada （ ) Pública

El objetivo de esta encuesta es evaluar su satisfacción con la silla de ruedas que usa y con los servicios relacionados. La encuesta consta de 12 preguntas.

- Para cada una de las preguntas, marque su nivel de satisfacción (que tan complacido está con la silla de ruedas y con los servicios relacionados) usando la siguiente escala de 1 a 5

\begin{tabular}{|c|c|c|c|c|}
\hline $\mathbf{1}$ & $\mathbf{2}$ & $\mathbf{3}$ & $\mathbf{4}$ & $\mathbf{5}$ \\
\hline Nada & No muy & Más o menos \\
Satisfecho & Satisfecho & Satisfecho & Muy Satisfecho \\
\hline
\end{tabular}

- Marque por favor con un círculo el número que describe mejor su grado de satisfacción, en cada una de las 12 preguntas.

- No deje preguntas sin responder

- Si su respuesta es 1, 2, 3 o 4 en algunas de las preguntas, por favor escriba en la sección de comentarios el por qué. 


\begin{tabular}{|c|c|c|c|c|}
\hline $\mathbf{1}$ & $\mathbf{2}$ & $\mathbf{3}$ & $\mathbf{4}$ & $\mathbf{5}$ \\
\hline Nada Satisfecho & $\begin{array}{c}\text { No muy } \\
\text { Satisfecho }\end{array}$ & $\begin{array}{c}\text { Más o menos } \\
\text { Satisfecho }\end{array}$ & Satisfecho & Muy Satisfecho \\
\hline
\end{tabular}

\section{DISPOSITIVO}

Qué tan satisfecho está con lo siguiente:

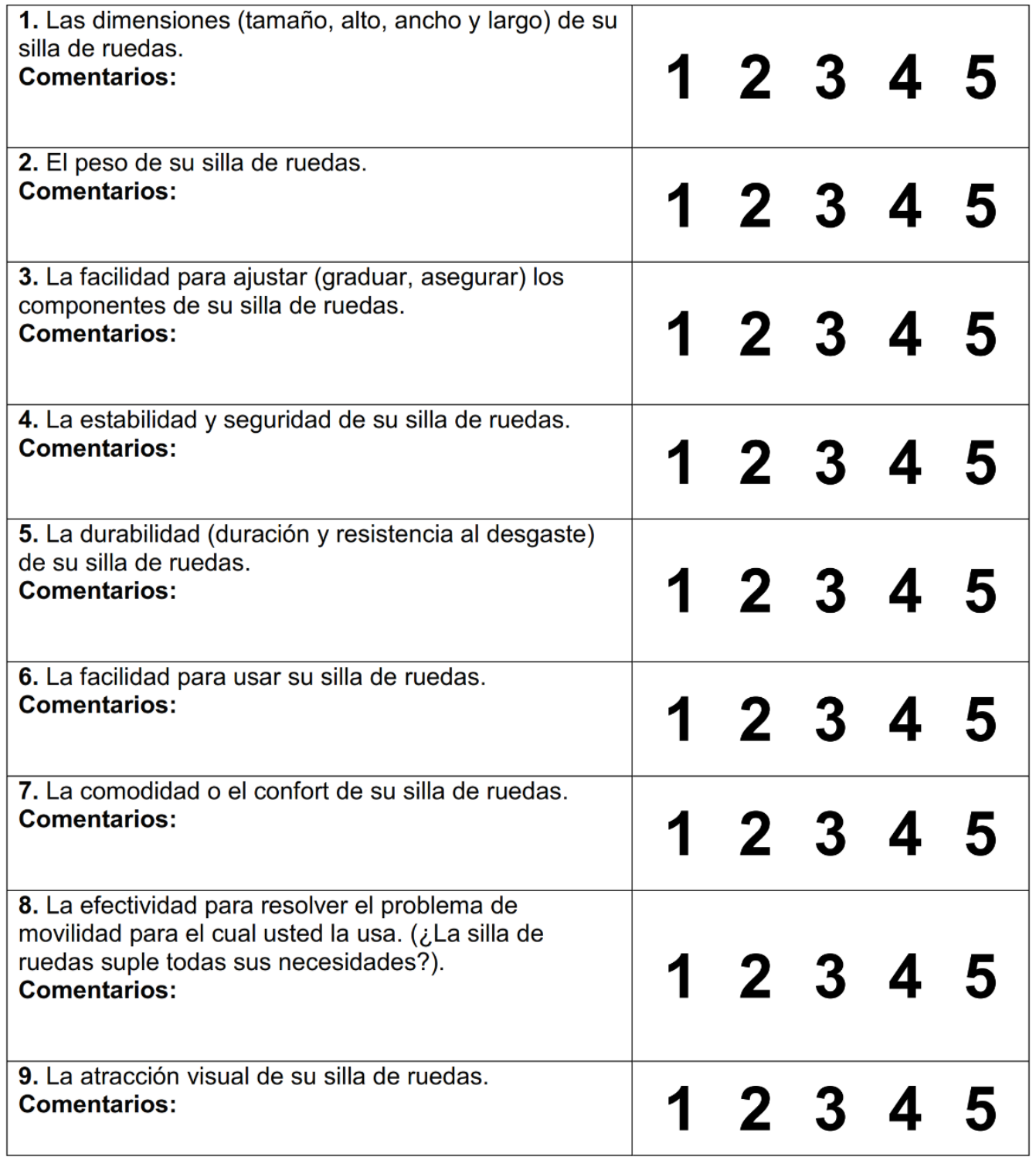




\begin{tabular}{|c|c|c|c|c|}
\hline $\mathbf{1}$ & $\mathbf{2}$ & $\mathbf{3}$ & $\mathbf{4}$ & $\mathbf{5}$ \\
\hline Nada Satisfecho & $\begin{array}{c}\text { No muy } \\
\text { Satisfecho }\end{array}$ & $\begin{array}{c}\text { Más o menos } \\
\text { Satisfecho }\end{array}$ & Satisfecho & Muy Satisfecho \\
\hline
\end{tabular}

\section{SERVICIOS}

$\begin{aligned} & \text { 10. ¿Qué tan satisfecho está usted con la reparación y } \\ & \text { el mantenimiento de su silla de ruedas? } \\ & \text { Comentarios: }\end{aligned}$
$\begin{aligned} & \text { 11. ¿Qué tan satisfecho se encuentra usted con la } \\ & \text { calidad de los servicios profesionales (información, } \\ & \text { atención y capacitación) que usted recibió para utilizar } \\ & \text { su silla de ruedas? } \\ & \text { Comentarios: }\end{aligned}$
$\begin{aligned} & \text { 12. ¿Qué tan satisfecho está usted con el servicio de } \\ & \text { seguimiento (servicio de soporte permanente) que } \\ & \text { usted recibió para su silla de ruedas? } \\ & \text { Comentarios: }\end{aligned}$

\section{PREGUNTA ADICIONALES}

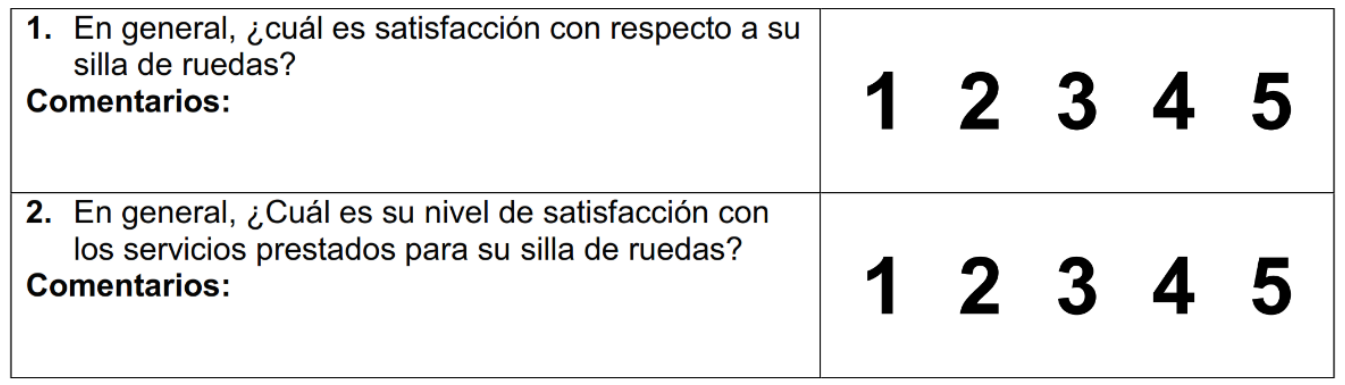


A continuación encontrará la lista de las 12 preguntas anteriores sobre satisfacción.

POR FAVOR SELECCIONE LAS TRES que considere más importantes y márquelas con una $\mathbf{X}$.

\begin{tabular}{|l|l|l|l|}
\hline & 1. Dimensiones & 7. Comodidad \\
\hline & 2. Peso & & 8. Efectividad \\
\hline 3. Ajuste & & 9. Atracción visual \\
\hline & 4. Seguridad & 10. Reparación y mantenimiento \\
\hline 5. Durabilidad & 11. Asistencia profesional \\
\hline 6. Facilidad de uso & $\begin{array}{l}\text { 12. Servicio de acompañamiento } \\
\text { continuo }\end{array}$ \\
\hline
\end{tabular}

\section{SECCIÓN DE PUNTAJE}

\section{Esta SECCIÓN es para el puntaje de sus respuestas NO ESCRIBA EN ELLA}

\begin{tabular}{|c|l|}
\hline Número de respuestas no válidas. & \\
\hline Subescala de la silla de ruedas. & \\
\hline Puntaje total del QUEST & \\
\hline $\begin{array}{c}\text { Las 3 preguntas más importantes de } \\
\text { satisfacción }\end{array}$ & 1. \\
\end{tabular}




\section{ANEXO C. Escala Diferencial Semántico}

\section{Escala Diferencial Semántico}

A partir del diseño de su silla de ruedas, considere cada una de las características presentadas. En un extremo se presentan características favorables de su silla de ruedas y en el otro extremo, características totalmente opuestas. Marque en uno de los círculos su evaluación considerando que cuanta más cerca esté a una característica, mayor es su concordancia con esta.

\begin{tabular}{|c|c|c|c|c|c|c|c|c|}
\hline-3 & & 1 & & 0 & & 1 & & 3 \\
\hline & -3 & -2 & -1 & 0 & 1 & 2 & 3 & \\
\hline No Atractiva & 0 & 0 & 0 & 0 & 0 & 0 & 0 & Atractiva \\
\hline Anticuada & 0 & 0 & 0 & 0 & 0 & 0 & 0 & Moderna \\
\hline $\begin{array}{r}\text { Difícil de } \\
\text { transportar }\end{array}$ & 0 & 0 & 0 & 0 & 0 & 0 & 0 & Fácil de transportar \\
\hline No personalizable & 0 & 0 & 0 & 0 & 0 & 0 & 0 & Personalizable \\
\hline Insatisfactoria & 0 & 0 & 0 & 0 & 0 & 0 & 0 & Satisfactoria \\
\hline Complicada & 0 & 0 & 0 & 0 & 0 & 0 & 0 & Simple \\
\hline Insegura & 0 & 0 & 0 & 0 & 0 & 0 & 0 & Segura \\
\hline Difícil de usar & 0 & 0 & 0 & 0 & 0 & 0 & 0 & Fácil de usar \\
\hline Incomoda & 0 & 0 & 0 & 0 & 0 & 0 & 0 & Cómoda \\
\hline $\begin{array}{r}\text { Difícil } \\
\text { mantenimiento }\end{array}$ & 0 & 0 & 0 & 0 & 0 & 0 & 0 & $\begin{array}{l}\text { Fácil } \\
\text { mantenimiento }\end{array}$ \\
\hline Frágil & 0 & 0 & 0 & 0 & 0 & 0 & 0 & Resistente \\
\hline Lenta & 0 & 0 & 0 & 0 & 0 & 0 & 0 & Rápida \\
\hline Frustrante & 0 & 0 & 0 & 0 & 0 & 0 & 0 & Motivadora \\
\hline Excluyente & 0 & 0 & 0 & 0 & 0 & 0 & 0 & Inclusiva \\
\hline Negativa & 0 & 0 & 0 & 0 & 0 & 0 & 0 & Positiva \\
\hline Introvertida & 0 & 0 & 0 & 0 & 0 & 0 & 0 & Sociable \\
\hline Improductiva & 0 & 0 & 0 & 0 & 0 & 0 & 0 & Productiva \\
\hline Dependiente & 0 & 0 & 0 & 0 & 0 & 0 & 0 & Independiente \\
\hline Tradicional & 0 & 0 & 0 & 0 & 0 & 0 & 0 & Innovadora \\
\hline
\end{tabular}

